\title{
EFEITO DOS INTERVALOS DE SIMULAÇÃO DE CHUVA SOBRE O COMPORTAMENTO DO GLIFOSATE, SOZINHO E EM MISTURA COM SURFACTANTES E ADITIVOS, NO CONTROLE DA GRAMA-SEDA (Q
}

JOSÉ EDUARDO BORGES DE CARVALHO

Orientador: Prof. Dr. RICARDO VICTORIA FILHO

Tese apresentada à Escola Superior de Agricultura "Luiz de Queiroz", da Universidade de São Paulo, para obtenção do título de Doutor em Agronomia, Área de concentração: Solos $\theta$ Nutrição de Plantas.

$P|R A C| C A B A$

Estado de São Paulo - Brasil

Novembro - 1985 


\author{
Aos meus filhos \\ PALLLA Q LEONARDO \\ $e$ aos meus pais \\ JOSE I VALMIRA
}

OFEREÇO.

A SELMA

DEDICO. 


\section{AGRADECIMENTOS}

o autor expressa seus agradecimentos as seguin tes pessoas e instituições:

- Ao Prof. Ricardo. Victória fil ho, pela compreensão, amizade e orientação durante o curso e execução des te trabalho.

- Aos professores do Departamento de Solos, Geo logia e Fertilizantes, pela amizade e dedicação na formação cien tífica.

- As Indústrias Monsanto pelo apoio logístico, e financeiro para a realização deste trabalho.

- A Escola Superior de Agricultura "Luiz de Queiroz", da Universidade de São Paulo, Piracicaba, SP, pela oportunidade concedida.

- Ao colega José Carlos Seraphin, pela orienta ção estatîstica e realização das anālises necessārias.

- Ao estagiārio Luís Paulo Antoniali, pelo esforço e dedicação.

- Aos funcionārios do setor de Horticultura em especial ao Sr. Luis Ferrari, da ESALQ/USP; que direta ou indiretamente colaboraram para a realização deste trabalho.

- A. Empresa Brasileira de Pesquisa Agropecuáa ria, pela oportunidade e facilidades oferecidas para a reali$z$ ação do curso de Pós-Graduação a nível de Doutoramento.

- Ao colega João Gaspar farias pelo auxílionas traduções da literatura consultada. 


\section{INDICE}

Pàgina

AGRADECIMENTOS ..................... i i

LISTA DE TABELAS .................... vi

LISTA DE FIGURAS $\ldots \ldots \ldots \ldots \ldots \ldots \ldots \ldots \ldots \ldots \ldots \ldots \ldots \ldots$

RES UMO

SUMMARY

1. INTRODUÇÃO

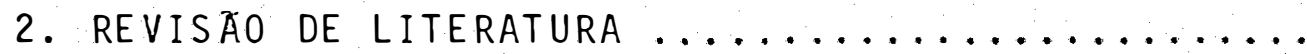

2.1. Efeito do volume da calda..............

2.2. Influência dos aditivos e surfactantes so-

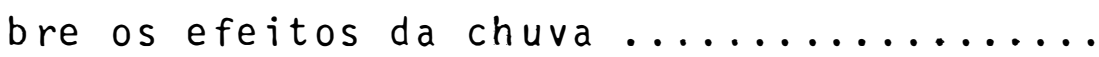

2.3. Efeitos das condições ambientais na perfor-

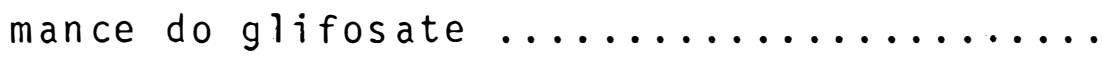

2.4. Efeito de aditivos e agentes complexantes.

2.5. Efeito dos surfacantes na eficiência do gli

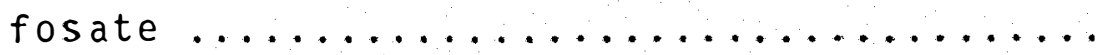

2.6. Efeito dos auitivos e surfactantes na absor ção e translocação do glifosate .........

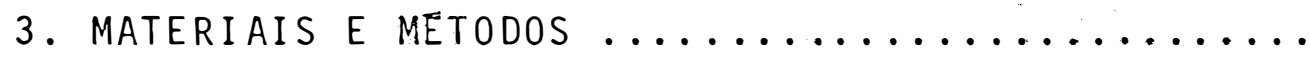

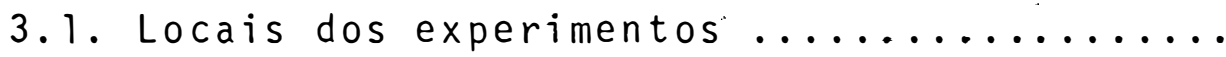

3.2. Experimentos em casa de vegetação ..........

3.3. Experimento em condições de campo (1985) ..

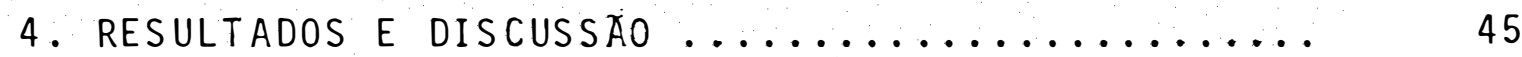

4.1. Experimento em casa de vegetação (1984) .. 45

4.2. Experimento em casa de vegetação (1985) ... 


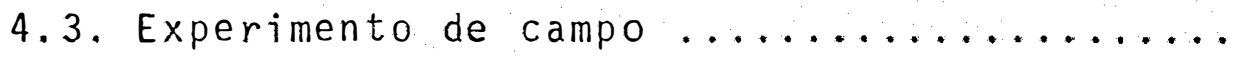

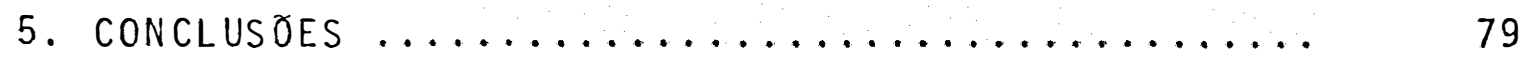

6. LITERATURA CITADA ..................... 81 

lo utilizado.nos dois experimentos em va $\operatorname{sos} \ldots \ldots \ldots \ldots \ldots \ldots \ldots \ldots \ldots . \ldots \ldots \ldots$

Tratamentos utilizados com as respecti vas doses do ingrediente ativo (i.a.), no primeiro experimento em casa de vegeta ção $\ldots \ldots \ldots \ldots \ldots \ldots \ldots \ldots \ldots \ldots \ldots$

03 Tratamentos utilizados, com as respecti vas doses do ingrediente ativo (i.a.), no segundo experimento em casa de vegeta-

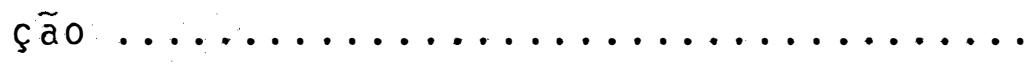

04 Escala de avaliação visual para o contro le de plantas daninhas pela Asociación La tinoamericana de Malezas (ALAM) ........

05 Características químicas e físicas do so 10 onde foi conduzido o experimento ....

06 Percentagem de controle da grama-seda pe los tratamentos, envolvendo as quatrofre quências de simulação de chuva nas seis épocas de avaliação (média de 4 repetí ções) $\ldots \ldots \ldots \ldots \ldots \ldots \ldots \ldots \ldots \ldots \ldots$

06 a Porcentagem de controle da grama-seda pe los tratamentos, envolvendo as quatrofre quências de simulação de chuva nas seis épocas de avaliação (média de 4 repetições) 
vii.

TABELA No

Pàgina

07

Biomassa verde epígea aos 60 DAT, envolvendo as quatro frequèncias de simula ção de chuva (média de 4 repetições) ...

08

Percentagem de controle da grama-seda pe los tratamentos envolvendo as quatro fre quências de simulação de chuva nas seis épocas de avaliação (média de 4 repetị

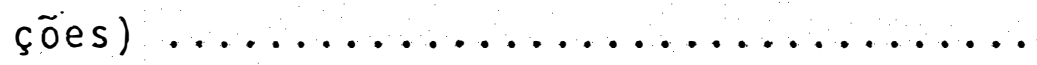

08a Percentagem de controle da grama-seda pe los tratamentos, envolvendo as quatrofre quências de simulação de chuva nas seis épocas de avaliação (média de 4 repetị

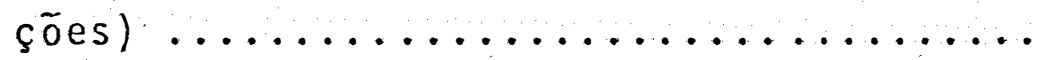

Percentagem de controle da grama-seda pe los tratamentos dentro de cada frequência de chuva e comparação de médias envolvendo todas avaliações ..............

09a Percentagem de controle da grama-seda pe los tratamentos dentro de cada frequência de chuva e a comparação das médias envolvendo todas avaliações .............

10 Biomassa verde epígea aos 60 DAT envolvendo as quatro frequéncias de chuva (mé dia de 4 repetições) $\ldots \ldots \ldots \ldots \ldots \ldots$

11 Comportamento e comparação entre os tratamentos nas duas épocas de avaliação e a anālise conjunta delas (média de 4 repeti-

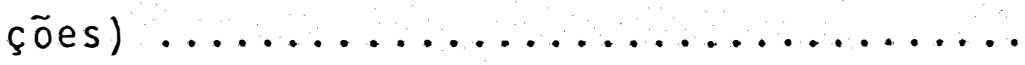


viji.

\section{LISTA DE FIGURAS}

FI GURA N

pägina

01

02 Curvas de resposta para o efeito das fre quências de simulação de chuva sobre o tratamento 1 ( $\mathrm{g} 1$ ifosate a $1,44 \mathrm{~kg} / \mathrm{ha}$ ), aos

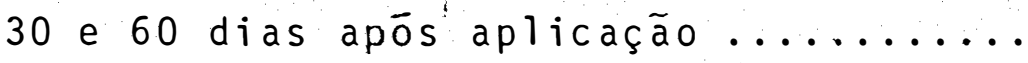

03 Curvas de resposta para o efeito das frequēncias de simulação de chuva sobre o tratamento 7 (glifosate a $1,44 \mathrm{~kg} / \mathrm{ha}+$ rit on $\times 45$ a $0,2 \% \mathrm{v} / \mathrm{v}$ ), aos 30 e 60 dias após aplicação ........

04 Curvas de resposta para o efeito das fre quências de chuva sobre o tratamento 9 (glifosate + Triton $\times 100$ a $1,44 \mathrm{~kg} / \mathrm{ha}+$ $0,2 \% \mathrm{v} / \mathrm{v})$, aos 30 e 60 dias após aplica

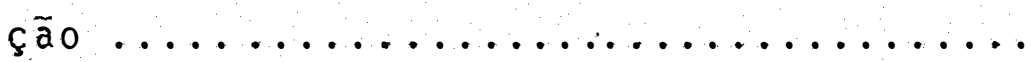

05 Curvas de resposta para o efeito das fre quēncias de simulação de chuva sobre $\overline{0}$ tratamento 11 (glifosate + Triton $\times 114$ a $1,44 \mathrm{~kg} / \mathrm{ha}+0,2 \% \mathrm{v} / \mathrm{v})$, aos 30 e $60 \mathrm{dias}$

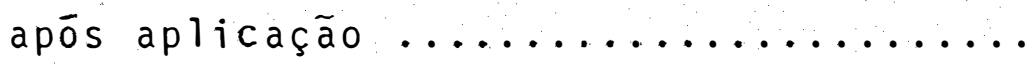

06 Curvas de resposta para o efeito das fre quências de chuva sobre o tratamento 13 (glifosate + Triton $A G-98$ a $1,44 \mathrm{~kg} / \mathrm{ha}+$ $0,2 \% \mathrm{v} / \mathrm{v})$, aos 30 e 60 dias após aplica ção $\ldots \ldots \ldots \ldots \ldots \ldots \ldots \ldots \ldots \ldots \ldots \ldots \ldots \ldots \ldots \ldots \ldots \ldots \ldots \ldots \ldots \ldots \ldots$ 
Curvas de resposta para o efeito das fre quēncias de simulação de chuva sobre o tratamento 15 (glifosate + Triton AF a $1,44 \mathrm{~kg} / \mathrm{ha}+0,2 \% \mathrm{v} / \mathrm{v})$, aos 30 e 60 dias

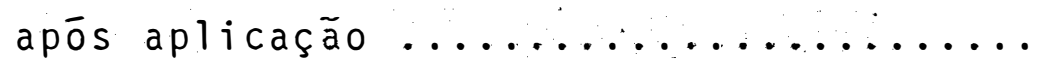

08 Curvas de resposta para o efeito das fre quēncias de simulação de chuva sobre o tratamento 17 (glifosate + sintergente a $\left.1,44 \mathrm{~kg} / \mathrm{ha}+0,2 \%^{\prime} \mathrm{v} / \mathrm{v}\right)$, aos 30 e 60 dias

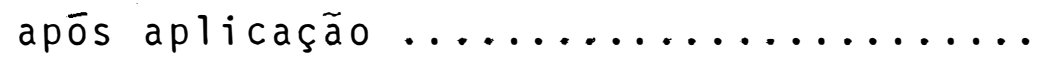

Curvas de resposta para o efeito das fre quências de simulação de chuva sobre o tratamento 25 (glifosate + Natur'L óleo a $\left.1,44 \mathrm{~kg} / \mathrm{ha}+{ }^{-} \mathrm{l}, 0 \% \mathrm{v} / \mathrm{v}\right)$, aos 30 e 60

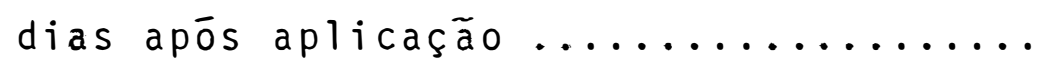

10 Efeito da frequència de uma chuva simula da ue $15 \mathrm{~mm}$ sobre o tratamento glifosate + Triton $\times 45(1,8 \mathrm{~kg} / \mathrm{ha}+0,2 \% \mathrm{v} / \mathrm{v}) \ldots \ldots$

11 Efeito da frequência de uma chuva simula da de $15 \mathrm{~mm}$ sobre o tratamento glifosate+ sulfato de amōnio $(1,8 \mathrm{~kg} / \mathrm{ha}+1,5 \% \mathrm{p} / \mathrm{v})$

12 Efeito da frequência de uma chuva simula da de $15 \mathrm{~mm}$ sobre o tratamento glifosate+ Natur'L óleo $(1,8 \mathrm{~kg} / \mathrm{ha}+1,0 \% \mathrm{v} / \mathrm{v}) \ldots$ 


\section{$\underline{C} \underline{U} \underline{R} \underline{R} \underline{\mathrm{C}} \underline{U} \underline{L} \underline{U} \underline{M}$ \\ $\underline{\mathrm{I}} \underline{\mathrm{I}} \underline{\mathrm{A}} \underline{\mathrm{E}}$}

(RESUMIDO)

JOSE EDUARDO BORGES DE CARVALHO, nasceu em 24 de agosto de 1949, no município de Conceição do Almeida, Estạ do da Bahia - Brasil. Filho de José Souza de Carvalho e Valmira Borges de Carvalho.

Em 1971, graduou-se em engenharia agronómica pela Escola de Agronomia da Universidade Federal da Bahia, Cruz das Almas, Bahia - Brasil.

Em fevereiro de 1972, ingressou na Associação Nordestina de Crédito e Assisténcia Rural da Bahia como exten sionista rural, desligando-se quatro meses mais tarde para assumir o cargo de pesquisador do Programa Solos Correção e Adubação na Cultura da Mandioca pelo convênio Universidade Fe deral da Bahia / Brascan Nordeste até dezembro de 1974.

Em março de 1974, iniciou o curso de Pós-Gradua çao em Fitotecnia a nível de Mestrado, na Escola Superior de Agricultura "Luiz de Queiroz", finalizando em fevereiro de 1976 . 
Em agosto de 1975, foi admitido pela Empresa Brasileira de Pesquisa Agropecuāria, lotado no Centro Nacional de Pesquisa de Mandioca e Fruticultura como pesquisador no pro grama de controle de plantas daninhas na cultura da mandioca.

Em março de 1979 iniciou o Curso de Pós-Gradua ção a nĩvel de Doutorado em Solos e Nutrição de Plantas, na Escola Superior de Agricultura "Luiz de Queiroz", concluindo os créditos em novembro de 1980 .

Em novembro de 1981, desligou-se da EMBRAPA e ingressou nas Indūstrias Monsanto S/A, ocupando o cargo de representante de desenvolvimento de produto até outubro de 1985 . 
xi i.

EFEITO DOS INTERVALOS DE SIMULAÇÃO DE CHUVA SOBRE

O COMPORTAMENTO DO GLIFOSATE, SOZINHO E EM MISTURA COM SURFACTANTES E ADITIVOS, NO CONTROLE DA GRAMA-SEDA (Cynodon dacty:on (L.) PERS.).

Autor: José Eduardo Borges de Carvalho orientador: Prof. Dr. Ricardo Victória Filho

\section{Resumo}

Com o objetivo de se estudar o efeito de 4 intervalos de simulação de chuva sobre o desempenho do glifosate [N-(Fosfonometil) Glicina] no controle da grama-seda (Cyno don dactylon (L.) Pers.), sozinho e em mistura com surfactantes e aditivos, instalou-se dois experimentos em casa de vegE tação nos anos agrícolas 1984 e 1985. Um terceiro experimento foi instalado em condições de campo em 1985 com o objetivo apenas de se avaliar o comportamento dos tratamentos testados em casa de vegetação, eliminando-se a variável chuva simulada.

A intensidade da chuva simulada foi estabelec $i$ da em $15 \mathrm{~mm}$ e os intervalos em $2,4,6$ e 8 horas apōs a ap 1 icação do herbicida.

0 delineamento experimental adotado para os dois experimentos em vasos foi um fatorial em blocos casualizados com 4 repetições. No primeiro experimento testou-se o fatorial $27 \times 4$ e no segundo $28 \times 4$, onde 27 e 28 significam 
xiii.

tratamentos e 4 os intervalos de simulação de chuva. Para o experimento em campo, adotou-se o delineamento em blocos ao acaso com 28 tratamentos e 3 repetições.

Aplicou-se os tratamentos com um pulverizador costal a pressão constante com consumo de calda de $1001 / \mathrm{ha}$.

0 efeito dos tratamentos no controle da gramaseda foi medido por avaliações visuais aos $10,20,30,40,50$ e 60 dias após a aplicação para os experimentos em vasos e aos 30 e 60 dias após a aplicação para o experimento de cam po .

Nenhum tratamento proporcionou, de maneira efi ciente, a redução para 2 horas entre a aplicação e a primeira chuva subsequente.

Os resultados alcançados mostraram que o Natur L öleo a $1 \%$ v/v foi o aditivo que proporcionou maior ativação do glifosate. Observou-se também que os surfactantes Triton X45 $(0,2 \% \mathrm{v} / \mathrm{v}), \quad$ Triton $\times 100(0,1-0,2 \% \mathrm{v} / \mathrm{v}), \quad$ Triton X $114(0,2 \% \mathrm{v} / \mathrm{v}), \quad$ Triton $A G-98(0,2 \% \mathrm{v} / \mathrm{v})$ e Sintergente $\quad(0,2 \% \mathrm{v} / \mathrm{v})$ aumentaram a velocidade da penetração cuticular e a absorção do glifosate. Uma chuva simulada ocorrida 4 horas apōs a aplicação não afetou a performance dos seguintes tratamentos:

- glifosate + Triton $\times 100(1,44 \mathrm{~kg} / \mathrm{ha}+0,2 \% \mathrm{v} / \mathrm{v})$;

- glifosate + Triton $\times 114$ (1,44 kg/ha $+0,2 \% \mathrm{v} / \mathrm{v})$;

- glifosate + Sintergente $(1,44 \mathrm{~kg} / \mathrm{ha}+0,2 \% \mathrm{v} / \mathrm{v})$;

- glifosate+ Triton $A G-98(1,44 \mathrm{~kg} / \mathrm{ha}+0,2 \% \mathrm{v} / \mathrm{v})$;

- glifosate + Natur' L oleo (1,44-1,80 kg/ha+1,0\% v/v);

- glifosate + Triton $\times 45(1,8 \mathrm{~kg} / \mathrm{ha}+0,2 \% \mathrm{v} / \mathrm{v})$;

- glifosate + Sulfato de amónio $\left(1,8 \mathrm{~kg} / \mathrm{ha}+2,5^{\circ} \mathrm{p} / \mathrm{v}\right)$. 
xiv.

EFFECTS OF RAINFALL SIMULATION INTERVALS ON GLYPHOSATE BEHAVIOR, ALONE AND IN COMBINATION WITH SURFACTANTS AND ADITIVES, IN BERMUDA GRASS (Cynodon dactylon (L.) PERS.) CONTROL

\author{
Author: José Eduardo Borges de Carvalho \\ Adviser: Prof. Dr. Ricardo Victöria Filho
}

\title{
SUMMARY
}

The effects of four rainfall simulation intervals on glyphosate [N(phosphonomethyl)glycine] performance in grama-seda (Cynodon dactylon (L.) Pers.) control were studied in two greenhouse experiments, in 1984 and 1985. A third field experiment was carried out to evaluate the greenhouse treatments without the rainfall simulation variable.

The rainfall simulation intensity was at $15 \mathrm{~mm}$, and the intervals were $2,4,6$ and 8 hours after the herbicide application.

The pot experiments design were randomized block factorials with four replications. A $27 \times 4$ factorial was used in the first experiment, and a $28 \times 4$ in the second experiment, where 27 and 28 are the treatments, and 4 the rainfall simulation intervals. In the field experiment a randomized block design with 28 treatments and 3 replications was used. 
The treatments were applied with a constant pressure portable sprayer, using 1001 of solution per hectare.

The effects of the treatments on burmuda grass control were measured at $10,20,30,40,50$, and 60 days after the herbicide application on the pot experiments, and at 30 and 60 days for the field experiment.

No treatment has given, defficiently, a two hour reduction between the application and first subsequent rain.

Results showed that the aditive Natur'Lóleo $1 \%$ v/v caused the highest glyphosate activation. The surfactants Triton $\times 45(0.2 \% \mathrm{v} / \mathrm{v})$, Triton $\times 100(0.7-0.2 \% \mathrm{v} / \mathrm{v})$, Triton $\times 114$ $(0.2 \% \mathrm{v} / \mathrm{v})$, Triton $A G-98(0.2 \% \mathrm{v} / \mathrm{v})$ and Sintergent $(0.2 \% \mathrm{v} / \mathrm{v})$ increased glyphosate cuticular penetration speed and absorption. A simulated rainfall 4 hours after the glyphosate application did not affect the performance of the following treatments:

- glyphosate + Triton X100 ( $1.44 \mathrm{~kg} / \mathrm{ha}+0.2 \% \mathrm{v} / \mathrm{v})$;

- glyphosate + Triton $\times 114(1.44 \mathrm{~kg} / \mathrm{ha}+0.2 \% \mathrm{v} / \mathrm{v})$;

- glyphosate + Sintergente $(1.44 \mathrm{~kg} / \mathrm{ha}+0.2 \% \mathrm{v} / \mathrm{v})$;

- glyphosate + Triton AG-98 (1.44 kg/ha + 0.2\% v/v);

- glyphosate + Natur'Lōleo (1.44-1,80 kg/ha + 1.0\% v/v);

- glyphosate + Triton $\times 45(1.80 \mathrm{~kg} / \mathrm{ha}+0.2 \% \mathrm{v} / \mathrm{v})$;

- glyphosate + ammonium sulphate $(1.80 \mathrm{~kg} / \mathrm{ha}+2,5 \% \mathrm{w} / \mathrm{v})$. 


\section{INTRODUGÃO}

A grama-seda (Cynodon dactylon (L.) Pers.) figura entre as mais importantes plantas daninhas perenes e invasoras da nossa agricultura. E uma das mais dispendiosas de erradicar, pelos métodos manuais e mecãnicos convencionais.

0 herbicida de maior eficiéncia no controle, em pós-emergēncia, desta planta daninha é o glifosate.

* O glifosate é um herbicida pós-emergente de am plo espectro de controle (BAIRD et alii, 1971). Ele é ativo sobre muitas espécies de plantas daninhas perenes e anuais, sendo absorvido e translocado no floema (BAIRD et alii, 1971; BEHRENS e ELAKKAD, 1972 e SPRANKLE et a $1 \mathrm{i} i, 1975 \mathrm{~b})$.

A aplicação do glifosate com aditivos e surfac tantes é um assunto que vem merecendo atenção de muitos pesquisadores devido ao uso às vezes, indiscriminado, com resultados contraditórios na maioria dos casos.

0 aumento da toxicidade do glifosate por mui- 
tos surfactantes tem sido atribuída a redução da tensão super ficial, aumentando a ārea molhada da follha.e a penetração cuticular. Uma vez absorvido ele ë rapidamente translocado pa ra as regiões de alta atividade metabölica, tanto das raízes como dos brotos ou rebentos (WYRILL, 1976).

Em estudos de casa de vegetação e condições de campo GUIMARAES (1981), concluiu que dos aditivos testados, o sulfato de amōnio foi o que proporcionou melhor ativação do glifosate no controle de cyperus rotundus. Os melho res resultados foram obtidos quando se adicionou 2,5 e $5,0 \mathrm{~kg}$ /ha desse aditivo. Relata ainda o autor que em condições de campo, a adição de $5,0 \mathrm{~kg} / \mathrm{ha}$ de sulfato de amōnio ao glifosaté, aumentou o nível de controle desta planta daninha.

Os resultados de ERICKSON e DUKE (1981b), mostraram que o movimentó do glifosate através da cutīcula em relação ao tempo foi linear, e que uma maior concentração deste pró duto proporcionou um aumento quase linear na penetração cuticular, enquanto que os incrementos na concentração do surfac tante produziram apenas pequenos acréscimos.

Glifosate aplicado nas concentrações de 10004000 ppm em Cynodon dactylon, foi absorvido dentro de 6 horas pelas plantas e foi transferido entre plantas através de ramos e raízes abaixo do solo, causando uma completa perda da ca pacidade de brotação desta planta daninha (LIU, 1981).

Segundo TROUTMAN et alii (1981), a adição de um surfactante aumentou a atividade do glifosate a $2,0 \mathrm{~kg}$ do 
i.a./ha, mas não a $3,0 \mathrm{~kg}$ do i.a./ha ou mais. Um periodo mínimo de 8 horas foi necessārio para quantidades biologicamente significativas de glifosate serem absorvidas por Agropyron re pens, e a absorção continuou através de uma exposição de 32 horas.

A absorção e o desempenho do glifosate tem sido afirmado por MERRIT (1980), que dependem diretamente da concentração do produto na gota e não do tamanho das gotas.

Quanto aos efeitos prejudiciais da chuva sobre as aplicações do glifosate os resultados de PULVER e ROMERo (1976), mostraram que este herbicida foi afetado por uma chuva 6 horas após a aplicação de $1,5 \mathrm{~kg}$ do i.a./ha e 2 horas para a dose de $3,0 \mathrm{~kg}$ do i.a./ha no controle de Cyperus rotun dus (tiririca) em estádio de crescimento vegetativo e que necessitou mais tempo para a penetração cuticular do glifosate em plantas de tiririca madura ou em floração já que o controle com $1,5 \mathrm{~kg} / \mathrm{ha}$ foi reduzido quando ocorreu uma chuva 12 horas ou 4 horas após a aplicação de $3,0 \mathrm{~kg} / \mathrm{ha}$.

TURNER (1976a), avaliou o efeito de uma chuva simulada de $5 \mathrm{~mm}$ nas frequências de $10 \mathrm{~min}, 30 \mathrm{~min}, 1$ hora, 4 horas e 24 horas após a aplicação e verificou algum efeito po sitivo do sulfato de amōnio minimizando o efeito da chuva pela lavagem do glifosate retido na superficie foliar de Agropyron repens.

A adição de Triton AE, um agente molhante e adesivo, não teve efeito na atividade do glifosate, porém re- 
duziu a lavagem pela chuva 1-2 horas apōs a aplicação. Estes mesmos autores observaram que o sulfato de amōnio a $6 \mathrm{~kg} / \mathrm{ha}$ melhorou a atividade do gi ifosate (RAO et alii, 1978).

os resultados dos trabalhos com o glifosate têm evidenciado sua vulnerabilidade aos efeitos da chuva antes de 6 a 8 horas apōs a aplicação, constituindo-se assim como um fator limitante a sua aplicação na época chuvosa do ano e que coincide com o perĩodo das mais altas infestações das plantas daninhas nas culturas.

Esse trabalho teve como objetivos verificar a possibilidade de aumentar a eficiência do glifosate no contro le da grama-seda com doses menores que a recomendada e reduzir o tempo necessārio entre a aplicação e uma chuva simulada, misturando aditivos e surfactantes ao glifosate; aplicado a um volume de pulverização de $1001 / h a$, utilizando-se bicos hidräulicos de baixo consumo. 
5.

\section{Revisão de Literatura :}

\subsection{EFEITO DO VOLUME DA CALDA}

Segundo MERRITT e TAYLOR (1978); mudanças no volume de aplicação e no tamanho das gotas podem ser acompanhadas por mudanças na retenção e na distribuição da aspersão; nas superfícies das plantas, como tambēm afetar a absor. ção e translocação dos defensivos agrícolas nos tecidos das plantas devido a variação na concentração dos ingredientes ati vos e aditivos.

Há muito tempo foi demonstrado por BLACKMAN et alii (1958), que o nĩvel de retenção de um produto pode ser. alterado por mudanças no volume de aspersão, tamanho médiodas gotas e tensão superficial, sendo que a natureza e magnitude das mudanças induzidas são dependentes das espécies de plantas pulverizadas.

Segundo TAYLOR (1981), diminuindo o volume de 
pulverização ou aumentando o tamanho das gotas, se reduz o nümero de gotas produzidas e, portanto, a possibilidade delas atingirem o alvo. As considerações de tamanho de gotas, volu me de aspersão e área de amostragem, revelam uma enorme varia ção no nümero de gotas que atingem um alvo. Por exemplo, a partir de uma pulverização com $51 /$ ha e gotas de $100 \mu \mathrm{m}, 955$ atingirão um alvo de $10 \mathrm{~cm}^{2}$, porēm se este diāmetro for de $400 \mu \mathrm{m}$ somente 15 o atingirão.

Trabalhos com'altos volumes de aplicação têm demonstrado que o máximo de retenção por planta de Avenua fatua, ocorre ao redor de $150 \mathrm{l} / \mathrm{ha}$. Gotas com diâmetro entre 100-400 $\mu m$ de uma solução aquosa ae barban, aplicadas em plantas jovens de A. fatua, foram igualmente bem retidas e a retenção foi linear até 150 l/ha (LAKE e TAYLOR, 1974). No entanto, quando as plantas foram pulverizadas com solução aquosa mais Agral 0,1\%v/v, LAKE (1977) achou que as gotas de $100 \mu \mathrm{m}$ foram melhor retidas que as de 200-600 $\mu \mathrm{m}$. Em trabalhos posteriores MERRITT e TAYLOR (1978), trabalhando com esta mesma planta, encontraram que a retenção de uma solução aquosa com $0,5 \%$ $v / v$ de Agral foi, em geral, melhor com gotas de diāmetro entre 150 e $250 \mu \mathrm{m}$ que as de $350 \mu \mathrm{m}$. Este efeito foi mais pronunciado nos maiores volumes de aplicação.

\section{Casseley et alii, citado por TURNER e LOADER} (1978b), sugerem que a melhor atividade do glifosate com baixos volumes de aplicação pode ser devida a uma melhor retenção das gotas na superfĩcie das folhas, maior concentração de 
herbicidas nas gotas, como tambēm sugere BALS (1978), e pelas diferenças da superficie da folha molhada pela pulverização.

Segundo SALINAS (1981) a translocação do glifosate em grama-seda foi mais lenta quando se usou altos volu mes de pulverização.

\subsection{INFLUENCIA DOS ADITIVOS E SURFACTANTES SOBRE OS EFEITOS DA CHUVA}

O'KEEFFE e TURNER (1978), verificaram que, uma chuva pesada 3 horas após aplicação, o controle tanto a curto como a longo prazo do Agropyron repens obtidos com a metade da dose normal do glifosate $(0,72$ do i.a./ha) foi marcadamen te aumentado pelo sulfato de amōnio a $10 \mathrm{~kg} / \mathrm{ha}$. 0 controle foi igual ao obtido com a dose normal de $1,44 \mathrm{~kg}$ do i.a./ha, porém sem o sulfato de amōnio o controle foi inadimissível pa ra aquela dose. Não se observou também um aumento na ativida de do glifosate na dose normal.

Um período sem chuva de pelo menos 4 horas foi necessārio após a aplicação de glifosate para se atingir um bom controle de Imperata cylindrica. 0 adesivo Triton AE a 0,66\% reduziu a lavagem somente quando a chuva ocorreu 2 horas após a aplicação (INDIA, TEA RESEARCH ASSOCIATION, 1977 ).

Pela pesquisa realizada por BEHRENS e ELAKKAD (1981) ficou evidenciado que o intervalo entre a aplicação do 
2,4-D e a primeira chuva para atingir um nível de controle de $80 \%$, daquele obtido sem chuva, variou de meno de 1 minuto pa ra Chenopodium album, a mais de 24 horas para Abutilon theophraste. A adição de um surfactante alquil aril polietoxietileno glicol na solução do herbicida, reduziu a dose necessāria para induzir níveis equivalentes de fitotoxicidade.

os resultados obtidos por SCHOLEY (1984), indi caram a efetividade do NU-Film-P na prevenção de perdas de glifo sate formulado como glifosate, da superfície da folha por uma rega artificial. Na dose de 1 l/ha o efeito do glifosate foi realçado pelo NU-Film-P, mesmo não ocorrendo rega. Isto suge re que NU-Film-P pode atuar como coadjuvante para melhorar a performance deste produto. Diferenças entre espécies foram observadas. A deficiência do glifosate no controle de cevada e Poa annua foi consideraveimente realçada pelo NU-Film-P e este efeito positivo ocorreu mesmo quando a rega foi feita 4 horas apōs a aplicação.

TURNER e LOADER (1984), estabeleceram que sul fato de amōnio aumentou a atividade do dichlorprop quando se aplicou uma chuva 2-24 horas apōs a áplicação, porēm esse aumento da atividade não foi observado quando a chuva ocorreu imediatamente após aplicação.

COOLS e LOCASCIO (1977), observaram que a adição de sulfato de amōnio não melhorou a atividade do glifosate.

\subsection{EFEITOS DAS CONDIÇOES AMBIENTAIS NA EFICIENCIA DO GLIFOSATE}

MOOSAVI-NIA e DORE (1979a,b) estudaram a influēn- 
cia de três regimes de umidade do solo, na eficiēncia do glifosate no controle de Imperata cylindrica e cyperus rotundus. Verificaram que para o glifosate aplicado na capacidade de campo diminuiu o peso seco da parte aērea em ambas espé cies, comprimento e peso seco do rizoma; e carbohidratos totais em I. cylindrica e número total de bulbos tubérculos em C. rotundus. Em contraste, o extremo "stress" de umidade do solo reduziu a atividade do glifosate, a qual pareceu estar relacionada com o comportamento fisiológico e morfológico das plantas devido ao tratamento de seca. Aplicação de àgua nas raĩzes das plantas crescendo sob "stress" de umidade do solo uma semana antes e uma semana após a pulverização de glifosate, aumentou a atividade deste produto, provavelmente devido a recuperação dos processos perturbados pelo déficit de umi dade do solo.

0 controle de Sorghum halepense por dalapon, a 1,12 $\mathrm{kg} / \mathrm{ha}$ sem surfacante, diminuiu ao aumentar a temperatura do ar de 16 para 27 para 380C. Plantas a 16 e 270 , com $100 \%$ de umidade relativa, foram mais susceptiveis ao dalapon sem surfactante do que as plantas vegetando a $35 \%$ UR. A presença de $1 \%$ de surfactante em soluções de dalapon, aumentou o controle. do S. halepense acima daquele obtido com dalapon sozinho a 27 e 380 , indiferente da U.R. Adicionando $1 \%$ de surfactante e mantendo-se a $100 \%$ de U.R. e 380 C, resultou em controle significativamente menor do que a $35 \%$ U.R. e 380̣. A adição de $0,1 \mathrm{M} \mathrm{KH}_{2} \mathrm{PO}_{4}$ nas misturas de dalapon t surfactante restau- 
rou a efetividade a $100 \%$ U.R. e 380 C. Dalapon aplicado sem surfactante foi mais danoso ao $S$. halepense cultivado a $40 \%$ de umidade do solo do que com $25 \%$ de umidade do solo, independente da temperatura do ar ou U.R. Quando as plantas foram mantidas a 27 ou $380 \mathrm{C}$ com $25 \%$ de umidade do solo, 0,1 M $\mathrm{KH}_{2} \mathrm{PO}_{4}+$ surfactante resultou em mais beneficios que o surfac tante sozinho no controle desta planta daninha. A $40 \%$ de umidade do solo, o. controle de $S$. halepense com dalapon + $1 \%$ de surfactante não foi melhorado com a adição de $\mathrm{KH}_{2} \mathrm{PO}_{4}$, independente da temperatura do ar (MCWHORTER e JORDAN, $1976)$.

COOLS e LOCASCIO (1977), verificaram que aplicações de glifosate feitas na primavera promoveram razoável controle de cyperus rotundus, enquanto aplicações no outono ou verão, promoveram excelente controle. Observaram também que dentro de uma estação, uma ou duas aplicações, espaçadas de uma semana, promoveram controle semelhante, exceto na primavera, onde duas aplicações foram significativamente melho res que uma. Controle quase completo foi obtido com aplicações feitas no verão e no outono.

Os resultados do trabalho realizado por JORDAN (1977), mostraram que a toxicidade de glifosate a Cynodon dacty lon aumentou significativamente com cada aumento da dose de 0,14 a $1,12 \mathrm{~kg} / \mathrm{ha}$. O autor usou como indices para a penetração e translocação do glifosate, a toxicidade visível, o peso fres- 
co das plantas tratadas e a rebrota de plantas cortadas rente ao solo 24 horas após o tratamento. Assim, o autor verificou que danos visiveis a $C$. dactylon, com $0,56 \mathrm{~kg} / \mathrm{ha}$ de glifosate foi maior a $100 \%$ do que a $40 \%$ de U.R., tanto a 22 como a 320. Os dados de peso fresco indicaram que a dose de 0,56 $\mathrm{kg} / \mathrm{ha}$ foi mais tóxica a $320 \mathrm{C}$ do que a $220 \mathrm{C}$, a $40 \%$ de U.R., mas não foi observada diferença a $100 \%$ de U.R. Menos de $10 \%$ do 14C-glifosate penetrou na folha tratada de C. dactylon a $220 \mathrm{C}$ e $40 \%$ de U.R., enquanto mais, de $70 \%$ penetrou na folha tratada a $320 \mathrm{C}$ e $100 \%$ U.R. Cinco a seis vezes mais glifosate foi translocado para a planta a 100 do que a $40 \%$ de U.R. Significativamente mais quantidade translocou-se da folha tratada para a planta a $320 \mathrm{C}$ do que a $22 \%$, a $40 \%$ de U.R., mas não foi observado aumento significante a $100 \%$ de U.R.

Segundo WILLS (1978), a toxicidade do glifosate em algodão foi afetada pela temperatura com 21 a $40 \%$ e inferior a 2500 do que a 350 C. A adição de surfactante, frequentemente, aumentou a toxicidade sob condições ambientais on de ela foi baixa inicialmente. Absorção e translocação de gli fosate foram afetadas primariamente pela umidade relativa. Em temperatura e dose constante do surfactante, houve um aumento de $3: a$ vezes na translocação.

Pelo trabalho desenvolvido por WHITWELL e SANTELMANN (1978), verifica-se que aplicações de glifosate de ju Tho a meados de outubro na dose de $3,4 \mathrm{~kg} / \mathrm{ha}$ ou mais, foram as mais efetivas no controle da grama-seda. Aplicações de 
glifosate na primavera foram ineficazes mesmo a $5,0 \mathrm{~kg} / \mathrm{ha}$. Os autores observaram que havia necessidade de uma substāncial fo lhagem de grama-seda para se obter o máximo controle com apli cações de glifosate em agosto.

CHASE e APPLEBY (1979), concluiram que doses de 1,2 e $3,0 \mathrm{~kg} / \mathrm{ha}$ do glifosate foram igualmente efetivas na estação chuvosa, mas a dose de $1,0 \mathrm{~kg} / \mathrm{ha}$ não foi adequada na estação seca. Em estudos em casa de vegetação esses mesmos autores verificaram que o glifosate a $2,0 \mathrm{~kg} / \mathrm{ha}$ foi mais efetivo em reduzir a rebrota de C. rotundus a $90 \%$ do que a $50 \%$ de U.R., e foi mais eficiente a -2 bar do que a -11 bar de potencial de água na planta. Assim trēs vezes mais $14 \mathrm{C}$ foi translocado, para as partes abaixo do solo a $90 \%$ do que a $50 \%$ de U.R., do mesmo modo que duas vezes mais translocou-se a -2 bar do que a -11 bar.

MCWHORTER et alii (1980), num estudo sobre a absorção e translocação de $14 C-g l i f o s a t e ~ e m ~ S$. halepense e so ja cultivar 'Lee 68', observaram que em $S$. halepense a absorção de 14C-glifosate praticamente dobrou e a transiocação aumentou ao aumentar a temperatura do ar de 24 para 350C. Em soja a absorção aumentou em $100 \%$ e a translocação em $120 \%$ ao se diminuir a temperatura de $350 \mathrm{C}$ para $240 \mathrm{C}$. Em ambas espêcies, a translocação foi frequentemente maior a $100 \%$ de U.R. do que a $45 \%$, e em umidade do solo de $20 \%$ (capacidade de campo) do que a $12 \%$ (próximo ao ponto de murcha).

Segundo WHITWELL et alii. (1980), umidade rela- 
tiva de $35 \%$ diminuiu a translocação de $140-g l$ ifosate para foIhas não tratadas de grama-seda crescendo a 3100 , comparada a uma umidade relativa de $80 \%$. Também diminuiu a transloca ção de $14 C-g l i f o s a t e$ para os rizomas e raizes de plantas cres cendo a $220 . \mathrm{C}$.

COUPLAND (1983), estudou os efeitos da luz, tem peratura e umidade no desempenho e translocação de glifosate em. Elymus repens e Agropyron repens durante o periodo de 48 horas após o tratamento e verificou que aumentos nos niveis dos três fatores resultaram em aumento do desempenho do herbicida. Em geral, afirma o autor, estas diferenças foram estatisticamente significativas em todos periodos de tratamento, exceto o mais longo, quando foi obtido controle quase total. Assim, os resultados ressaltaram a importante influência dos fatores ambientais no desempenho a curto prazo do herbicida, no período pós-aplicação. Segundo ainda o autor, aumento nos níveis de luz e temperatura aumentaram a translocação do glifosate para o colo e rizomas, porém o aumento da umidade rela tiva não mostrou efeito significativo.

\subsection{EFEITO DE ADITIVOS E AGENTES COMPLEXANTES}

Segundo BLAIR (1975), glifosate a $0,5-1,0 \mathrm{~kg}$ do i.a./ha controlou A. repens em condiçōes de campo e que a adição de butilfosfato ácido ou sulfato de amônio ao líquido 
pulverizado melhorou o nível de controle obtido com glifosato sozinho. Este autor afirmou ainda que a adição de nitrato de amônio não proporcionou algum efeito positivo.

Notāvel ativação do glifosate foi obtido com sulfato de amōnio nas doses de 1,25 a $10 \mathrm{~kg} / \mathrm{ha}$. Outros compostos como o fosfato de amōnio, butilfosfato de amōnio e uréia proporcionaram uma ativação aproximada (SUWUNNAMER e PARKER, 1975).

PREEST (1975), aplicou $3,9 \mathrm{~kg} / \mathrm{ha}$ de glifosate e não conseguiu controle satisfatōrio do Pteridium aquilinum var. esculentum. A adição de óleo diesel, mais emulsifi cante (22 1/ha e $0,41 / h a$, respectivamente) causaram um decréscimo muito significativo em nümero de folhas e peso seco da folhagem 17 meses após o tratamento. Esta melhoria foi atribuĩda a a umento de entrada e absorção do glifosate causa das pela emulsão de óleo diesel.

Trabalhos realizados por TURNER (1976b); FIVELANDT (1978) e ZEMANEK et alii (1979) mostraram que a adição de sulfato de amōnio as pulverizações de glifosate tem, frequen temente, aumentado a atividade deste produto no controle de Agropyron repens. A adição de $5 \%$ peso/volume de sulfato de amōnio em $0,4 \mathrm{~kg} / \mathrm{ha}$ de glifosate reduziu o nūmero de brotos viáveis dos rizomas/planta, 5 meses após aplicação de 186 para 26 , do mesmo modo que 1,25 e $2,5 \mathrm{~kg} / \mathrm{ha}$ de sulfato de amōnio proporcionou um melhor controle para $0,25 \mathrm{~kg} / \mathrm{ha}$ do glifosate.

Vărios àcidos que são agentes complexantes re- 
alçaram os efeitos do glifosate e dichlorprop. Ambos os herbicidas foram ativados pelo ortofosfórico, cítrico, tartárico, lático, oxālico e gliçōlico. Outros ácidos que não são agentes complexantes tiveram pequeno ou nenhum efeito. A atividade do glifosate foi aumentada pelo EDTA, enquanto os efei tos do dichlorprop foram realçadas por EDTA, NTA e polifosfatos. Sugere-se que a ativação foi devida a interação com cál cio ou outros ions metálicos, os quais iriam, alternativamen. te, imobilizar os herbicidas! Em experimentos de campo, os ácidos ortofosfórico e oxálico aumentaram os efeitos do gli fosate na viabilidade das brotações de A. repens. Sulfato de amōnio teve efeitos similares. Contudo, em contraste com experimentos de casa de vegetação, muitas misturas triplas de um ácido, sulfato de amōnio e glifosate foram antagōnicas (TUR NER e LOADER, 1978a).

o trabalho conduzido por HARVEY e POTTS (1978), mostrou que glifosate a 0,72 e $1,44 \mathrm{~kg} / \mathrm{ha}$, com e sem sulfato de amónio, aplicado com bicos convencionais e de gota controlada proporcionou reduções na população de A. repens levemente menores na dose de $0,72 \mathrm{~kg} / \mathrm{ha}$ do que na de $1,44 \mathrm{~kg} / \mathrm{ha}$ de glifosate. Afirmaram ainda estes mesmos autores que o sulfato de amōnio não deu um efeito consistente e as reduções dos tratamentos com equipamento de gota controlada foram levemente menores do que aquelas obtidas com pulverização convencional.

Glifosate com e sem sulfato de amónio foi apli 
cado com equipamento convencional e CDA em A. repens. Um ano após o tratamento, o controle desta planta daninha variou de 74-98\% em um local e de 61-85\% em outro local. Glifosate na dose recomendada pelo fabricante + sulfato de amōnio deu o resultado mais consistente. Na metade desta dose o glifosate deu resultados inferiores, os quais foram significativamente me Ihorados pela adição de sulfato de amônio (UK, MINISTRY OF AGRICULTURE, FISHERIES AND FOOD, AGRICULTURAL DEVELOPMENT AND ADIVISORY SERVICE, 1978).

ZAMBIA, DEPARTMENT OF AGRICULTURE (1979), concluiu que glifosate isoladamente deu melhor controle de cynodon dactylon a 3 do que a 1,51 do produto/ha $(88 \%$ comparado com $45 \%)$. A adição de sulfato de amônio e aplicação combaixo volume, elevaram o nĩvel de controle com glifosate a 1,5 1/ha ao mesmo nível da dose de 3,0 1/ha.

SHARMA et alii (1980), estudaram o efeito. de caolin a $3,6 \mathrm{~kg} / \mathrm{ha}$ e sulfato de amōnio a 1,$25 ; 2,5$ e $5,0 \mathrm{~kg} /$ ha, na atividade herbicida de glifosate a 0,$56 ; 0,84$ e 1,12 $\mathrm{kg} / \mathrm{ha}$. Concluíram os autores que o controle foi aumentado com a adição de caolin a $3,6 \mathrm{~kg} / \mathrm{ha}$ e sulfato de amōnio a $1,25 \mathrm{~kg} /$ ha, nas duas doses mais altas de glifosate e que o sulfato de amōnio não mostrou algum efeito sinergístico no glifosate a $0,56 \mathrm{~kg} / \mathrm{ha}$, enquanto as duas doses maiores de sulfato de amónio diminuiram a atividade de todas as doses de glifosate.

Em experimento de vaso e de campo, adições de $1-10 \%$ v/v de sulfato de amôrio e/ou $0,1-2,5 \%$ v/v de surfactan 
te aumentou a fitotoxicidade em Agropyron repens das pulverizações.contendo $0,2-0,5 \mathrm{~kg}$ de glifosate. Resultados semelhantes foram obtidos com sal isopropilamina de glifosate e formulado como "Roundup". Concentrações mais altas de sulfato de amōnio sem surfactante, geralmente tiveram menos efeito na fitotoxicidade. Enquanto vários surfactantas aumentaram a ati vidade de glifosate a efetividade destes produtos variaram de acordo com a presença ou ausência de sulfato de amōnio. Quando usado isoladamente, os produtos relativamente hidrofílicos não-iōnicos, ou catiōnicos, foram mais efetivos. Em mistura com sulfato de amōnio, contudo, o surfactante mais lipofilico deu resultados superiores. Sulfato de amónio (5\%) com um surfactante lipofilico catiónico (0,5\% ethomeen C12) aumentaram os efeitos da aplicação de gota controlada em volume muito baixo, assim como na pulverização convencional em volume médio. Em um experimento de campo, $0,25 \mathrm{~kg} / \mathrm{ha}$ de glifosate aplicado com os aditivos citados, em 20 l/ha de solução, teve o mesmo efeito na viabilidade de brotos do que $1,0 \mathrm{~kg} / \mathrm{ha}$ apli cado com equipamento convencional (TURNER e LOADER, 1980).

Usando Panicum repens como planta teste, SHARMA e SUNDAR (1981), estudaram os efeitos de Caolin, grau medicinal, a $1,5,2,5$ e $3,5 \mathrm{~kg} / \mathrm{ha}$ e sulfato de amōnio a 1,25 $\mathrm{kg} / \mathrm{ha}$, na atividade de glifosate a $0,42,0,84$ e $1,16 \mathrm{~kg} / \mathrm{ha}$ em 4501 da solução/ha. Concluĩram os autores que a atividade do glifosate a $0,84 \mathrm{~kg} / \mathrm{ha}+$ Caolin a $2,5 \mathrm{~kg} / \mathrm{ha}$ foi signifi cativamente maior do que glifosate na mesma dose isoladamente, 
e foi comparável com glifosate na dose mais alta com ou sem caolin. Admitiram ainda, que a adição de sulfato de amōnio au mentou a atividade de glifosate nas duas doses mais baixas, mas, não teve efeito na dose mais alta de glifosate.

Em condições controladas de casa de vegetação e laboratōrio, foram estudados os efeitos da formulação e aditivos na arividade do glifosate na presença de cátions divalentes. Ions de $\mathrm{Ca}^{2+}$ ou $\mathrm{Mg}^{2+}$ em solução, reduziram ou impe diram completamente a fitotoxicidade de glifosate ao trigo cultivar scout 66, em doses de aplicação menores ou igual a 0,4 kg do i.a./ha. Foi obtida evidência para a formação de complexos entre molëculas deglifosate eions de $\mathrm{Ca}^{2+}$, usando titurações potenciométricas e espectroscopia de infravermelho. A atividade do glifosate, tanto em āgua deionizada como em soluções de cloreto de cälcio 0,005 ou 0,002 M, foi maior quando combinada com surfactante não-iōnico do que quando usado como a formulação comercial. (Roundup). A adição de hexametafosfato de sōdio não aumentou adequadamente a atividade do glifosate em solução de $\mathrm{Ca}^{2+}$. Acido nitrilotriacētico (NTA) aumentou a atividade mas, EDTA foi o mais efetivo dos agentes quelantes testados. EDTA foi mais efetivo em restaurar a atividade do glifosate com surfactante não-iōnico do que com surfac tante catioñico. Sem EDTA, as doses de glifosate maiores ou iguais a $0,4 \mathrm{~kg}$ do i.a. /ha foram equivalentes àquelas do herbicida a $0,1 \mathrm{~kg} / \mathrm{ha}+1 \%$ de EDTA (SHEA e TUPY, 1983).

Segundo BUHLER e BURNSIDE (1983a) o glifosate 
foi menos tóxico quando aplicados em soluções de $10 \mathrm{ml}$ de $\mathrm{CaCl}_{2}, \mathrm{FeSO}_{4}, \mathrm{Fe}_{2}\left(\mathrm{SO}_{4}\right)_{3}, \mathrm{MgSO}_{4}, \mathrm{NaHCO}_{3}, \mathrm{Na}_{2} \mathrm{CO}_{3}$ e $\mathrm{ZnSO}_{4}$, do que em àgua destilada. Adicionando $\mathrm{H}_{2} \mathrm{SO}_{4}, \mathrm{HCl}, \mathrm{HClO}_{4}$, ácidos acético e lático a 5,10 ou $50 \mathrm{ml}$ na solução de pulverização resultou em aumentos variáveis na toxicidade do glifosate. $\mathrm{H}_{2} \mathrm{SO}_{4}$ foi o mais efetivo em aumentar a toxicidade do glifosate quando adicionado a água de pulverização. Baixando o pH da solução de pulverização, pelo uso de tampões o ácido fósfó. rico não aumentou a toxicidade do glifosate.

\subsection{EFEITO DOS SURFACTANTES NA EFICIENCIA DO GLIFOSATE}

Segundo RIEMER (1973), glifosate (como Mon 0139 ) a 2,2-6,7 kg/ha num volume de calda de 75 a 302 l/ha + surfactante a $1 \%$ resultou em $65-90 \%$ de controle da rebrota de P. communis, $0,70-1,0 \mathrm{~m}$ de altura. 0 controle aumentou com a dose. Afirma ainda o autor que alto volume de pulveriza ção reduziu o controle na dose de $2,22-4,44 \mathrm{~kg} / \mathrm{ha}$, mas foi me lhorado nela adição de mais surfactante a $1 \% \mathrm{v} / \mathrm{v}$.

0 controle de Amaranthus retroflexus foi melhorado pela adição de $0,1 \%$ de surfactante na dose mais baixa de glifosate, mas não na alta. Glfosate a $1,68 \mathrm{~kg} / \mathrm{ha}+$ surfactante foi necessário para o controle de mais de $80 \%$ de $S$. exaltata (MCWHORTER, 1977).

Segundo WYRILL e BURNSIDE (1977), as aminas eto 
xiladas foram sempre o mais efetivo grupo dos surfactantes estudados. Eter não-ionico e ester etoxilados combinados com uma dimetil amina ou um sal quaternārio de amōnio foram mais efetivos que alguns destes surfactantes usados sozinhos. A efeti vidade dos surfactantes aminas etoxiladas foi alterada pelas mudanças de pH. Afirmaram os autores que os surfactantes cationnicos tenderam a ser mais efetivos que os não iōnicos eque o surfactante a base de amina foi mais efetivo com o aumento da conceñtração para $0,3 \% \mathrm{p} / \mathrm{v}$. Eter esteārico etoxilado e amina surfactante, mostraram excelente efeito para valores do balanço hidrofílico-lipofílico de 15 a 16 e 19 a 20 , respecti vamente. Afirmaram ainda que aqueles com um baixo balanço hi drofilico-lipofilico foram usualmente menos efetivos.

os resultados de BUNDICK e MITCHELL(1979), mostraram que um surfactante aniōnico foi menos efetivo do que os não-iōnicos na performance do glifosate e que o aumento da concentração do surfactante melhorou a atividade deste herbicida.

Alguns trabalhos como o de RICHARD Jr. e SLIFE (1979), mostraram que o surfactante, devido a maior molhagem da folha, promove uma maior penetração passiva rápida no início e que não aumenta com o tempo. 0 aumento da concentra ção externa tem efeito, nesta fase, entretanto, a fase ativa da absorção é mais demorada e exige maior tempo para ocorrer. A adição de sulfato de amōnio $5 \% \mathrm{p} / \mathrm{v}$, aumentou a atividade de glifosate de $0,33-1,0 \mathrm{~kg} / \mathrm{ha}$. 0 sulfato de 
amōnio ativou este herbicida em volume de aplicação de 26-480 1/ha. Os surfactantes geralmente aumentaram a efetividade do glifosate, exceto Agral 90 a $1 \%$, o qual foi antagōnico. Ethylan TT15 e Ethylan TF, que são surfactantes catiōnicos, a $2 \% \mathrm{p} / \mathrm{v}$, foram mais efetivos do que o não-iōnico Agral, também a $2 \% \mathrm{p} / \mathrm{v}$, quando usado glifosate e na presença de sulfato de amōnio. Escorrimento da folha 24 horas após a pulverizaçãore duziu a atividade do herbicida, mesmo quando sulfato de amonio e surfacantes estavam présentes (AMPONG-NYARKO, 1980).

T.estes com uma série de surfactantes não - iōnicos combinados com glifosate no controle de colza e outros cereais, mostraram que a efetividade de doses baixas do herbi cida $(0,14$ e $0,21 \mathrm{~kg} / \mathrm{ha})$ foi aumentada pela adição de Tween 20, $X-77$ e Triton $x 100$ (CANADA, AGRICULTURE CANADA, RESEARCH STATION, 1981$)$.

Segundo O'SULLIVAN e O'DONOVAN (1980), a mistura de tanque de glifosate a $0,21 \mathrm{~kg} / \mathrm{ha}$ com bromoxynil/MCPA, bromoxynil, MCPA, 2,4-D ou dicamba mostrou um antagonismo na atividade do glifosate em gramineas, 5 dias após o tratamento. Essa redução inicial no controle de gramineas anuais com as misturas foi superada em muitos casos pela adição de Tween 20 .

Os resultados de CHYKALIUK et aliji (1980), mos traram que glifosate a $3,36 \mathrm{~kg} / \mathrm{ha}+$ Triton $A G 98$ a $1 \%$, produziram uma resposta fitotóxica mais rápida e melhor controle de Helianthus ciliaris do que glifosate isoladamente ou com o 
surfactante X-77. A adição de Triton AG-98, aumentou a absor ção de 14C-glifosate tanto por Franseria tomentosa como por Solanum eleganifolium sob condições de laboratório.

JORDAN (1981), mostrou que a toxicidade de gli.

fosate $(0,84 \mathrm{~kg} / \mathrm{ha})$ para $C$. dactylon aumentou ao diminuir o volume de pulverização de 374 para 47 1/ha. Segundo o autor a adição de surfactante ao glifosate formulado sem surfactante (Mon 0139), aumentou o dano a C. dactylon em cada volume. de pulverização testado. A formulação comercial de glifosate (Mon 0139) + surfactante, foi a mais tóxica das 3 formulações testadas. A rebrota de C. dactylon cortado rente ao so 10, 48 horas após o tratamento com Mon 0139.com um consumo de calda de $47 \mathrm{~T} / \mathrm{ha}$ foi de $10 \%$ em relação a testemunha não tra tada, comparada com 100\% após tratamento com mon 0139 a 374 1 de calda/ha.

Uma extensa série de estudos de campo tēm indi cado que adições de surfactantes de 0,5 a $1 \%$ podeli aumentar a eficiēncia do glifosate no controle de Agropyron repens, espe ciaimente nas doses mais baixas. O efeito do surfactante $\bar{e}$ marcante na dose de $2,22 \mathrm{~kg} / \mathrm{ha}$ de glifosate. Condições ótimas para o controle desta planta daninha, com glifosate tanbém mascaram o efeito do surfactante em doses mais baixas. Foi concluído que o maior benefício obtido pela adicão de surfac tante é a maximização do controle de A. repens quando as apli cações de glifosate ocorrem após o estádio de 6 folhas (ERICL SON E DUKE, 1981a). 
Segundo TROUTMAN et alii (1981), a adição de um surfactante aumentou a atividade do glifosate a $2 \mathrm{~kg} / \mathrm{ha}$, mas não a $3 \mathrm{~kg} / \mathrm{ha}$ ou acima. Um perĩodo minimo de 8 horas foi necessārio para quantidades biologicamente signifi cantes de glifosate serem absorvidas, e a absorção continuou atravēs de uma exposição de 32 horas. No campo, danos aumentaram ao ser retardado o corte até 12 dias.

Os resultados de STUDT e NELSON (1981), em trabalhos de campo, que os surfactantes Tween $20, x-77$ e Triton $X-100$ aumentaram a atividade de doses baixas de glifosate em colza, trigo, aveia e cevada. Sob condições de casa de vegetação os autores observaram que Tween 20 e Triton X-A especial aumentaram a atividade do glifosate em aveia e cevada. Em cevada, concentrações de pelo menos $0,5 \% \mathrm{v} / \mathrm{v}$ de Tween 20 e $0,25 \% \mathrm{v} / \mathrm{V}$ de Triton $X-A$ especial foram necessárias para aumentar a fitotoxicidade do glifosate. Segundo os mesmos auto res, Bennes 36 , Cittowet Plus e Dupont WK reduziram a ativida de do glifosate nos testes de casa de vegetação e campo, enquanto Atplus $411 F$, Surfel e Triton-X-114 reduziram a fitotoxicidade do glifosate apenas no campo. A atividade de baixas doses de glifosate foi reduzida com o aumento do volume de pulverização.

Segundo TURNER (1981), quando o glifosate é aplicado sem suifato de amōnio, surfactante com um balanço hidrofîlico-lipofílico de 16-18 são mais efetivos. Contudo, em misturas com sulfato de amōnio, surfactantes mais lipofílicos 
(6-12) são superiores. Em experimentos de campo, surfato de amōnio e surfactantes salientaram significativamente o desempenho de baixas doses de glifosate formulado como Roundup. Afirma ainda o autor que em experimentos de vasos, o desempenho das doses mais altas de glifosate foi salientado quando uma chuva simulada foi aplicada dentro de 6 horas após a apli cação.

A adição de um surfactante não-iônico a $0,5 \%$. $v / v$ melhorou o desempenho do:glifosate em muitos dos testes. (DUTT, 1981).

A absorção de 2,4-D, dicamba e do sal isopropi lamina de glifosate por folhas terminais e basais de c. xaene foi aumentada pela adição do surfactante SA-77 (4-isoprope nil-l-methilciclohexano + emulsificadores näo especificados), sendo maior o efeito nas folhas basais. Na auséncia do surfactante, a absorção dos herbicidas foi maior nas folhas terminais do que nas basais. A absorçäo de glifosate foi maior nas folhas terminais do que nas basais. A absorção de glifosate foi maior nas folhas terminais coletadas após um período de umidade adequada do que apōs condições secas (SOTERES et ali i, 1983).

Segundo BUHLER e BURSIDE (1983b), a adição de surfactante não afetou o controle de gramineas quando se apli cou 0,2 ou $0,4 \mathrm{~kg}$ do i.a./ha de glifosate em um volume de cal da de $26 \mathrm{l} / \mathrm{ha}$, mas o surfactante aumentou o controle com glifosate aplicado a 48, 95 ou $1901 /$ ha de consumo de calda. Afir- 
ma o autor que o "stress" de āgua reduziu a eficiēncia do gli fosate em todos estádios de crescimento das plantas e aplica ção apōs o inîcio do florescimento também resultou em redução do controle máximo de plantas daninhas foi obtido com aplicações de glifosate nas plantas em crescimento ativo, com adequa da umidade do solo e temperatura favorável.

\subsection{EFEITO DOS ADITIVOS E SURFACTANTES NA ABSORÇÃO E TRANSLOCAÇATO DO GLIFOSATE}

TURNER e LOADER (1974), observaram que quando certos herbicidas solūveis em àgua foram formulados em öleo e ägua pelo uso de surfactante apropriados, como co-solvente con fere propriedades normalmente associadas com soluções de óleos, incluindo fácil passagem através da casca ou cutícula da folha.

Segundo GOTTRUP et alii. (1976), o glifosate mo veu-se rapidamente no apoplasto e simplasto. Alta umidade e/ou surfactante aumentaram a quantidade de 14C-glifosate absorvido e translocado, comparado com aquele em baixa umidade e/ou sem surfactante.

Segundo os resultados obtidos por ZANDSTRA e NISHIMOTO (1977), a translocação de l4C-glifosate de folhas tratadas de Cyperus rotundus para outras partes da planta aumentou em $5 \%$ da quantidade aplicada no 10 dia para $19 \%$ no 40 dia 
apōs a aplicação com o passar do tempo; o 140 total transloca do aumentou nos tubérculos e diminuiu levemente nas folhas.

A adição de sulfato de amônio à solução proporcionou um aumento de 3 vezes na quantidade do glifosate ab sorvido e translocado. A concentração ótima determinada de sulfato de amōnio na solução foị em torno de 1\%. A temperatu ra e a umidade relativa exerceram notável influência na quantidade do produto absorvido e translocacio esta influéncia foi aumentada na presença do aditivo (LUND-HOIE, 1979).

CHYKALIUK et alii (1979), observaram que 99\% foi desenvolvido pelas folthas de S. halepense, comparado com $30 \%$ de absorção pelas folthas de Helianthus ciliaris. Contudo, quando Trigon AG-98 foi adicionado ao 14C-glifosate e aplicado na superficie foliar de H. ciliaris, a absorção foi aumentada para $99 \%$.

Afirmam ainda os autores que estudos de campo também indicaram controle mais räpido e permanente de $H$. ciliaris com o Triton AG-98 mais glifosate comparado a glifosa te comercialmente formulado.

Os resultados de PENNER e ROGGENBUCK mostraram que a adição de sais de amônio, como esperado, não aumentou a absorção e fitoxicidade do glifosate.

LISH e MESSERSMITH (1979), observaram que houve uma tendéncia do aumento da translocação do glifosate para as partes abaixo da ārea tratada com o aumento da concentração do produto na calda.

Segundo MERRIT (1980), a absorção e o desempe- 
nho do glifosate não foram afetados pelo tamanho da gota, mas foram aumentados por gotas com mais altas concentrações do herbicida.

AHMADI et alii (1980), estudaram o efeito do estādio de crescimento e o "stress" de água no controle de C. dactylon e na absorção e translocação do glifosate e observaram que o herbicida foi menos efetivo em niveis de umidade do solo, abaixo da capacidade de campo ( $30 \%$ de umidade). Segundo os autores, em umidade do solo de $10 \%$ (-37 bar), a absorçãode 14C-glifosate foi grandemente reduzida em plantas tratadas tan to a $75 \mathrm{~cm}$ como a $15 \mathrm{~cm}$ de altura. Em umidade do solo de $10 \%$ somente 15 a $20 \%$ do $14 \mathrm{C}$-glifosate foi absorvido enquanto que a $40 \%$ de umidade do solo, a absorção foi de $62 \%$. A adição de Terbutrine ao glifosate resultou em diminuição da translocação para todos os níveis de umidade do solo, exceto o de $20 \%$ a $15 \mathrm{~cm}$ de altura.

Os efeitos da temperatura e do fotoperiodismo, na translocação do glifosate em A. repens indicaram que para as condições de Nova York, as épocas ótimas para aplicar glifosate estão compreendidas entre fins de maio a outubro (MAJEK, 1980).

Segundo HILLER e SMID (1981), sob condições de casa de vegetação 14C-glifosate aplicado na folhagem de batata voluntária foi translocado para todas as partes da planta, dentro de quatro dias.

Os resultados de HARRISON et alii (1981), indi 
caram que o pré-tratamento com GAF 141 a 2000 ppm, aumentou a translocação de dicamba em $197 \%$, e a de glifosate em $80 \%$, em relação a testemunha. Os aumentos apōs o pré-tratamento com GAF 010 a 2000 ppm foram $293 \%$ e 203\%, respectivamente. Em todos os tratamentos, uma proporção significativamente maior de dicamba do que de glifosate foi translocada para todas as partes da planta. Segundo os autores não foram observadas di ferenças significativas na quantidade absorvida e retida nas folhas, para ambos herbicidas, por 48 horas.

BALYAN et alii. (1981) estudaram o efeito de so luções de glifosate nas concentrações de 0,2;0,4 e 0,6\% apli cadas em Typha angustata e observarali nue ramos cortacios rente ao solo $15,24,48,72$ e 96 horas após apiicação do glifosate reduziu a rebrota de $T$. angustata paralelamente a aumento da concentração de $0,2 \%$ para $0,4 \%$. Na concentração de $0,2 \%$, ocorreu máxima translocação após 72 horas. Concluem os autores que para o controle completo desta planta daninha, foram necessários intervalos de 96 horas, 24 horas e 12 horas, apös a aplicação e o corte para as doses de $0,2 \% ; 0,4 \%$ e $0,6 \%$, res pectivamente.

Glifosate a 0,56 e $2,22 \mathrm{~kg} / \mathrm{ha}$ deu melhor controle de A. repens, no campo, quando apiicados em baixos volu mes do que em altos volumes (19 versos $234 \mathrm{l} / \mathrm{ha}$ ). Estudos pos teriores a campo e em casa de vegetação indicaram que o desem penho do glifosate no controle desta planta daninha, sob condições ambientais desfavoráveis, poderia ser melhorado pelo aumento 
da concentração do herbicicia e do surfactante, provavelmente pelo aumento da penetração cuticular. Maiores níveis de $14 C-g l i f o s a t e$ foram translocados nas plantas que cresciam a $210 \mathrm{C}$ do que naquelas que cresciam tanto a 11 como a 320C. Plan tas crescendo a $320 \mathrm{C}$ foram as que mais responderam aos aumentos das concentrações de glifosate e surfactante (ERICKSON, $1981)$.

Segundo GHANUNI (1981), māxima absorção de $14 C$ -glifosate por Convolvulus arvensis ( $30 \%$ do total aplicado), ocorreu em 144 horas. Porëm, translocação da radioatividade ocor reu através da planta dentro de 2,5 horas apös aplicação.

No experimento realizado por. O'DONOVAN e O'SUL LIVAN (1982), ficou demonstrado que a absorção de 14C-glifosa te pela cevada cv'Summit', continuou por até 24 horas, mas não ocorreu mais absorção com 48 horas apōs aplicação. Segundo os autores, ocorreu uma considerāvel redução na ásorção e translocação do glifosate quando este foi aplicado na super fície dá folha em uma mistura com a formulação comercial de 2,4-D amina; 2,4-D ester ou bromoxinil. Os herbicidas 2,4-D amina e bromoxinil foram responsäveis pela redução na absorção e translocação de $14 C-g l i f o s a t e$.

SOTERES (1982) verificou que a absorção de 2,4-D, dicamba e glifosate, tanto em folhas basais como termi nais, foi aumentada pela adição de SA-77 (4-isopropenil-1-me thilciclohexano + emulsificador), mas o aditivo resultou em maiores aumentos na absorção nas folhas basais do que nas fo- 
lhas terminais. Comenta ainda o autor que micrografias de mi croscōpio eletrónico da superfície das folkas tratadas com SA-77, mostraram uma alteração da cera epicuticular, o que talvez colaborou para o aumento da absorção.

Segundo DOLL e PIEDRAHITA (1982), dose de 1,5 $-2,0 \mathrm{~kg} / \mathrm{ha}$ de glifosate inibiram a brotação de tubërculos de Cyperus rotuncius e que foram necessärias 72 horas para comple tar a translocação com $1,0 \mathrm{~kg} / \mathrm{ha}$, enquanto 36 horas foram suficientes com $2,0 . \mathrm{kg} / \mathrm{ha}$.

DEVINE e BANDEEN (1983), observaram que em A. repens crescendo em condições de campo no outono, a absorção do glifosate pelas folhas não ulirapassou 3 dias após aplicação, enquanto a translocação para os rizomas continuou até 7 dias apōs aplicação. 
31 .

\section{Materiais e Métodos}

\subsection{LOCAIS DOS EXPERIMENTOS}

A pesquisa foi desenvolvida atraves de experi mentos com herbicidas aplicados por pulverizador convencional equipado com bico TK SS. 50 de baixo consumo de calda (350 ml/ min), conduzidos sob condições de casa de vegetação e de campo.

Na casa de vegetação do Departamento de Agricultura e Horticultura da Escola Superior de Agricultura "Luiz de Queiroz", da Universidade de São Paulo; foram conduzidos dois experimentos em vasos para o controle de cynodon dactyLon (L.) Pers. (grama seda), submetidos a quatro intervalos de chuva simulada.

O experimento de campo foi instalado e conduzi do na área experimental da Escola de Agronomia da Universidade Federal de Goiäs, em Goiānia-Go. 
O clima da região de Piracicaba - SP é Cwa, pe la classificação de KUPPEN (SETZER, 1966), ou seja, mesotērmico úmido subtropical com inverno seco. A situação geogräfi ca.de Piracicaba - SP é longitude 47038'00"W; latitude 22042' 9"S; altitude $540 \mathrm{~m}$.

o clima da região de Goiānia-GO é B ${ }_{2} W B^{\prime} 4 a^{\prime}$ segundo THORNTHWAITE (LOBATO, 1972), ou seja:

$B_{2}=c l i m a$ ümido cujo indice efetivo de umidade è de $42 \%$;

$W=$ moderada deficiência hïdrica no inverno;

$B^{\prime} 4=$ quarto mesotérmico;

$a^{\prime}=$ com pequena variação estaciorial.

Goiãnia-GO apresenta as seguintes coordenadas geogrāficas: longitude 49015'29" W.Grwe latitude 16940'21"S.

\subsection{EXPERIMENTOS EM CASA DE VEGETAÇĀO}

3.2.1. No dia 08/09/84, foram plaritados estolões de grama seda em vasos plásticos com capacidade de $950 \mathrm{~m}$ ? e com quatro furos no fundo. Em cada vaso foram colocados cinco es tolões. Cada estolão continha, em média, trēs gemas das quais duas eram enterradas e uma ficava para fora. Este mesmo procedimento foi seguido para o experimento instalado no dia $10 / 01 / 85$. 


\subsubsection{Solo utilizado.}

Nos dois experimentos em vasos o solo utilizado foi uma Terra Roxa Estruturada série "Luiz de Queiroz", Cu彑 jas caracteristicas quîmicas e físicas encontram-se na Tabela 1 .

Tabela 1. Caracteristicas quĩmicas e físicas do solo utilizado nos dois experimentos em vasos.

\begin{tabular}{|c|c|c|c|c|c|c|c|c|c|c|}
\hline $\mathrm{pH}$ & $\begin{array}{l}\mathrm{C} \\
\%\end{array}$ & $\mathrm{PO}_{4}^{3-}$ & $\mathrm{K}^{+}$ & $\mathrm{Ca}^{2+}$ & $\mathrm{Mg}^{2+}$ & $\mathrm{A}^{3+}$ & $\mathrm{H}^{+}$ & & Limo & Argila \\
\hline, 4 & 0,99 & 0,05 & 0,28 & 3,48 & 0,76 & 0,08 & 3,84 & 42,1 & 24,3 & 33,6 \\
\hline
\end{tabular}

3.2.3. Herbicida
a) Glifosate

Formulações comerciais utilizadas: Roundup, Sting e Rodeo (Mon 0139).

Ingrediente ativo: $N$-(Fosfonometil)glicina.

Características principais: As formulações comerciais utilizadas são do tipo concentrado solúvel (C.S.) contendo no Roundup $360 \mathrm{~g} ! 1$, no Rodeo $480 \mathrm{~g} / 1$ e no Sting $150 \mathrm{~g} / 1$ do equivalente ácido. O glifosate è um herbicida de translo- 
cação apo-simplástica, que controla plantas daninhas mono e dicotiledōneas como tambēm plantas perenes devido a sua eficiente translocação aos órgãos de propagação situadas no so10. E um herbicida que atua inibindo a biossintese de aminoācidos aromáticos. E recomendado para aplicação em pōs-emergència, devido à forte adsorção que sofre pelos colóides do solo.

A $O L_{50}$ oral aguda, para ratos, é de $4.320 \mathrm{mg} /$ $\mathrm{kg}$ de peso vivo.

\subsubsection{Surfactantes e aditivos utilizados nos experimentos}

Foram utilizados: Frigate (Amina graxa etoxila da) (catiônico); Triton X45 (octil fenoxi polietoxi etanol); Triton X100 (alquil aril poliester álcool); Triton X1.14 (octil fenoxi polietoxi etanol); Triton AG-98 (octil fenoxi polietcxi etanol); Triton AF (octil fenoxi polietoxi etanol); Sinter gente (amina graxa condensada) (não ionnicos); Aterbane(fenoxi polietoxi etanol + doctil sulfocianato de sódio) (aniōnico); Atlas G3780A (amina graxa etoxilada líquida) (catiōnico); NUFilm-P (Poli-1-P-menthene) (agente adesivo); sulfato de amōnio e Natur'L óleo (óleo vegetal com duas filtragens).

\subsubsection{Tratamentos}

As combinações entre doses do herbicida surfac tantes e aditivos resultaram nos tratamentos que estão nas Ta belas 2 e 3 . 
Tabela 2. Tratamentos utilizados com as respecticas doses do ingrediente ativo (i.a.), no primeiro experimento em casa de vegetação. Experimento 1984.

\begin{tabular}{|c|c|c|c|}
\hline TRATAMENTOS/ & NOME & DOSES & CONSUMO \\
\hline PRODUTOS & COMERCIAL & $\mathrm{kg}$ do i.a./ha & CALDA I/ha \\
\hline 01. GTifosate & Roundup & 1,44 & 100 \\
\hline 02. Gl ifosate & Rodeo & 1,44 & 100 \\
\hline 03. Glifosate & Sting & 1,44 & -100 \\
\hline 04. Glifosate+Frigate & Roundup & $1,44+0,2 \% v / v$ & 100 \\
\hline 05. Glifosate+Frigate & Roundup & $1,44+0,4 \% v / v$ & 100 \\
\hline 06. Glifosate+Triton $\times 45$ & Roundup & $1,44+0,1 \% \mathrm{v} / \mathrm{v}$ & 100 \\
\hline 07. GTifosate+Triton $\times 45$ & Roundup & $1,44+0,2 \% v / v$ & 100 \\
\hline 08. Glifosate+Triton $\times 100$ & Roundup & $1,44+0,1 \% v / v$ & 100 \\
\hline 09. Glifosate+Triton $\times 100$ & Roundup & $1,44+0,2 \% v / v$ & 100 \\
\hline 10. Glifosate+Triton X114 & Roundup & $1,44+0,7 \% \mathrm{v} / \mathrm{v}$ & 100 \\
\hline 11. Glifosate+Triton Xi14 & Roundup & $1,44+0,2 \% v / v$ & 100 \\
\hline 12. Glifosate+Triton AG-98 & Roundup & $1,44+0,1 \% \mathrm{v} / \mathrm{v}$ & 100 \\
\hline 13. Glifosate+Triton AG-98 & Roundup & $1,44+0,2 \% v / v$ & 100 \\
\hline 14. Glifosate+Triton AF & Roundup & $1,44+0,1 \% v / v$ & 100 \\
\hline 15. Glifosate+Triton AF & Roundup & $1,44 \div 0,2 \% \mathrm{v} / \mathrm{v}$ & 100 \\
\hline 16. Glifosate+Sintergente & Roundup & $1,44+0,1 \% v / v$ & 100 \\
\hline 17. Glifosate+Sintergente & Roundup & $1,44+0,2 \% v / v$ & 100 \\
\hline 18. Glifosate+NU-Film-P & Roundup & $1,44+0,1 \% \mathrm{v} / \mathrm{v}$ & 100 \\
\hline 19. Glifosate+NU-Film-P & Roundup & $1,44+0,2 \% \mathrm{v} / \mathrm{v}$ & 100 \\
\hline 20. GTifosate+At las $G 3780 \mathrm{~A}$ & Rodeo & $1,44+0,1 \% \mathrm{v} / \mathrm{v}$ & 100 \\
\hline 21. Glifosate+Atlas G3780A & Rodeo & $1,44+0,2 \% \vee / v$ & 100 \\
\hline 22. Glifosate+S. de amônio & Roundup & $1,44+2,5 \% p / v$ & 100 \\
\hline 23. Glifosate+S. de amōnio & Roundup & $1,44+5,0 \% \mathrm{p} / v$ & 100 \\
\hline 24. Glifosate+Natur' Lóleo & Roundup & $1,44+0,5 \% v / v$ & 100 \\
\hline 25. Glifosate+Natur'Lóleo & Roundup & $1,44+1,0 \% v / v$ & 100 \\
\hline 26. Glifosate+Aterbane & Roundup & $1,44+0,2 \% v / v$ & 100 \\
\hline 27. Glifosate (Testemunha) & Roundup & 1,44 & 100 \\
\hline 28. Testemunha s/produto & - & - & - \\
\hline
\end{tabular}


Tabela 3. Tratamentos utilizados, com as respectivas doses do ingrediente ativo (i.a.), no segundo experimento em casa de vegetação. Experimento 1985.

\begin{tabular}{|c|c|c|c|}
\hline $\begin{array}{l}\text { TRATAMENTOS/ } \\
\text { PRODUTOS }\end{array}$ & $\begin{array}{l}\text { NOME } \\
\text { COMERCIAL }\end{array}$ & $\begin{array}{l}\text { DOSES } \\
\mathrm{kg} \mathrm{do} \mathrm{i} . \mathrm{a} . / \mathrm{ha}\end{array}$ & $\begin{array}{l}\text { CONSUMO } \\
\text { CALDA } 1 / \text { ha }\end{array}$ \\
\hline 01. G1ifosate & Roundup & 1,44 & 100 \\
\hline 02. Glifosate & Roundup & 1,80 & 100 \\
\hline 03. Glifosate & Roundup & 2,16 & 100 \\
\hline 04. Glifosate & Sting & 1,80 & 100 \\
\hline 05. Glifosate & Rodeo & 1,80 & 100 \\
\hline 06. Glifosate+Frigate & Roundup & $1,80+0,2 \% \mathrm{v} / \mathrm{v}$ & 10 \\
\hline 07. Glifosate+Frigate & Roundup & $1,80+0,4 \% v / v$ & 100 \\
\hline 08. GTifosate+Triton $\times 45$ & Roundup & $1,80+0,1 \% \mathrm{v} / \mathrm{v}$ & 100 \\
\hline 09. Glifosate+Triton $\times 45$ & Roundup & $1,80+0,2 \% \mathrm{v} / \mathrm{v}$ & 100 \\
\hline 10. Glifosate+Triton $\times 100$ & Roundup & $1,80+0,1 \% \vee / v$ & 100 \\
\hline 11. Glifosate+Triton $\times 100$ & Roundup & $1,80+0,2 \% \mathrm{v} / \mathrm{v}$ & 100 \\
\hline 12. Glifosate+Triton $\times 114$ & Roundup & $1,80+0,7 \% v / v$ & 100 \\
\hline 13. Glifosate+Triton $\times 114$ & Roundup & $1,80+0,2 \% \mathrm{v} / \mathrm{v}$ & 100 \\
\hline 14. Glifosate+Triton AG-98 & Roundup & $1,80+0,1 \% \mathrm{v} / \mathrm{v}$ & 100 \\
\hline 15. Giifosate+Triton AG-98 & Roundup & $1,80+0,2 \% v / v$ & 100 \\
\hline 16. Glifosate+Triton AF & Roundup & $1,80+0,1 \% v / v$ & 100 \\
\hline 17. GTifosate+Triton AF & Roundup & $1,80+0,2 \% v / v$ & 100 \\
\hline 18. Glifosate+S intergente & Roundup & $1,80+0,1 \% \mathrm{v} / \mathrm{v}$ & 100 \\
\hline 19. Glifosate+S intergente & Roundup & $1,80+0,2 \% \mathrm{v} / \mathrm{v}$ & 100 \\
\hline 20. Glifosate+NU-Film-P & Roundup & $1,80+0,1 \% \vee / v$ & 100 \\
\hline 21. Glifosate+NU-Film-P & Roundup & $1,80+0,2 \% \mathrm{v} / \mathrm{v}$ & 100 \\
\hline 22. Glifosate+Atlas G3780A & Rodeo & $1,80+0,1 \% \mathrm{v} / \mathrm{v}$ & 100 \\
\hline 23. Glifosate+Atlas G3780A & Rodeo & $1,80+0,2 \% \mathrm{v} / \mathrm{v}$ & 100 \\
\hline 24. Glifosate+S. de amōnio & Roundup & $1,80+2,5 \% p i v$ & 100 \\
\hline 25. Glifosate+S. de amōnio & Roundup & $1,80+5,0 \% \mathrm{p} / \mathrm{y}$ & 100 \\
\hline 26. Glifosate+Natur'Löleo & Roundup & $1,80+1,0 \% v / v$ & 100 \\
\hline 27. Glifosate+Natur'Lóleo & Roundup & $1,80+2,0 \% v / v$ & 100 \\
\hline 28. Glifosate (Testemunha & Roundup & 1,80 & 100 \\
\hline 29. Testemunha s/produto & - & - & - \\
\hline
\end{tabular}


3.2.6. Delineamento experimental

0 delineamento experimental adotado para os ex perimentos em vasos foi um esquema fatorial em blocos casuali zados com quatro repetições. No primeiro experimento adotouse o fatorial $27 \times 4$ e no segundo $28 \times 4$, onde 27 e 28 significam tratamentos e 4 as frequencias de chuva.

\subsubsection{Adubação e condução das plantas de grama seda}

Os experimentos em vasos não foram adubados. Pa ra uniformizar a altura e idade dos colmos da grama seda antes da aplicação, fez-se uma poda na folhagem do segundo experimento com uma antecedéncia aproximada de um més da aplica ção. Para o primeiro experimento não se adotou tal procedimen to.

\subsubsection{Equipamento de aplicação}

Utilizou-se um pulverizador costal a pressão constante da R\&D Sprayer, modelo A e barra com $1,0 \mathrm{~m}$ de comprimento, com dois bicos do tipo defletor TK SS.50, distancia dos $1,0 \mathrm{~m}$ um do outro e trabalhando com uma pressão de $2,1 \mathrm{~kg} /$ $\mathrm{cm}^{2}$. Este equipamento foi utilizado na instalação dos dois experimentos em casa de vegetação e no de campo. 0 consumode calda para os trés experimentos foi de $1001 / \mathrm{ha}$. 


\subsubsection{Aplicação dos tratamentos e condições} climäticas.

\section{a) Experimento em vasos 1984:}

A aplicação foi realizada no dia $28 / 10 / 84$, ou seja, 50 dias apōs o plantio, quando a grama seda tinha uma altura aproximada de $0,25 \mathrm{~m}$. No começo da aplicação a temperatura dentro da casa-de-vegetação era de $280 \mathrm{C}$ e a umidade re lativa $59 \%$.

A aplicação foi iniciada às $7 \mathrm{~h}$ e $30 \mathrm{~min}$ e terminada às 9:00 h. Ao final da aplicação a temperatura dentro da casa de vegetação era de 31,50 C e $52 \%$ a umidade relati va do ar.

b) Experimento em vasos 1985:

A aplicação foi realizada no dia 22/02/85, ou seja, 43 dias após o plantio. A grama seda tinha uma altura. em torno de 0,20m. No iñ̄cio da aplicação a temperatura dentro da casa de vegetação era de $26,50 \mathrm{C}$ e a umidade relativa 87\%. A aplicação começou às $7 \mathrm{~h}$ e $45 \mathrm{~min}$ e terminou às $8 \mathrm{~h}$ e 48 min. Ao final da aplicação, a temperatura era de $30,50 \mathrm{C}$ e $82 \%$ de umidade relativa do ar.

\subsubsection{0 simulador}

Consiste num grande coletor de ăgua contendo na parte superior uma tela em inox sobre a qual são colocados os va 
sos. A parte mecãnica é composta por um micromotor elétrico Sermar de 30 rpm e uma eletrovālvula que determina o corte do fluxo de água, que ficam acima da tela de inox com altura regulável. Foi colocada uma redução $2: 1$ para que a barrinha metálica, onde foram colocados dois bicos 80.03 nas extremida des, girasse a 15 rpm (figura 1). 0 fluxo de àgua é gerado por uma bomba centrifuga com retorno e um manómetro que determina a uniformidade deste fluxo.

\subsubsection{Chuva simulada}

Cada tratamento foi submetido a quatro intervalos de chuva ou seja: $2,4,6$ e 8 horas apōs aplicação dos tratamentos. A quantidade de chuva simulada determinada foi de $15 \mathrm{~mm}$ ou $15 \mathrm{litros} / \mathrm{m}^{2}$. Calculou-se a quantidade de àgua a cair em cada vaso em função da ärea do vaso. Assim, cada vaso colocado no simulador recebia $185 \mathrm{ml}$ de água, corresponden te a intensidade da chuva simulada pretendida.

\subsubsection{Avaliação dos experimentos.}

Os experimentos em casa de vegetação foram ava 7 iados a cada 10 dias a partir dos 10 até 60 dias após a apli cação. o controle da grama seda foi registrado mediante avaliação visual, usando-se a escala da Asociaciōn Latinoamerica na de Malezas (ALAM), que se encontra ria Tabela 4.

$\mathrm{Na}$ ūltima avaliação aos 60 dias após aplicação, foi tomado o número de plantas remanescentes por vaso 

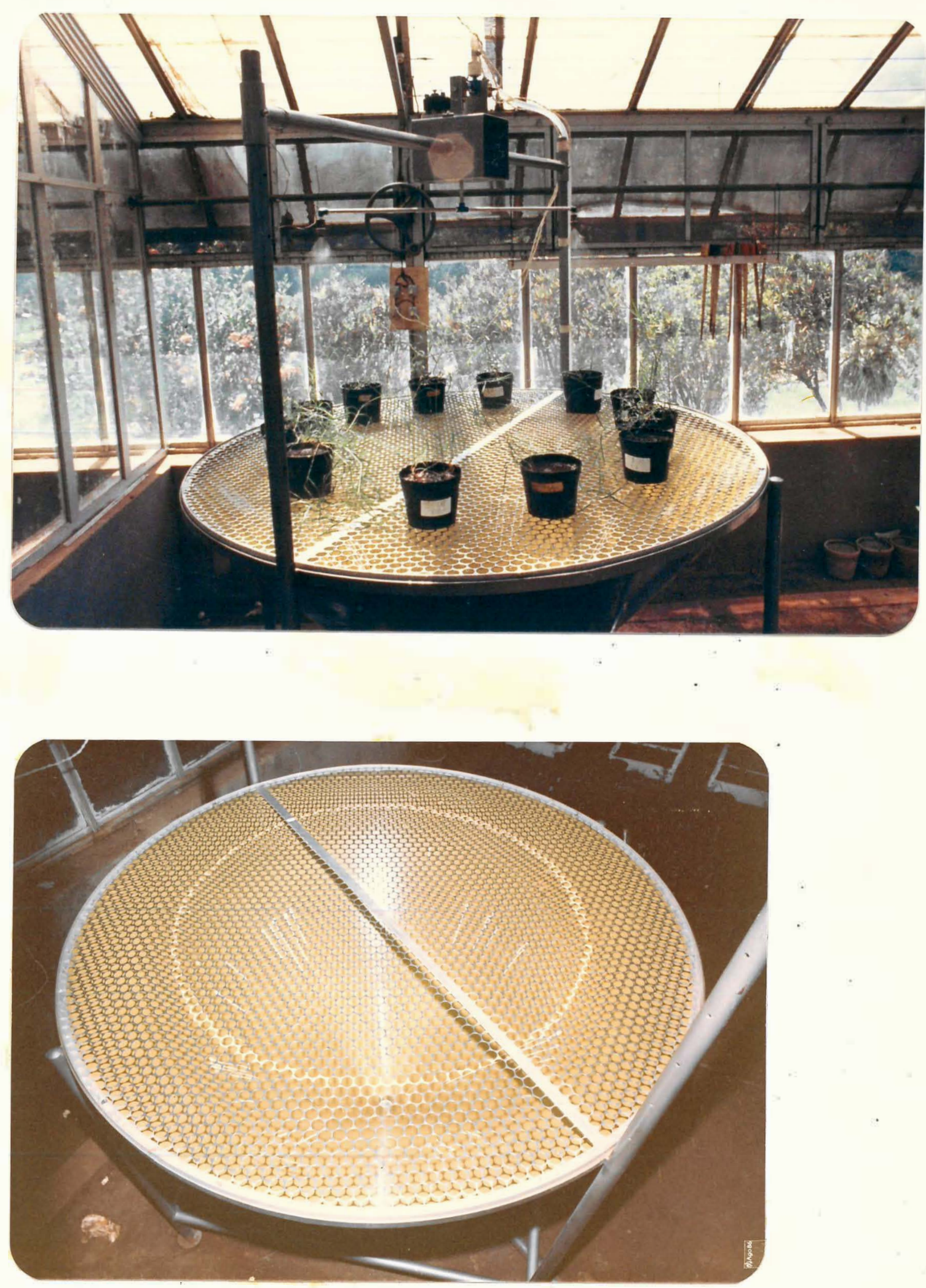

Figura 1. Aspectos do simulador de chuvas. 
nos dois experimentos, bem como determinado o peso da matéria fresca de cada vaso.

Tabela 4. Escala de avaliação visual para o controle de plantas dani.nhas dela Asociaciōn Latinoamericana de Malezas (ALAM).

Indice

Controle das plantas daninhas

\begin{tabular}{cc}
\hline $0-40$ & nulo a fraco \\
$41-60$ & regular \\
$61-70$ & suficiente \\
$71-80$ & Bom \\
$81-90$ & muito bom \\
$91-100$ & excelente \\
\hline
\end{tabular}

Fonte: Revistá ALAM 1(1): 35-38, 1974.

\subsubsection{Anälises estatisticas}

Nos dois experimentos em väsos foram realizadas anālises de variāncia e comparações de médias pelo teste de Tukey a $5 \%$ de probabilidade sobre os valores originais das avaliações visuais de controle de mortalidade, valores transformados em arc sen $\sqrt{x+1}$ e sobre suas ordens dentro de cada bloco. Dado a semelhança dos resultados entre as trés anälises, optou-se pelos dados originais, pois segundo CoNover (1980), se duas anālises chegam a resultados semelhantes (são semelhantes), e assim dā-se preferencia pela anāilise dos dados origirais. Se a anālise dos dados originais discrepa das anālises de ordem, fica-se com a ordem, pois atende melhor às suposições da anālise de variância ou do modelo. 
Quando a interação entre intervalos de chuva e herbicida foi significativa, fez-se o desdobramento e o estudo de regressão dos tratamentos dentro de cada frequência.

os dados obtidos com o peso da biomassa verde foram submetidos a anălise estatística, empregando-se assim como nas avaliações visuais, o teste $F$ e para a comparação das médias o Teste de Tukey a $5 \%$ de probabilidade.

\subsection{EXPERIMENTO EM CONDIÇOES DE CAMPO (1985)}

3.3.1. Classificação e análise do solo

Foi instalado em um Latossolo Vermelho-Amarelo diströfico e cujas características físico-químicas encontramse na Tabela 5 .

Tabela 5. Características químicas e físicas do solo onde foi conduzido o experimento.

\begin{tabular}{|c|c|c|c|c|c|c|c|c|c|c|}
\hline $\mathrm{pH}$ & $\begin{array}{l}\text { C } \\
\%\end{array}$ & $\begin{array}{c}\mathrm{P} \\
\mathrm{ppm}\end{array}$ & $\mathrm{Ca}^{2+}$ & $\begin{array}{l}\mathrm{Mg}^{2+} \\
\text { meq/100 }\end{array}$ & $\begin{array}{l}\mathrm{K}^{+} \\
\mathrm{Og} \mathrm{gle}\end{array}$ & $\begin{array}{l}A 1^{3+} \\
\text { TFSA }\end{array}$ & $\mathrm{H}^{+}$ & $\begin{array}{c}\text { Areia } \\
\%\end{array}$ & $\begin{array}{c}\text { Limo } \\
\%\end{array}$ & $\begin{array}{c}\text { Argila } \\
\%\end{array}$ \\
\hline 5,2 & 1,82 & 6,1 & 0,1 & 0,6 & 0,14 & 0,4 & 4,3 & 73 & 7 & 20 \\
\hline
\end{tabular}

3.3.2. Herbicida utilizado.

Descrito no item 3.2.3. 
3.3.3. Surfactantes e aditivos testados

Descrito no item 3.2.4.

\subsubsection{Tratamentos.}

Os tratamentos testados neste experimento encontram-se na Tabela 3.

\subsubsection{Delineamento experimental.}

0 delineamento experimental adotado foi 0 de blocos ao acaso com 28 tratamentos e 3 repetições.

A ārea da parcela foi de $4 \mathrm{~m} \times 3 \mathrm{~m}$, totalizando $12 \mathrm{~m}^{2}$, sendo a ārea total do experimento de $1392 \mathrm{~m}^{2}$.

\subsubsection{Equipamento de aplicação.}

Descrito no item 3.2.8.

\subsubsection{Estādio de aplicação.}

Os tratamentos foram aplicados quando a grama seda estava na prefloração, traduzida pelo aparecimento das primeiras inflorescências. A cobertura do solo por esta plan ta daninha era de aproximadamente $90 \%$ e com uma al tura média de 0,20m. A aplicação foi no dia 25/02/85, iniciando-se äs $9 \mathrm{~h}$ e 20 min e terminando às 11 horas e $30 \mathrm{~min}$. 


\subsubsection{Condições climāticas na aplicação.}

No momento da aplicação o solo estava úmido e a grama seda em excelente atividade fisiológica. A umidade relativa do ar variou de $71 \%$ no início da aplicação a $58 \%$ ao final. Quanto a temperatura ela oscilou de $280 \mathrm{C}$ a $310 \mathrm{C}$. 0 ceu variou de claro a parcialmente encoberto, e a velocidade do vento de $4-6 \mathrm{~km} /$ hora.

\subsubsection{Avaliação do experimento}

Foram realizadas duas avaliações visuais do ín dice de mortalidade aos 30 e 60 dias após aplicação, usando se a escala da Asociación Latinoamericana de Malezas (ALAN), jä descrita na Tabela 4.

\subsubsection{Anālise estatistica}

Adotou-se o mesmo procedimento dos experimentos em casa de vegetação, utilizando-se, tambēm, neste experimento os dados originais. 


\section{Resultados e Discussão}

\subsection{EXPERIMENTO EM CASA DE VEGETAÇAO (1984)}

Nas Tabelas 6 e 6 a são apresentadas as compara ções de médias de todos os tratamentos pelo teste de Tukey. a $5 \%$ de probabilidade envolvendo todas as frequências de simulação de chuva nas 6 avaliações realizadas. Observa-se por esta tabela que alguns tratamentos jā apresentavam aos 10 dias após aplicação indices de controle de Cynodon dactylon (L.) Pers., superiores ao glifosate sozinho. Acredita-se que este fato esteja relacionado com um possível efeito sinergistico dos surfactantes e do óleo vegetal ao glifosate, aumentando a velocidade da penetração cuticular e consequentemente, maior absorção.

Este comportamento foi mantido pela maioria deles, nas avaliações subsequentes e aos 60 dias apōs aplicação, verificou-se que aqueles tratamentos que apresentaram, inicialmente, os melho- 
Tabela 6. Percentagem de controle da grama-seda pelos tratamentos, envolvendo os quatro intervalos de simulação de chuva nas seis épocas de avaliação (média de 4 repetiçôes). Experimento 1984.

TRATAMENTOS/

PRODUTOS
DOSE

$\mathrm{kg}$ do $\mathrm{ia/ha}$
$\%$ CONTROLE

10 DAT 20 DAT 30 DAT

01. Glifosate (Roundup)

02. Glifosate (MON 0139)

03. Glifosate (Sting)

04. Glifosate+Frigate

05. Glifosate+Frigate

06. Glifosate+Triton $\times 45$

07. Glifosate+Triton $\times 45$

08. Glifosate+Triton $\times 100$

09. Glifosate+Triton $\times 100$

10. Glifosate+Triton $\times 114$

11. Glifosate+Triton $\times 114$

12. Giifosate+Triton AG-98 1,44+0, 1\%v/v

13. Glifosate+Triton $\mathrm{Ag}-98.1,44+0,2 \% \mathrm{~V} / \mathrm{V}$

14. Glifosate+Triton $A F$

$1,44+0,1 \% v / v$

15. Glifosate+Triton AF

$1,44+0,2 \% v / v$

16. Glifosate+Sintergente

$1,44+0,7 \% v / v$

17. Glifosate+Sintergente

$1,44+0,2 \% v / v$

18. Glifosate+NU-Film-P

$1,44+0,1 \% \mathrm{v} / \mathrm{v}$

19. Glifosate+NU-Film-P

$1,44+0,2 \% v / v$

20. MON $0139+$ At las $\quad 3780 \mathrm{~A}$

21. MON 0139+At 1as G3780A

$1,44+0,1 \% \mathrm{v} / \mathrm{v}$

$1,44+0,1 \% v / v$

$1,44+2,5 \% \mathrm{p} / \mathrm{v}$

22. Glifosate+S. de amõnio

23. Glifosate+S. de amōnio $1,44+5,0 \% \mathrm{p} / \mathrm{v}$

24. Glifosate+Natur'Lóleo $1,44+0,5 \% \mathrm{v} / \mathrm{v}$

25. Glifosate+Natur'Lóleo 1,44+1,0\%v/v

26. Glifosate+Atae rbane $1,44+0,2 \% v / v$

27. Glifosate-Roundup-Test.

\begin{abstract}
1,44
\end{abstract}
*3, 1abcdef $45,6 \mathrm{abcd}$

$58,1 \mathrm{abcd}$

4,0 abcd $28,1 d$

$36,2 d$

$0,0 f$

$2,2 i$

$5,6 f$

$0,9 f$

$2,2 i$

$1,9 f$

2,5 bcdef

29 , obcdef

37,2 de

$0,0 f$

$1,2 i$

$3,1 f$

$14,4 a$

$67,5 a$

$87,5 a$

$0,6 \mathrm{f}$

$4,4 a b c d$

$12,8 \mathrm{fghi}$

$11,9 \mathrm{~h}$

$52,8 \mathrm{abc}$

$75,0 \mathrm{abc}$

1,6 cdef

21,9 defgh

36,2 de

$5,9 a b c$

$51,9 a b c$

$70,0 \mathrm{abc}$

$0,3 e f$

$2,5 \mathrm{hi}$

$0,0 f$

$10,0 a b$

$46,6 a b c$

$74,4 a b c$

$0,0 f$

3,1 hi

$0,6 f$

3,4 abcde

$42,8 a b c d$

$83,7 a b$

1,6 cdef

36, labcd

$50,3 b c d$

$6,2 a b c$

$65,3 a b c$

$80,0 a b$

$0,0 f$

$9,7 a b$

$0,3 e f$

4,4 cdef

$8,1 \mathrm{ghi}$

$0,3 f$

$40,6 \mathrm{abcd}$

$51,9 b c d$

11,2 efghi $6,2 f$

1,6 cdef

23,7 cdefg

$41,2 \mathrm{~cd}$

5,0 abcd

11,2 efghi

$10,6 \mathrm{ef}$

0, ef

$37,2 \mathrm{abcd}$

62,5 abccie

$7,5 a b c$

$7,5 \mathrm{ghi}$

$7,8 f$

$0,0 f$

$48,1 a b$

$79,7 a b$

0,9 def
3, ihi

$23,7 b c$ def
$1,2 f$

$40,6 \mathrm{~cd}$

(*) Médias seguidas pela mesma letra não diferiram estatisticamente pelo teste de Tukey a $5 \%$ de probabilidade. 
Tabela 6a. Percentagem de controle da grama-seda pelos tratamentos, envol vendo os quatro intervalos de simulaçäo de chuva nas seis épocas de avaliação (média de 4 repetiçoes).

TRATAMENTOS/

PRODUTOS

\section{DOSE \\ $\mathrm{kg}$ do ia/ha}

$\%$ CONTROLE

40 DAT

50 DAT

60 DAT

$* 56,2$ abcdef 65,6 abcde 62,8 abcd

01. Glifosate (Roundup)

1,44

50,0 abcdefg 57,5 bcdef

$55,6 \mathrm{bcde}$

02. Glifosate (MON 0139)

1,44

1,44

$28,4 \mathrm{fg}$

$26,9 \mathrm{ghi}$

$16,9 h \mathrm{i}$

04. Glifosate+Frigate

$1,44+0,2 \% v / v$

$47,5 \mathrm{fg}$

31,9 efghi 13, thi

05. G] ifosate+Frigate

$1,44+0,4 \% v / v \quad 28,7 \mathrm{fg}$

57,4 cdefg

$59,0 \mathrm{abcd}$

06. Glifosate+Triton $\times 45$

$1,44+0,1 \% \mathrm{v} / \mathrm{v} \quad 28,4 \mathrm{fg}$

20, Ohij

$11,9 i$

07. Glifosate+Triton $X 45$

$1,44+0,2 \% \mathrm{v} / \mathrm{v} \quad 75,9 \mathrm{ab}$

$84,4 a$

$86,9 a$

08. Glifosate+Triton $\times 100$

$1,44+0,1 \% \mathrm{~V} / \mathrm{v} \quad 27,2 \mathrm{~g}$

$79,7 a$

29,7 fgh

$20,6 \mathrm{fghi}$

09. Glifosate+Triton $\times 100$

$1,44+0,2 \% \mathrm{v} / \mathrm{v}$

40,6 de fg

$85,3 \mathrm{a}$

88,12

10. Glifosate+Triton $\times 114$

$1,44+0,1 \% v / v$

$7 i, 6 a b c$

46,2 defghi

43,1 de fgh

11. Glifosate+Triton $\times 114$

$7,44+0,2 \% \mathrm{v} / \mathrm{v}$

$24,4 \mathrm{gh}$

$77,2 a b c$

$85,0 \mathrm{ab}$

$16,9 \mathrm{ij}$

13, ihi

$69,7 a b c d$

$82,5 a b$

$81,9 a b c$

$32,5 \mathrm{efg}$

25,Oghi

$17,5 \mathrm{hi}$

$74,1 a b$

$82,8 a b$

$80,3 \mathrm{abc}$

15. Glifosate+Triton AF
16. Glifosate+Sintergente

17. Glifosate+Sintergente

18. Glifosate+NU-Film-P

$1,44+0,2 \% \mathrm{v} / \mathrm{v}$

$50,6 a b c d$

$1,44+0,2 \% \mathrm{v} / \mathrm{v} \quad 77,5 \mathrm{ab}$

50,6 cdefg

51,9 coe

85,0 a

$87,5 a$

$1,44+0,1 \% \mathrm{v} / \mathrm{v}$

$27,8 \mathrm{fg}$

20, Ohij

$15,6 h i$

19. Glifosate+NU Film-P

$1,44+0,2 \% \mathrm{v} / \mathrm{v}$

60,0 abcde

61,8 abcde

$62,5 a b c d$

20. MON $0139+$ At 1as G $3780 A$

27. MON $0139+A t 7 a s$ G 3780 A

22. Glifosate+S. amōnio

$1,44+0,7 \% \mathrm{v} / \mathrm{v}$

28, if $\mathrm{g}$

23 , Ighi

$20,6 g h i$

$1,44+0,2 \% \mathrm{v} / \mathrm{v}$

42,5 cdefg

48,4 defgh

48,4 defg

$1,44+2,5 \% \mathrm{p} / \mathrm{v} \quad 25,6 \mathrm{gh}$

$22,7 \mathrm{hi}$

$18,7 \mathrm{ghi}$

$1,44+5,0 \% p / v$

67,6 abcde

$67,2 a b c d$

$72,5 a b c d$

$1,44+0,5 \%$, v $31,2 \mathrm{efg}$

$31,9 \in$ fghi

27,5 efghi

$1,44+1,0 \%$ v/v $81,2 a$

$83,4 a b$

$86,5 \mathrm{a}$

$1,44+0,2 \% \mathrm{v} / \mathrm{v} \quad 35,6 \mathrm{efg}$

$25,3 \mathrm{ghi}$

$16,2 \mathrm{hi}$

52 , 8abcdefg 61,6 abcdef 49,7 def

27. Glifosate(Roundup)-Test. 1,44

40,82

36,41

35,16

C.V. $(\%)$

(*) Médias seguidas pela mesma letra näo diferiram entre si estatisticamente pelo teste de Tukey a $5 \%$ de probabilidade. 
res percentuais de controle são os mesmos que proporcionaram indices médios de controle, envolvendo todas as frequénciasde simulação de chuva, superiores a $80 \%$, considerado neste trabalho como o limite mínimo aceitável para o controle da grama -seda.

Esses tratamentos, em ordem decrescente, foram os seguintes:

Trat. no

\begin{tabular}{|c|c|}
\hline & lifosate + Triton $\times 100(1,44 \mathrm{~kg} / \mathrm{ha}+0,2 \% \mathrm{v} /$ \\
\hline 17 & - glifosate + Sintergente $(1,44 \mathrm{~kg} / \mathrm{ha}+0,2 \% \mathrm{v} / \mathrm{v})$ \\
\hline 07 & - glifosate + Triton $\times 45(1,44 \mathrm{~kg} / \mathrm{ha}+0,2 \% \mathrm{v} / \mathrm{v})$; \\
\hline 2 & - glifosate + Natur' L óleo $(1,44 \mathrm{~kg} / \mathrm{ha}+1,0 \% \mathrm{v} / \mathrm{v})$ \\
\hline & - glifosate+ Triton $\times 114(1,44 \mathrm{~kg} / \mathrm{ha}+0,2 \% \mathrm{v} / \mathrm{v}$ \\
\hline & - glifosate + Tr.iton $A G-98(7,44 \mathrm{~kg} / \mathrm{ha}+0,2 \% \mathrm{v} / \mathrm{v})$; \\
\hline & - glifosate + Triton AF $(1,44 \mathrm{~kg} / \mathrm{ha}+0,2 \% \mathrm{v} / \mathrm{v})$ \\
\hline
\end{tabular}

Nas avaliações aos 30 e 60 dias após a aplicação a anālise estatisstica identificou interação significatị va entre Herbicidas (Tratamentos) $x$ intervalos de simulaçãode chuva. Fez-se um estudo de regressão e ficou constatado que os melhores tratamentos jā mencionados, foram tambēm aqueles que aos 60 dias após aplicação apresentaram indices de con-. trole para uma chuva simulada de $15 \mathrm{~mm}, 4$ horas após aplicação, iguais ou superiores ao limite minimo estipulado. Dentre estes tratamentos uma exceção apenas foi feita ao glifosate + Triton $\times 45(1,44 \mathrm{~kg} / \mathrm{ha}+0,2 \% \mathrm{v} / \mathrm{v})$ que atingiu um percentual de controle de $72,5 \%$ mas, incluido dentre os melhores uma vez 
que na Tabela 6 e 6 a foi um dos que apresentou os mais altos Indices de mortalidade e tambēm por apresentar îndice de $80 \%$ aos 30 e 60 DAT para uma chuva 2 horas apōs aplicação.

Assim a discussão dos resultados serä concentra da na comparação dos melhores tratamentos entre si e ao trata mento glifosate (Roundup) aplicado sozinho a $1,44 \mathrm{~kg} / \mathrm{ha}$, submetido tambēm à mesma chuva simulada.

$\mathrm{Na}$ Figura 2 são apresentadas as curvas de regressão para o Tratamento 1 (glifosate a $1,44 \mathrm{~kg} / \mathrm{ha}$ ). Observa-se que o comportamento do produto foi semelhante tanto aos 30 como aos 60 dias apōs a aplicação. Do mesmo modo, consta tou-se que houve uma resposta linear no controle da gramaseda quando se dilatou o prazo para 6 e 8 horas entre a aplicação e a primeira chuva subsequente.

Esperava-se tambëm que o bico de baixo volume utilizado (TK SS.50), proporcionasse maior penetração cuticular do glifosate, pelo aumento da concentração deste produto na calda de pulverização, dispensando assim a mistura de surfactantes pa ra minimizar o efeito prejudicial da chuva simulada.

Pelos resuitados do Tratamento 7 (glifosate + Triton $\times 45$ a $1,44 \mathrm{~kg} / \mathrm{ha}+0,2 \% \mathrm{v} / \mathrm{v})$, nota-se que tanto aos 30 como aos 60 dias apōs aplicação os indices de controle para uma chuva simulada 2 horas añós aplicação eram de $80 \%$. Houve um ligeiro deç̄escimo para a frequéncia de 4 horas, atribuído a algum fator inerente a prōpria planta, e independente da performance do tratamento (Figura 3 ). 


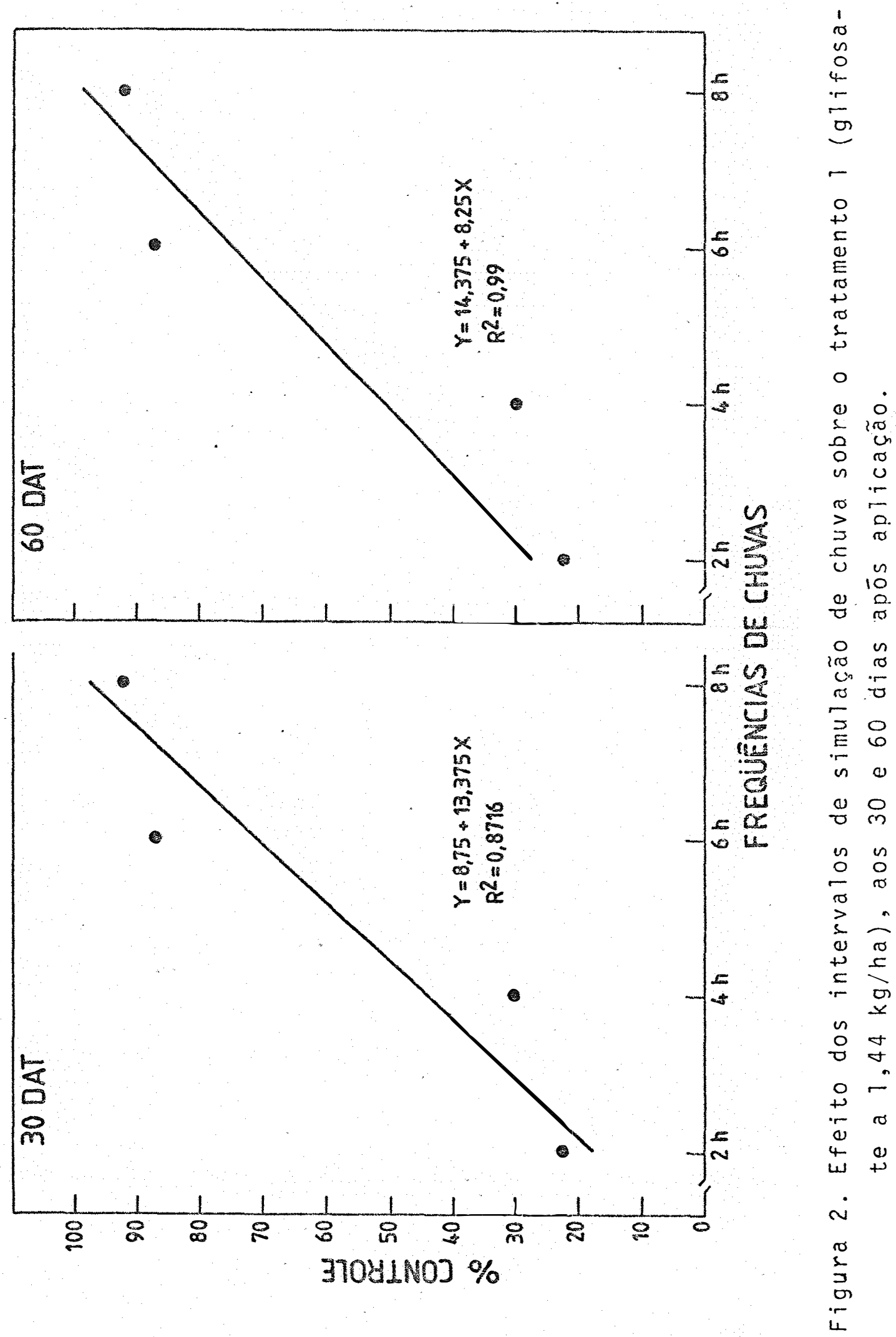


51.

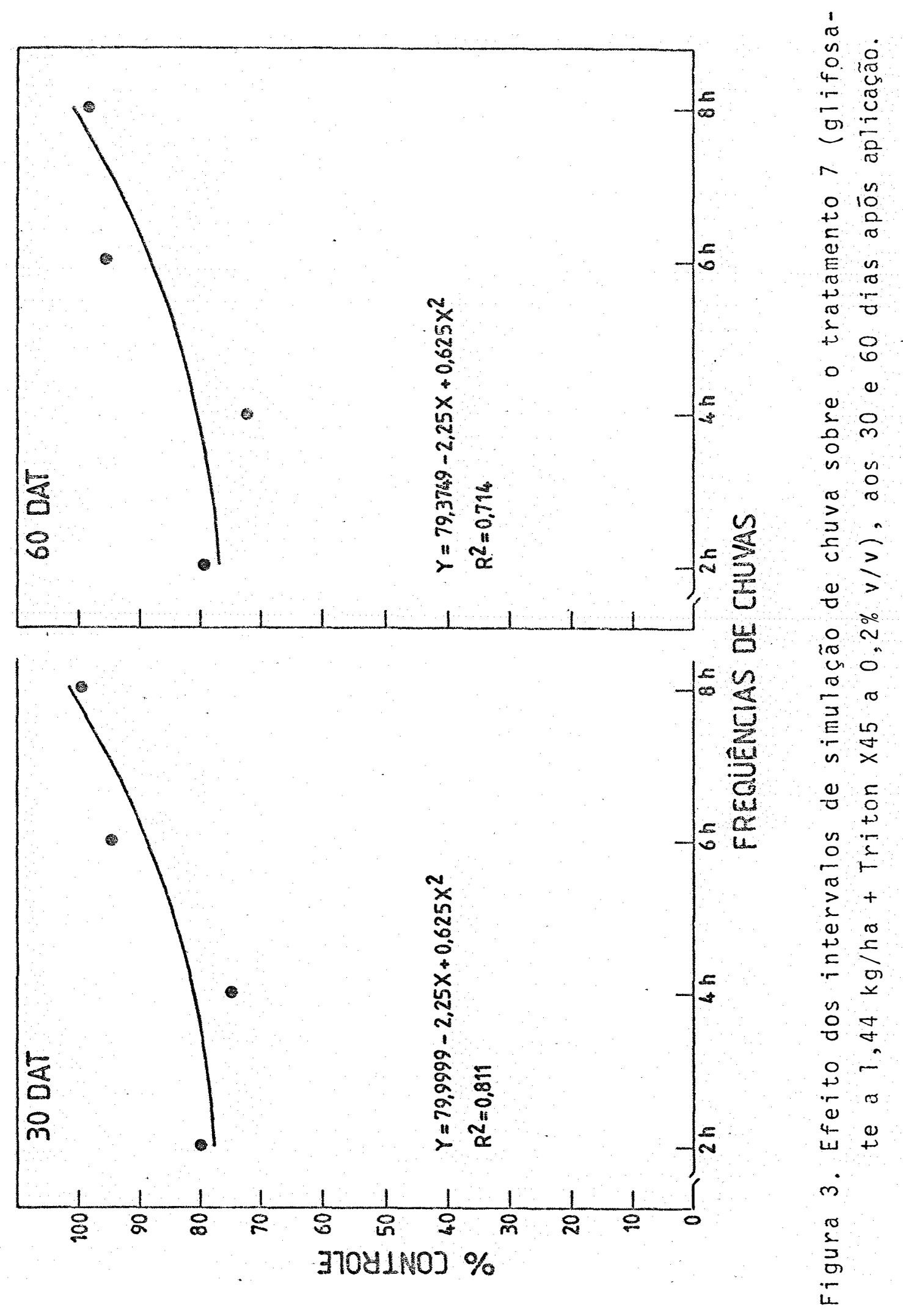


Nos demais tratamentos, glifosate + Triton X100 (Figura 4); glifosate + Triton X114 (Figura 5); glifosate + Triton AG-98 (Figura 6); glifosate + Sintergente (Figura 8); todos a $1,44 \mathrm{~kg} / \mathrm{ha}+0,2 \% \mathrm{v} / \mathrm{v}$ e glifosate + Natur'L ōleo a $1,44 \mathrm{~kg} / \mathrm{ha}+1,0 \% \mathrm{v} / \mathrm{v}$ (Figura 9), os resultados mostrados foram bastante coerentes nas avaliações aos 30 e 60 dias apōs aplicação, exceção feita ao glifosate + Triton AF a 1,44 kg/ $h a+0,2 \%$ v/v (Figura 7) que para os intervalos de chuva 2 e 4 horas apōs aplicação, houve uma redução nos indices de controle dos 30 para os 60 dias apōs aplicação.

Comparando-se as curvas de regressão da ültima avaliação de controle da grama-seda, mostradas nas figuras 3 a 9 com a Figura 2, verifica-se que os surfactantes Triton $X$ 100, Triton $\times 174$, Trigon AG-98, Triton $\times 45$ na concentração de $0,2 \%$ v/v e o Natur'L ōleo a $1,0 \%$ v/v, aumentạ ram a eficiēncia do glifosate no controle da grama-seda e reduziram em $66 \%$ o tempo mínimo necessārio entre a aplicação e uma chuva, estipulado pelo fabricante em 6 horas, e que com a adição desses surfactantes pode ser reduzida para 4 horas.

Contudo, quando se manteve o intervalo de 6 horas, jā mencionado, entre a aplicação e a chuva simulada, foi suficiente para anular o efeito benéfico destes surfactantes e do óleo vegetal, confirmando mais uma vez que a adição deles é in dispensāvel nara minimizar o efeito da chuva. Os resultados de LIU (1981), sustentam esta afirmativa uma vez que concluiu que em 


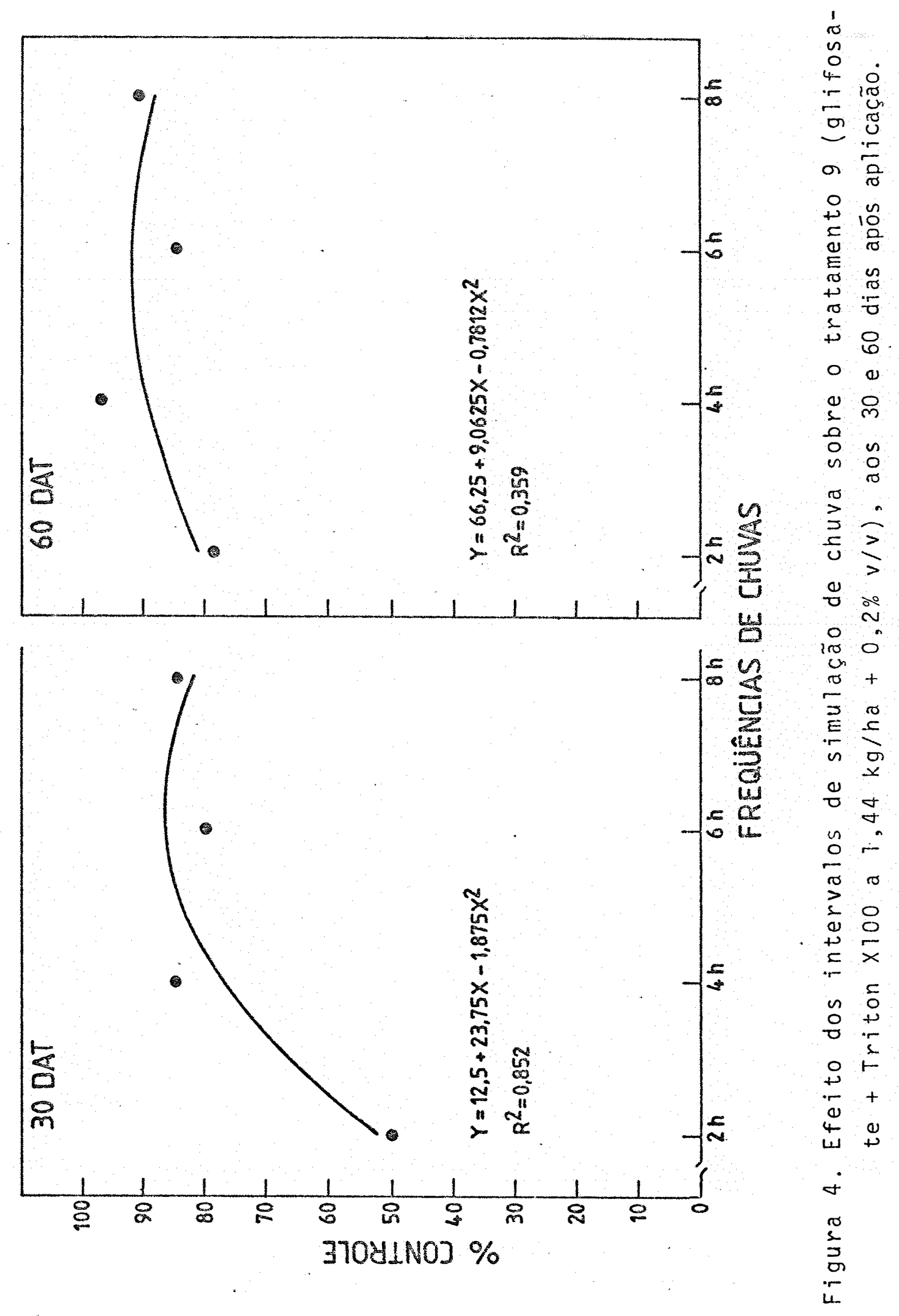


54.

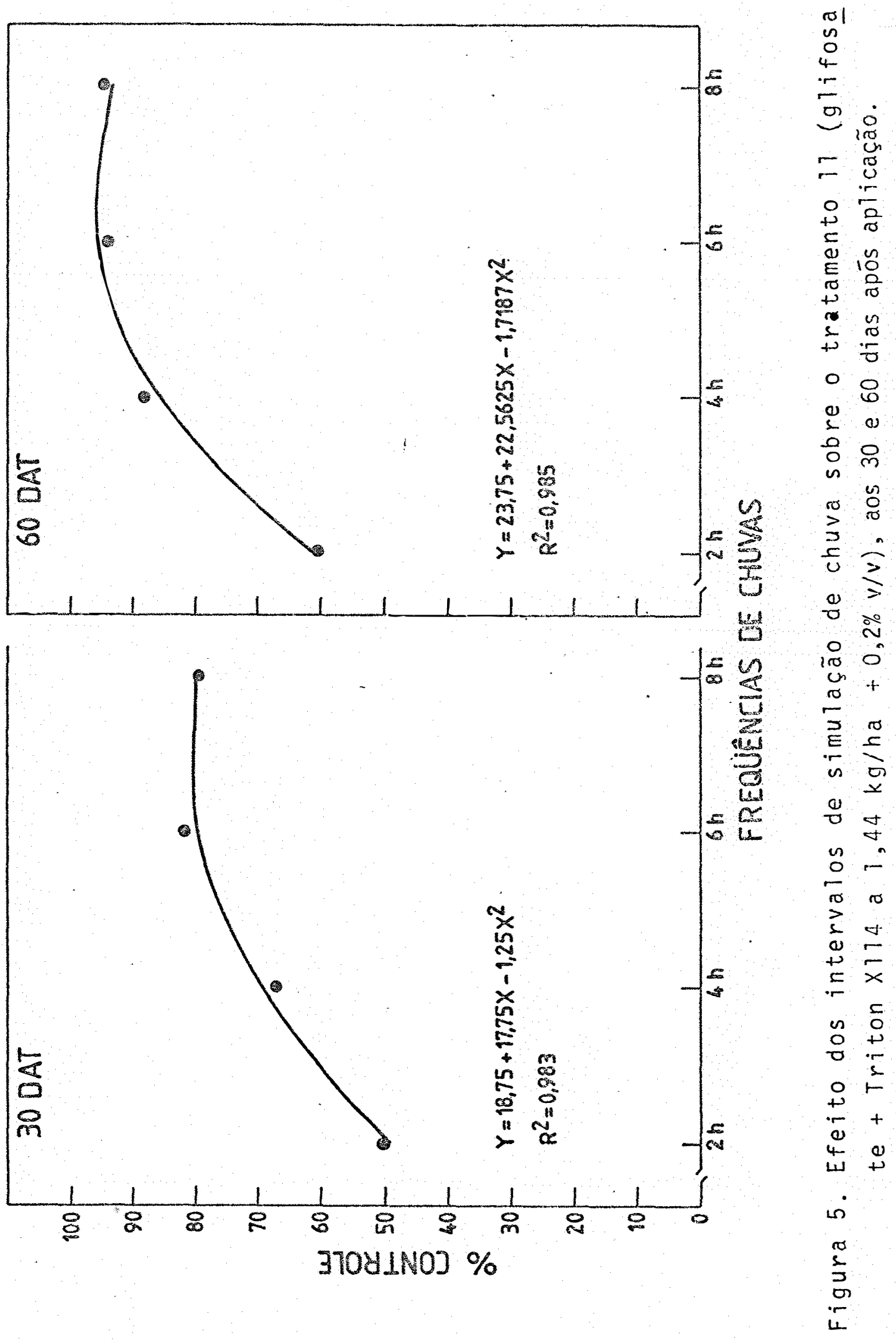




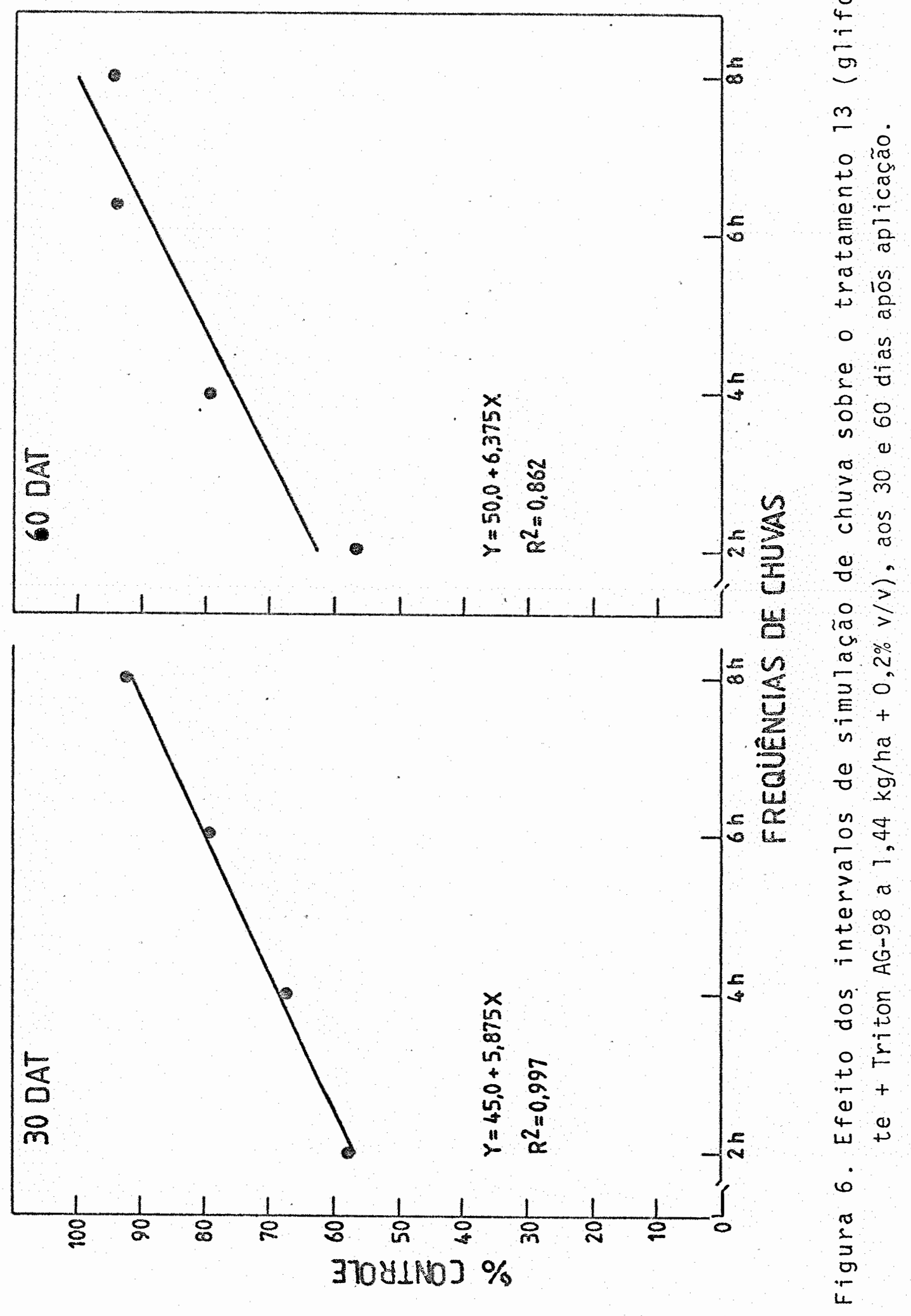




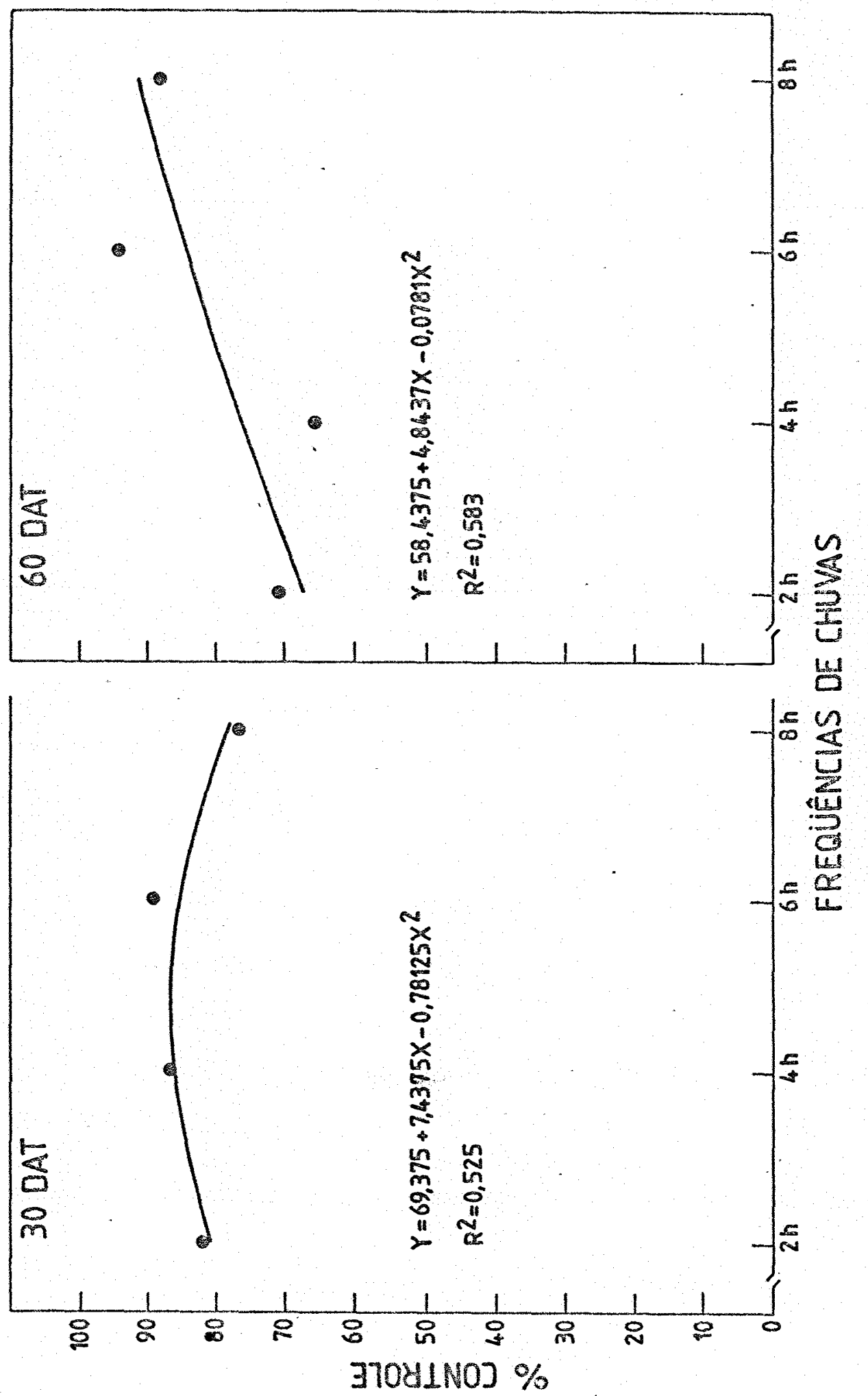

0
0
0
4
5
0

$\leftarrow$

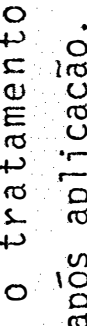

Q $v$

0 0

( 0

$\begin{array}{ll}\pi & 0 \\ 2 & 0 \\ \frac{2}{U} & 0\end{array}$

o $n$

0

on $>$

이 $>$

E N

in 0

0.

m $\frac{5}{0}$

$0 \pm$

$\nabla+$

i) -

+

- L

n 5

0 +

01

$+$

4 क क

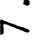

10
2
0
0
11 


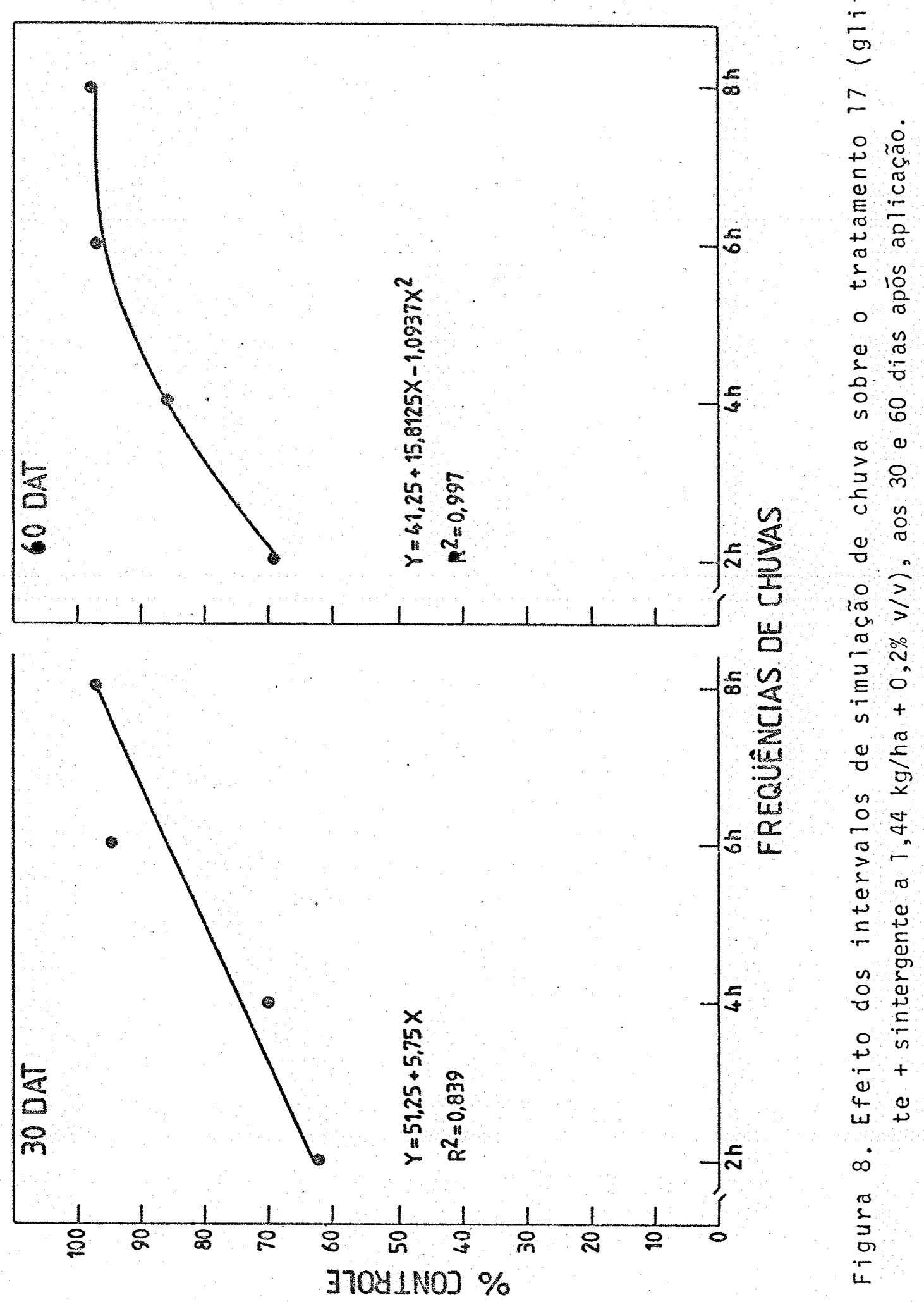




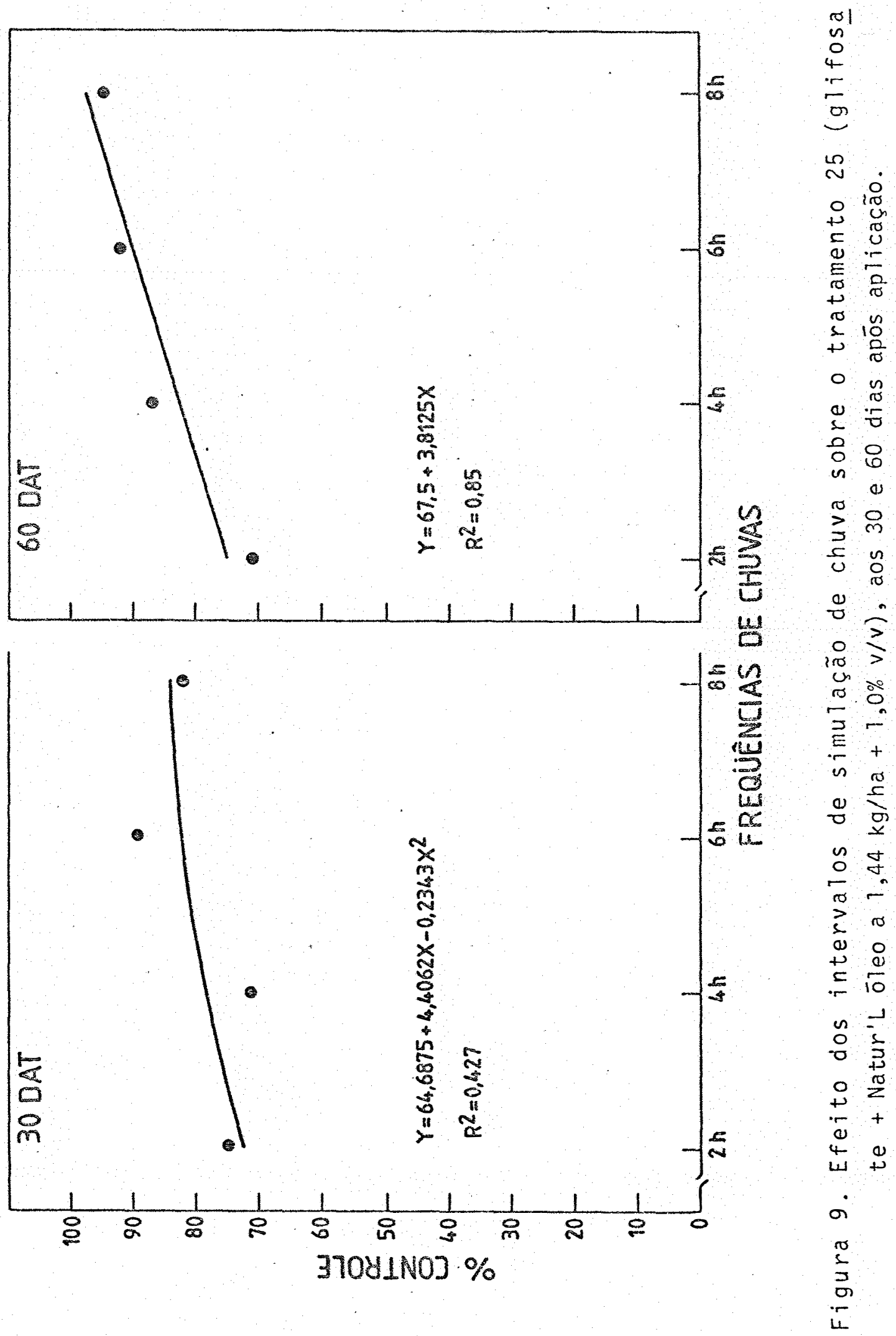


grama-seda (Cynodon dactylon L. Pers.); a grande maioria do glifosate aplicado sō foi absorvido pelas plantas dentro de 6 horas.

os resultados deste trabalho estão concordantes tambēm, com aqueles obtidos por INDIA, TEA RESEARCH ASSOCIATION (1977) e RAO et alij (1978), em que a adição do Triton $A E$ não teve um grande efeito na atividade do glifosate, mas reduziu o efeito prejudicial de uma chuva 1-2 horas após aplicação do herbicida, do mesmo modo que a adição do sulfato de amōnio não proporcionou redução no tempo necessārio entre a aplicação e a primeira chuva como cita TURNER (1976).

Comparando-se as curvas de regressão dos melho res tratamentos, entre si, observa-se que eles apresentaram comportamento semelhante não havendo diferença significativa en tre as 4 frequéncias de chuva estudadas, dentro de cada tratamento, pela comparação de mēdịas pelo teste de Tukey a $5 \%$ de probabilidade aos 60 dias apōs aplicação.

0 aumento da atividade de glifosate aos 10 DAT, pela adição de alguns surfactantes a $0,2 \%$ v/v (Tabela 6 e $6 a$ ) foi tambēm observado aos 30 e 60 dias após a aplicação, concordando assim com a literatura, on de os trabalhos tēm confirmado que o uso de surfactantes melhoram a atividade do glifosate no controle dé vārias plantas daninhas, principalmente quando são utilizadas doses mais baixas que as normalmente recomendadas para este produto (WYRILL, 1976; MCWHORTER, 1977 ; RICHARD Jr. e SLIFE, 1979 ; CHY- 
KALIUK et a $1 \mathrm{i} i, 1980$; JORDAN, 1981; ERI.CKSON e DUKE, 1981; TROTMAN et alii, 1981; DUTT, 1981 e TURNER, 1981).

Acredita-se que o efeito sinergistico destes surfactantes adicionados ao glifosate, minimizando o efoito da chuva simulada quatro horas apōs aplicação esteja relacionaco com uma maior absorção e translocação do produto por facilitar sua penetração cuticular. Esta afirmativa é sustentata na literatura pelos trabalhos de TURNER e LOADER (1974); GOTTRUP et alii (1976); CHYKALIUK et alii (1979); MCALLISTER e HADERLIE (1979); e também pelos trabalhos de ZANDSTRA e NISHIMOT0, 1977); ERICKSON e DUKE (1981); HILLER e SMID (1981), BALYAN et alii. (1981); GHANUNI (1981); O'DONOVAN e O'SULLIVAN (1981); DOLL e PIEDRAHITA (1982) e DEVINE e BANDEEN (1983), cujos resultados mostraram que o movimento do glifosate atravēs da cutícula é linear ao tempo e que a absorção e translocação nas diversas plantas daninhas testadas, prolongou-se na maioria dos casos até 72 horas após a aplicação, dependendo da concentração do produto na calda de pulverização.

Neste trabalho não se observou também algum efeito da ionogeneidade dos surfactantes na atividade do glifosate estan do assim, em discordāncia com WIRILL (1976) e AMPONG - NYARKO (1980) que afirmaram serem os surfactantes catiōnicos mais efe tivos que os não iônicos. Houve contudo, certa concordância com os resultados alcançados por BUNDICK e MITCHELL (1979); CHYKALIUK et alii (1980), STUDT e. NELSON (1981) e DUTT(1981), que afirmaram serem os surfactantes não-iōnicos os que maior ativação proporcionaram ao glifosate. 
Quanto a mistura de ōleo; o Natur'L ōleo na maior dose, contribuiu para um controle muito bom da gramaseda aos 60 dias apōs ap̣licação assim como, reduziu de 6 para 4 horas o tempo mînimo necessärio entre aplicação do glifosate e uma chuva apōs. Acredita-se também que a melhoria da eficiéncia do produto esteja associada ao aumento da penetração cuticular ou absorção passiva. PREEST (1975), chegou a resultados semelhantes com a mistura de öleo diesel ao glifosate. Resultados desta natureza também foram encontrados por TURNER (1976b), com a mistura de $10-20 \%$ de öleo solubilizado em soluções aquosas de herbicidas.

A adição de sulfato de amōnio a $5 \%$ p/v não apre sentou neste trabalho resultado muito consistente no aumento da atividade do glifosate como também não interferiu de maneira efetiva na redução da eficiência pela chuva. Este resultado é concordante com os de SHARMA et alii (1980) e SHARMA E SUNDAR (1981), que obtiveram resultados inconsisten tes para as doses menores de glifosate e nenhum efeito sinergîstico nas doses mais altas deste herbicida porém, discorda daqueles obtidos por BLAIR (1975); TURNER (1976); O'KEEFFE. e TURNER (1978); FIVELANDT (1978); TURNER e LOADER (1980), GUIMARAES (1981) e de SATYANARAYANA e RAMACHANDRAN (1980) e ZEMANEK (1978) onde constataram que além de ampliar o espectro, aumentou a percentagem de controle de Agropyron repens e de outras latifoliadas de mais dificil controle pelo glifosate. 
outros autores como TURNER e LOADER (1978a) e SHEA e TUPY (1983), observaram que os agentes complexantes EDTA e NTA, aumentaram muito mais a atividade do glifosate que a adição do sulfato de amōnio e atribuîram a interações destes agentes com o cálcio e outros ions metáiticos que iriam imobilizar o produto.

0 resultado da anālise estatística do peso da matēria fresca, encontra-se na Tabela 7 . A comparação de médias pelo teste de Tukey a $5 \%$ de probabilidade mostrou que os tratamentos que apresentaram menor peso medio por planta foram também aqueles que apresentaram os maiores îndices de controle da grama-seda, confirmando assim, os dados das avaliações visuais.

\subsection{EXPERIMENTO EM CASA DE VEGETAÇAO (1985)}

Um segundo experimento foi instalado em casa de vegetação utilizando-se uma dose mais alta de glifosate no controle da grama-seda em relação ao primeiro experimento em casa de vegetação.

Pelas Tabelas 8 e $8 a$, verifica-se que o aumento da dose de glifosate não melhorou sua performance sozinho, ou em misturas com surfactantes e aditivos no controle des ta planta daninha. De um modo geral os indices de controle foram inferiores aos obtidos com a dose de $1,44 \mathrm{~kg} / \mathrm{ha}$ de gli- 
Tabela 7. Biomassa verde epígea aos 60 DAT envolvendo os quatro interva10 de simulação de chuva (média de 4 repetiçóes). Experimento 1984.

\begin{tabular}{|c|c|c|}
\hline $\begin{array}{l}\text { TRATAMENT } / \\
\text { PRODUTOS }\end{array}$ & $\begin{array}{l}\text { DOSES } \\
1 \mathrm{~kg} / \mathrm{ha}\end{array}$ & $\begin{array}{c}\text { PESO EM GRAMOS } \\
60 \text { DAT }\end{array}$ \\
\hline 01. Glifosate (Roundup) & 1,44 & 1,77 defg * \\
\hline 02. Glifosate (MON 0139) & 1,44 & $2,24 a b c d e f g$ \\
\hline 03. Glifosate (Sting) & 1,44 & 2,91 abcde \\
\hline 04. Glifosate + Frigate & $1,44+0,2 \% v / v$ & $3,77 \mathrm{ab}$ \\
\hline 05. Gifosate + Frigate & $1,44+0,4 \% v / v$ & 2,19 abcdefg \\
\hline 06. Glifosate + Triton $\times 45$ & $1,44+0,1 \% \mathrm{v} / \mathrm{v}$ & 2,92 abcde \\
\hline 07. Glifosate + Triton $\times 45$ & $1,44+0,2 \% v / v$ & $0,40 \mathrm{~g}$ \\
\hline 0. Glifosate + Triton $\times 100$ & $1,44+0,7 \% \mathrm{v} / \mathrm{v}$ & 2,79 abcdef \\
\hline 09. Giffosate + Triton $\times 100$ & $1,44+0,2 \% \mathrm{v} / \mathrm{v}$ & $0,80 \mathrm{fg}$ \\
\hline 10. Glifosate + Triton $\times 114$ & $1,44+0,7 \% v / v$ & 1,56 cdefg \\
\hline 11. Glifosate + Triton X114 & $1,44+0,2 \% v / v$ & $0,79 \mathrm{fg}$ \\
\hline 12. Glifosate + Triton $A G-98$ & $1,44+0,7 \% \mathrm{v} / \mathrm{v}$ & 3,12 abcd \\
\hline 13. Glifosate + Triton AG-98 & $1,44+0,2 \% v / v$ & 1,03 efg \\
\hline 14. Glifosate + Triton AF & $1,44+0,1 \% \mathrm{~V} / \mathrm{V}$ & $3,50 a b c$ \\
\hline 15. Glifosate + Triton AF & $1,44+0,2 \% \mathrm{v} / \mathrm{v}$ & $0,77 \mathrm{fg}$ \\
\hline 16. Glifosate + Sintergente & $1,44+0,1 \% \mathrm{v} / \mathrm{v}$ & 1,75 bcdefg \\
\hline 17. Glifosate + Sintergente & $1,44+0,2 \% \mathrm{v} / \mathrm{v}$ & $0,81 \mathrm{fg}$ \\
\hline 18. Glifosate + NU-Film-P & $1,44+0,1 \mathrm{v} / \mathrm{v}$ & 3,48 a \\
\hline 19. Glifosate + NU-Film-P & $1,44+0,2 \% v / v$ & 1,32 defg \\
\hline 20. MON $0139+$ Atlas $63780 \mathrm{~A}$ & $1,44+0,1 \% v / v$ & 2,59 abcdef \\
\hline 21. MON $0139+$ At las G3780A & $1,44+0,2 \% v / v$ & 1,39 defg \\
\hline 22. Glifosate + S. de amōnio & $1,44+2,5 \% \mathrm{p} / \mathrm{v}$ & 2,29 abcdefg \\
\hline 23. Glifosate $+S$. de amönio & $1,44+5,0 \% \mathrm{p} / v$ & $1,03 \mathrm{efg}$ \\
\hline 24. Glifosate + Natur' óleo & $1,44+0,5 \mathrm{v} / \mathrm{v}$ & 2,14 abcdefg \\
\hline 25. Glifosate + Natur' óleo & $1,44+1,0 \% v / v$ & $0,44 \mathrm{~g}$ \\
\hline 26. Glifosate + Aterbane & $1,44+0,2 \% v / v$ & 2,56 abcolef \\
\hline 27. Glifosate (Testemunha) & 1,44 & 1,26 defg \\
\hline 28. Testemunha absoluta & - & $3,22 \mathrm{abcd}$ \\
\hline
\end{tabular}

(*) Médias seguidas pela mesma letra não diferem entre si estatisticamente por Tukey a $5 \%$ de probabilidade. C.V. $=79,61 \%$. 
Tabela 8. Percentagen de controle da grama-seda pelos tratamentos envolvendo os quatro intervalos de simulaçao de chuva nas seis épocas de ava liação (média de 4 repetições). Experimento 1985.

\begin{tabular}{|c|c|c|c|c|}
\hline \multirow{2}{*}{$\begin{array}{l}\text { TRATAMENTOS/ } \\
\text { PRODUTOS }\end{array}$} & \multirow{2}{*}{$\mathrm{kg} \mathrm{di} \mathrm{ia/ha}$} & \multicolumn{2}{|c|}{$\%$ CONTROLE } & \multirow[b]{2}{*}{30 DAT } \\
\hline & & 10 DAT & 20 DAT & \\
\hline 01. Glifosate. & 1,44 & $9,37 \mathrm{~h}\left({ }^{*}\right)$ & $11,87 n$ & $25, \mathrm{Ce}$ \\
\hline 02. Glifosate & 1,8 & $23,12 \mathrm{efg}$ & $31,25 \mathrm{~m}$ & $43,75 \mathrm{de}$ \\
\hline 03. Glifosate & 2,16 & 26,8 Jbcdef & 41,12 defghijl & $58,12 a b c d$ \\
\hline 04. Glifosate (Sting) & 1,8 & $32,5 a$ & 47,5 cdefghi 31 & $60,62 a b c d$ \\
\hline 05. Glifosate (MON 0139) & 1,8 & 23,75 defg & $45,87 \mathrm{fghijl}$ & $54,37 \mathrm{abcd}$ \\
\hline 06. Glifosate+Frigate & $1,8+0,2 \% \mathrm{v} / \mathrm{v}$ & $22,5 \mathrm{fg}$ & $41,25 j 1$ & $53,75 b c d$ \\
\hline 07. Glifosate+Frigate & $1,8+0,4 \% v / v$ & $23,12 \mathrm{efg}$ & 45,62 fghij & $67,25 a b c d$ \\
\hline 08. Glifosate+Triton $\times 45$ & $1,8+0,1 \% v / v$ & $27,5 \mathrm{abcdef}$ & $56,25 a b$ & $68,75 a b c$ \\
\hline 09. Glifosate+Triton $\times 45$ & $1,8+0,2 \% v / v$ & $28,12 \mathrm{bcde}$ & $55,24 a b c a$ & $56,25 a b c$ \\
\hline 10. Glifosate+Triton $\times 100$ & $1,8+0,1 \% v / v$ & $24,37 \mathrm{cdefg}$ & $44,37 h i j l$ & $56,87 a b c a$ \\
\hline 11. Glifosate+Triton $\times 100$ & $1,8+0,2 \% v / v$ & 27,5 bcdef & 52,5 abcdefgh & $64,37 a b c$ \\
\hline 12. Glifosate+Triton $\times 114$ & $1,8+0,1 \% \mathrm{v} / \mathrm{v}$ & 26,87 bc def & 50,62 bcdefghi & $67,5 \mathrm{abc}$ \\
\hline 13. GlifosaterTriton X114 & $1,8+0,2 \% \mathrm{v} / \mathrm{v}$ & $30,62 a b$ & $53,75 a b c d e f$ & $63,75 a b c$ \\
\hline 14. Glifosate+Triton AG-98 & $1,8+0,1 \% v / v$ & 27,5 bcalef & 54,37 abcde & $68,12 a b c$ \\
\hline 15. Glifosate+Triton AG-98 & $1,8+0,2 \% v / v$ & $28,75 \mathrm{abcd}$ & $50,62 \mathrm{bcdefghi}$ & $65,0 a b c$ \\
\hline 16. Glifosate+Triton AF & $1,8+0,1 \% v / v$ & $21,25 \mathrm{~g}$ & $42,5 i j 1$ & $51,87 \mathrm{bcd}$ \\
\hline 17. GlifosaterTriton AF & $1,8+0,2 \% v / v$ & 25,0 cdefg & $45, \operatorname{lghij}]$ & $51,25 b c d$ \\
\hline 18. Glifosate+Sintergente & $1,8+0,1 \% \mathrm{v} / \mathrm{v}$ & 25,0 cdefg & 52,5 abcdefgh & $66,87 a b c$ \\
\hline 19. Glifosate+Sintergente & $1,8+0,2 \% v / v$ & $29,37 a b c$ & $55,62 a b c$ & $70,0 a b$ \\
\hline 20. Glifosate+NU-Film-P & $1,8+0,1 \% \mathrm{v} / \mathrm{v}$ & 26,25 bcdefg & 48,75 bcdefghij & $60,0 a b c d$ \\
\hline 2]. Glifosate+NU-Film-P & $1,8+0,2 \% v / v$ & $25,62 \mathrm{bcde} f g$ & 48,75 bcdefghij & $57,5 a b c d$ \\
\hline 22. MON $0139+A t$ las C $3780 A$ & $1,8+0,1 \% \mathrm{v} / \mathrm{v}$ & $26,25 b c d e d g$ & 39,371 & $50,0 \mathrm{~cd}$ \\
\hline 23. MON 0139+Atlas G3780A. & $1,8+0,2 \% v / v$ & $28,75 \mathrm{abcd}$ & 46,25 efghijl & $59,37 a b c d$ \\
\hline 24. G]ifosatetS. de amōnio & $1,8+2,5 \% p / v$ & $29,37 a b c$ & $53,12 a b c d e f g$ & $66,25 a b c$ \\
\hline 25. Glifosate+S. de amōnio & $1,8+5,0 \% \mathrm{p} / \mathrm{v}$ & $22,5 \mathrm{fg}$ & $41,25 j 1$ & $51,87 \mathrm{bcd}$ \\
\hline 26. Glifosate+Natur'Löleo & $1,8+1,0 \% \mathrm{v} / \mathrm{V}$ & 28,12 bcde & $59,37 a$ & $73,75 a$ \\
\hline 27. Glifosate+Natur'Lóleo & $1,8+2,0 \% \mathrm{v} / \mathrm{v}$ & 27,65 bcdef & 50,62 bcdefghi & $65,0 \mathrm{abc}$ \\
\hline 28. Glifosate (Testemunha) & 1,8 & $24,37 \mathrm{cdefg}$ & $44,37 h i j l$ & $58,12 a b c d$ \\
\hline 0.107 & & 20,50 & 25,06 & 25,13 \\
\hline
\end{tabular}

(*) Médias seguidas pela mesma letra não diferiram estatisticamente entre si pelo teste de Tukey a $5 \%$ de probabilidade. 
Tabela 8a. Percentagem de controle da grama-seda pelos tratamentos, envolven do os quatro intervalos de simulação de chuva nas seis épocas de avaliação (média de 4 repetiçoes). Experimento 1985.

TRATAMENTOS/

PRODUTOS
DOSE

$\mathrm{kg}$ do ia/ha
$\%$ CONTROLE

40 DAT $\quad 50$ DAT

$25,0 j(*)$

$20,0 \mathrm{~h}$

$40,0 \mathrm{~g}$

63,75 bcdef

$68,75 \mathrm{bcdef}$

60, oef.

$58 ; 12 f$

67,5 bcdef

$78,5 \mathrm{abcd}$

71, 9 abcde

62,5 cdef

$68,75 \mathrm{bcdef}$

67,5 bcdef

$72,5 \mathrm{abcd}$

77,87 abcde

$73,75 a b c$

$60,0 \mathrm{ef}$

$65,62 \mathrm{bcdef}$

71,25 abcde

$75,0 a b$

$66,87 \mathrm{bcdef}$

65,62 bcdef

$57,5 f$

64,37 bcdef

$75,0 \mathrm{ab}$

$58,72 f$

$82,5 a$

$68,75 b c d e f$

61,25 def

$77,5 \mathrm{a}$

$67,5 a b c d e$

56,87 efgh
60 DAT

$27,87 \mathrm{c}$

$47,87 \mathrm{bc}$

$63,75 a b$

$69,37 \mathrm{a}$

$65,62 a b$

$61,25 a b$

$68,75 a$

$68,12 a$

$73,12 a$

$71,87 a$

$77,87 a$

69,37 a

$75,0 a$

$72,5 a$

$72,5 a$

$68,12 a$

$59,37 \mathrm{ab}$

$71,25 a$

$81,25 a$

$70,0 \mathrm{a}$

$61,87 a b$

$58,12 a b$

$68,12 a$

$1,8+2,5 \% \mathrm{p} / \mathrm{v} \quad 65$, obcdef

76,87 a

$1,8+5,0 \% \mathrm{p} / \mathrm{v} \quad 56,25 \mathrm{fgh}$

$$
1,8
$$

$61,25 a b$

$83,12 a$

$71,25 a$

$64,37 a b$

23,26

24,33

c. V. (\%)

29,49

$\left({ }^{*}\right)$ Médias seguidas pela mesma letra não diferiram estatisticamente entre si pelo teste de Tukey a $5 \%$ de probabilidade. 
fosate e suas misturas, no experimento instalado em 1984. Acre dita-se que a explicação para estes resultados sejam as condi ções ambientais durante e logo apōs a aplicação. Trabalhos realizados por COOLS e LOCASCIO (1977); WHITWELL e SANTELMAN (1978); CHASE (1979) @ ilAJEK (1980); mostraram que o controle de Cynodon dactylone A. repens com glifosate tem eficiências diferentes nas diversas estações do ano, independemente da dose utilizada. Acreditam alguns destes autores que a temperatura e o fotoperiodismo tenham efeito marcante nestes resul tados, pela influēncia na translocação do produto. Em outros trabalhos realizados por WILLS (1978); MCWHORTER et alii (1980), ficou confirmado que em condições de alta umidade relativa a toxicidade do glifosate foi diminuida em temperatu ras mais altas que amenas. Discorda contudo dos resultados de JoRDAN (1974). No momento da aplicação do herbicida neste segundo experimento, tinha-se alta umidade relativa $(82 \%)$ e alta temperatura $(30,50 \mathrm{C})$ ao conträrio, do primeiro experimento, onde a umidade relativa média era $(52 \%)$ e a temperatura elevada $(31,50)$.

Observa-se ainda que as doses de 1,44 e $1,8 \mathrm{~kg}$ Iha do glifosate aplicadas isoladamente foram as que apresentaram, aos 60 dias apōs aplicação, os mais baixos îndices de controle, quando submetidas a uma chuva simulada, diferindo dos demais tratamentos (Tabelas 8 e $8 a$ ).

Não se observou um efeito marcante dos surfactantes e aditivos na performance do glifosate. Exceção feita aos tratamentos 26 (glifosate + Natur'L 01 eo a $1,8 \mathrm{~kg} / \mathrm{ha}+1,0 \%$ 
$\mathrm{v} / \mathrm{v})$ e glifosate + Sintegente $(1,8 \mathrm{~kg} / \mathrm{ha}+0,2 \% \mathrm{v} / \mathrm{v})$, em que os indices de controle da grama-seda sobressairam-se em relação aos demais tratamentos, independente do intervalo da chuva simulada de $15 \mathrm{~mm}$ e aos 60 dias apōs aplicação jā ultrapassava o limite minimo determinado de $80 \%$.

A anālise estatîstica năo revelelou interação signifi cativa entre Herbicidas $x$ Intervalos de chuva nas avaliações individuais realizadas, mas mostrou quando se envolveu todas avaliações.

Apesar da maioria dos tratamentos não atingirem, numa média geral, o indice mīnimo de controle de $80 \%$, atribuĩdo às condições ambientais na aplicação, procurou-se evidenciar graficamente alguns tratamentos que permitiran reduzir o tempo mínimo necessārio para a ocorréncia da primeira chuva após aplicação. Tomou-se assim, as percentagens médias absolutas de controle dentro de cada avaliação e, verificou se que os tratamentos 9 (glifosate + Triton $\times 45$ a $1,8 \mathrm{~kg} / \mathrm{ha}$ t $0,2 \% \mathrm{v} / \mathrm{v}) ; 24$ (glifosate + sulfato de amōnio a $1,8 \mathrm{~kg} / \mathrm{ha}$ + $2,5 \% \mathrm{p} / \mathrm{v}$ ); e 26 (glifosate + Natur'L óleo a $1,8 \mathrm{~kg} / \mathrm{ha}+1,0 \%$ v/v), possibilitaram a redução de 6 para 4 horas entre a apli cação e a chuva simulada de $15 \mathrm{~mm}$, uma vez que estes intervalos de chuva comportaram-se de maneira semelhante, mantendo a eficiência do herbicida.

Apesar de envolver dados de todas avaliações e por isto apresentar percentuais de controle abaixo do minimo jā mencionado, o desdobramento da interação Herbicidas $x$ Intervalos de chuva sustenta estatisticamente, pela compara- 
ção de médias pelo teste de Tukey a $5 \%$ de probabilidade, a representação gräfica dos tratamentos 9, 24 e $26 \%$ (Figuras 10 , 11 e 12) e evidencia tambēm outros tratamentos que não apresentaram diferença significativa entre os intervalos de 4 e 6 horas apōs aplicação (Tabelas 9 e 9 a).

Explica-se o fato dos tratamentos 2 e 3 não so ferem redução da eficiência submetidas a uma chuva simulada de $15 \mathrm{~mm} 4$ horas apës aplicação pelo aumento da dose que alia da ao baixo consumo de calda de 100 l/ha, aumentarari consideravelmente a concentração do produto na solução proporcionando mais rāpida penetração cuticular e absorção, minimizando o efeito da chuva. Trabalhos da literatura sustentam esta afir mativa pois têm sido concordantes quanto ao efeito linear entre a concentração do glifosate na solução è sua penetração, absorção e translocação (MERRITT e TAYLOR, 1978; LISti e MESSERSMITH, 1979; MERRITT, 1980; ERICKSON, 1981; OAVIES E TAY LOR, 1981; BALYAN et alii, 1981 e BARRIGA, 1984).

Quanto aos demais tratamentos que não tiveram suas eficiēncias significativamente reduzidas quando submeti das a uma chuva simulada 4 horas apös aplicação, os resulta dos confirmam a participação positiva dos surfactantes e aditi vos no aumento da velocidade de absorção e translocação do gli fosate jā discutida e confrontada com a literatura no primeiro experimento instalado em casa de vegetação.

0 sulfato de amōnio a $2,5 \% \mathrm{p} / \mathrm{v}$, contrariando os resultados do experimento ànterior, possibilitou a redução 


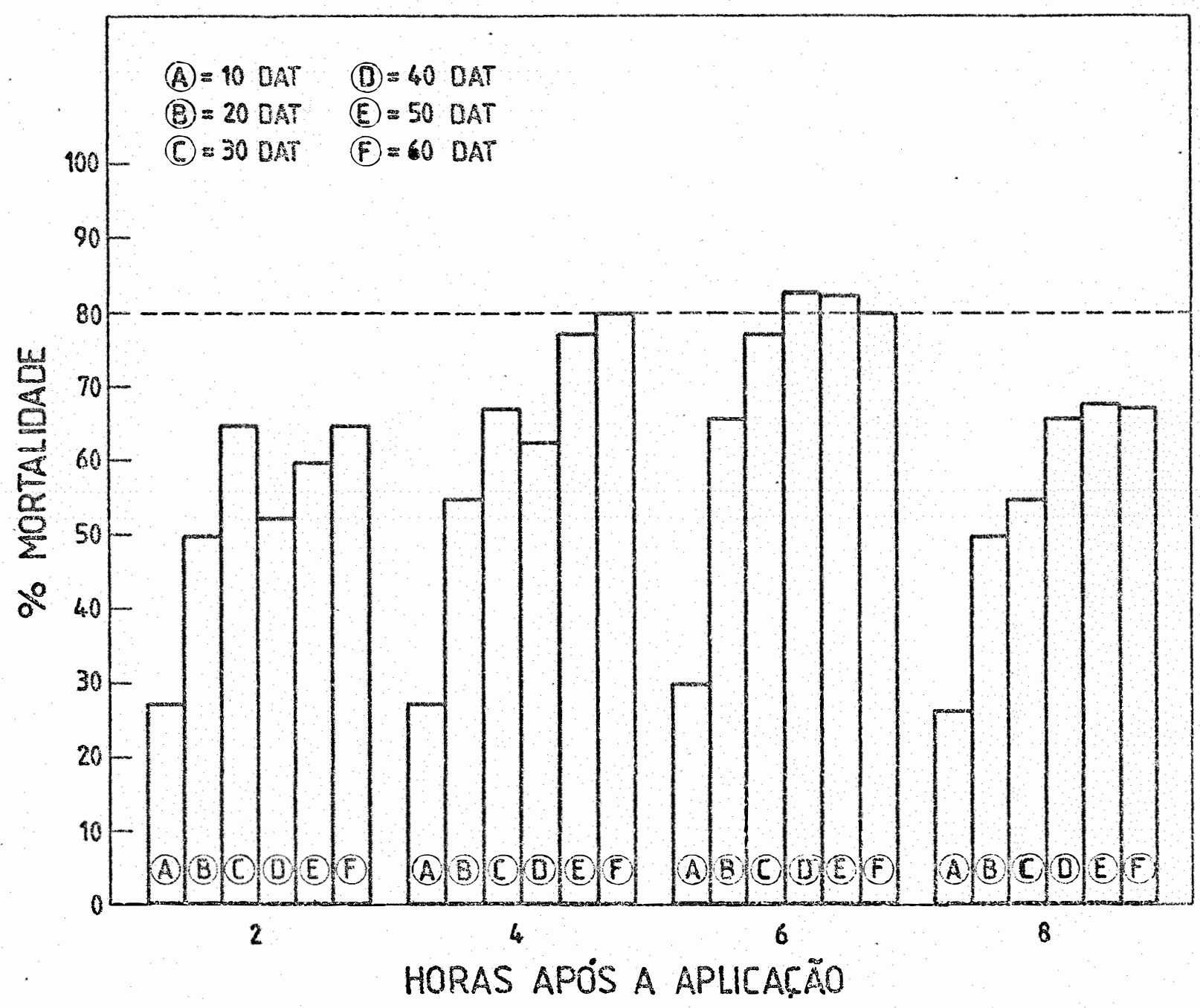

Figura 10. Efeito dos intervalos de uma chuva simulada de $15 \mathrm{~mm}$ sobre o tratamento glifosate + Triton $\times 45$ (1),8 kg/ ha $+0,2 \% \mathrm{v} / \mathrm{v})$. 


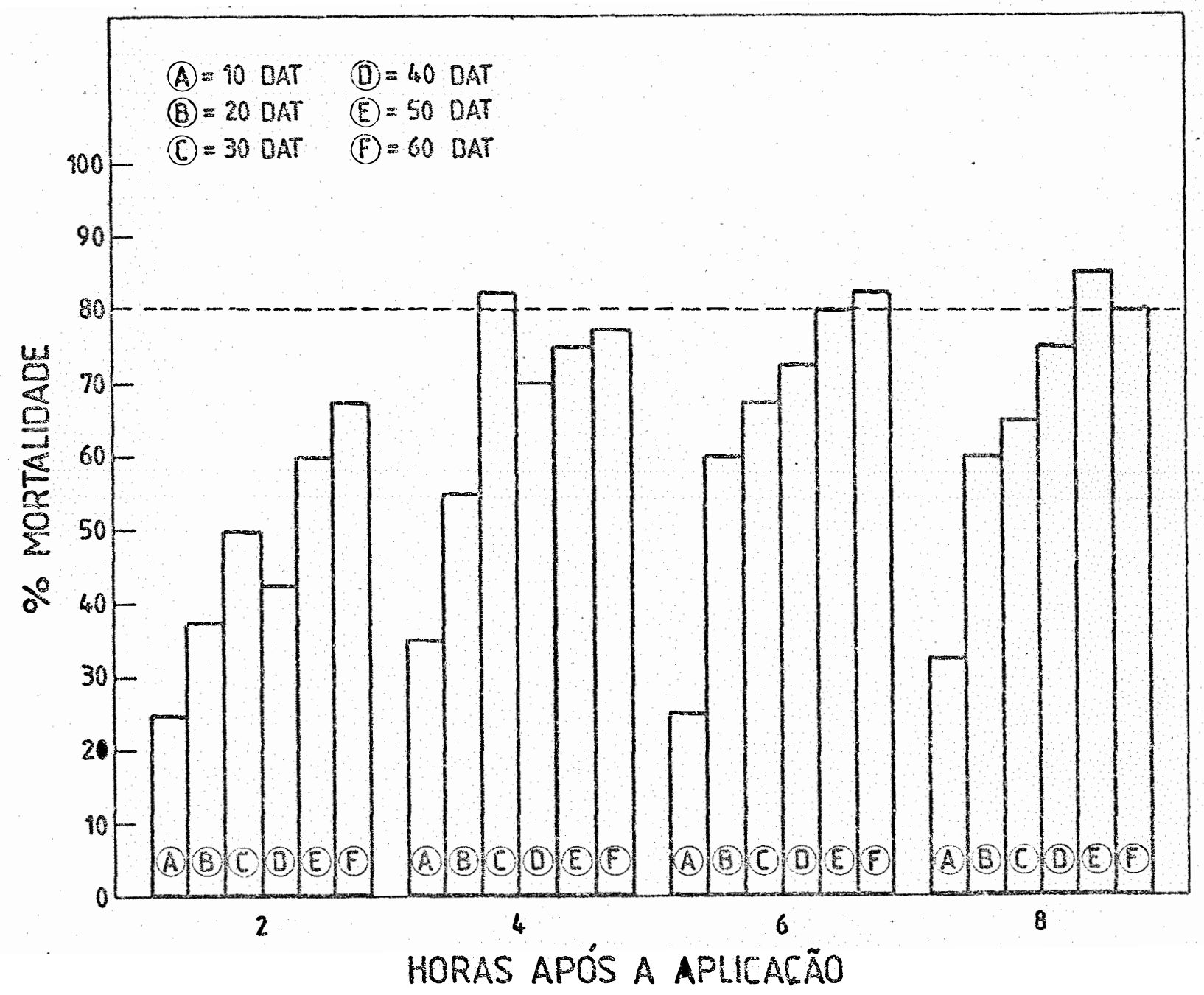

Figura 11. Efeito dos intervalos de uma chuva simulada de 15 mm sobre o tratamento glifosate + sulfato de amónio $(1,8 \mathrm{~kg} / \mathrm{ha}+2,5 \% \mathrm{p} / \mathrm{v})$. 


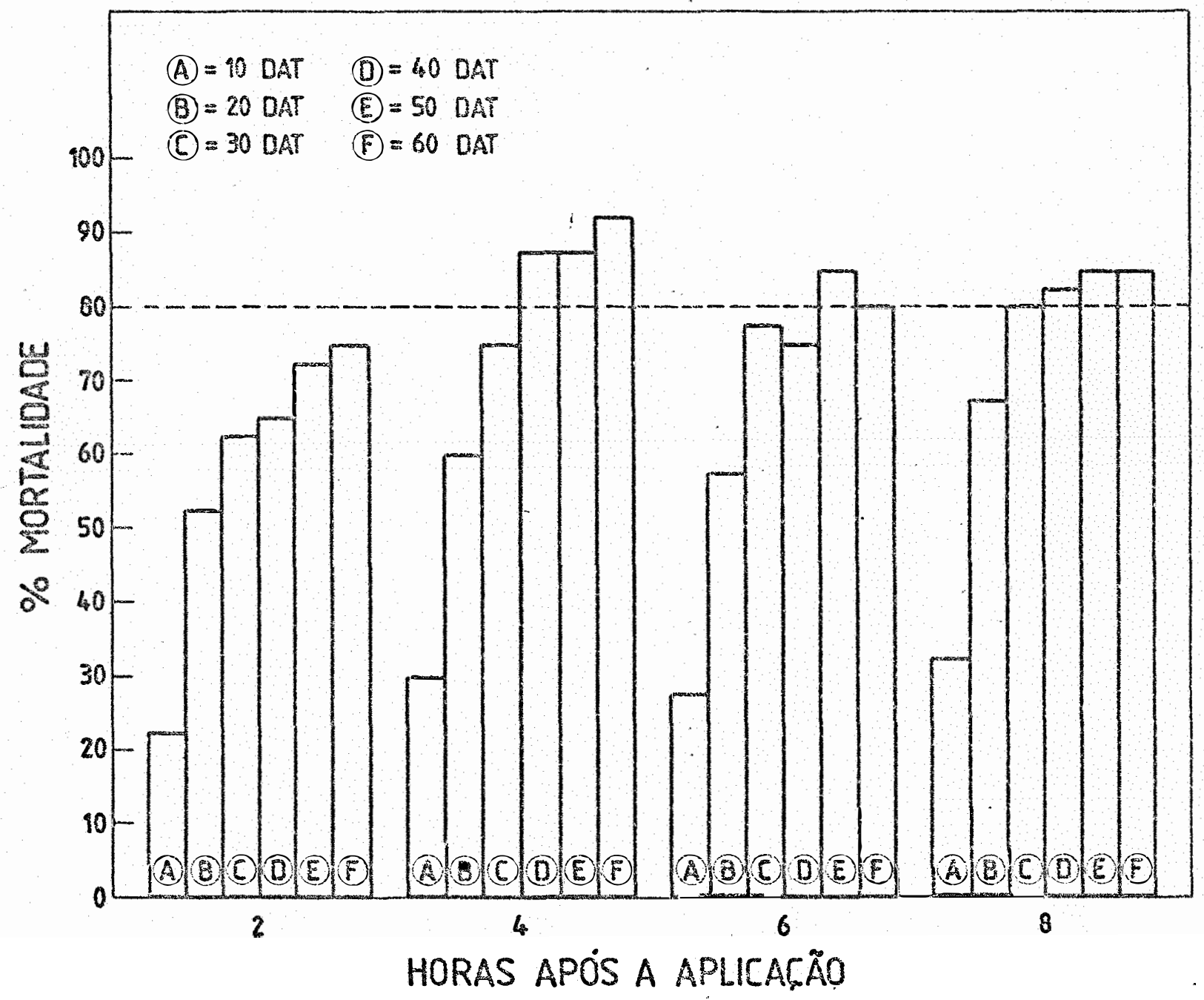

Figura 12. Efeito dos intervalos de uma chuva simulada de 15 mm sobre o tratamento glifosate + Natur'L öleo $(1,8$ $\mathrm{kg} / \mathrm{ha}+1,0 \% \mathrm{v} / \mathrm{v})$. 
Tabela 9. Percentagem de controle da grama-seda pelos tratamentos dentro de cada intervalo de chuva e comparação de médias envolvendo todas avaliações.

\begin{tabular}{|c|c|c|c|c|}
\hline $\begin{array}{l}\text { TRATAMENTOS/ } \\
\text { PRODUTOS }\end{array}$ & $\begin{array}{c}\text { DOSE kg } \\
\text { do i.a./ha }\end{array}$ & $\begin{array}{l}\text { FREQUENCIA } \\
\text { DE CHUVA }\end{array}$ & $\begin{array}{l}\% \text { MEDIA } \\
\text { CONTROLE }\end{array}$ & $\underset{\text { TE }}{\text { CONTRAS }}$ \\
\hline \multirow[t]{4}{*}{ 02. Glifosate } & 1,8 & 2 horas & 27,97 & $b(*)$ \\
\hline & & 4 horas & 30,83 & $b$ \\
\hline & & 6 horas & 35,83 & b \\
\hline & & 8 horas & 53,33 & a \\
\hline \multirow[t]{4}{*}{ 03. Glifosate } & 2,16 & 2 horas & 34,87 & $c$ \\
\hline & & 4 horas & 54,58 & $b$ \\
\hline & & 6 horas & 56,66 & $a b$ \\
\hline & & 8 horas & 66,25 & a \\
\hline \multirow[t]{4}{*}{ 07. Glifosate+Frigate } & $1,8+0,4 \% v / v$ & 2 horas & 47,08 & $b$ \\
\hline & - & 4 horas & 47,91 & b \\
\hline & & 6 horas & 53,33 & $\mathrm{~b}$ \\
\hline & & 8 horas & 68,75 & a \\
\hline \multirow[t]{4}{*}{ 09. G7ifosate+Triton $\times 45$} & $1,8+0,2 \% v / v$ & 2 horas & 53,33 & $b$ \\
\hline & & 4 horas & 67,66 & $a b$ \\
\hline & & 6 horas & 70,0 & a \\
\hline & & 8 horas & 56,12 & $b$ \\
\hline \multirow[t]{4}{*}{ 12. Glifosate+Triton $\times 114$} & $1,8+0,1 \% v / v$ & 2 horas & 44,16 & c \\
\hline & & 4 horas & 57,08 & $b$ \\
\hline & & 6 horas & 57,50 & b \\
\hline & & 8 horas & 71,25 & a \\
\hline
\end{tabular}

DMS $=11,297$

(*) Médias seguidas pela mesma letra não diferiram entre si estatisticamente pelo teste de Tukey a $5 \%$ de probabilidade. 
Tabela 9a. Percentagem de controle da grama-seda pelos tratamentos dentro de cada intervalo de chuva e a comparaçäo das médias envolven do todas avaliações.

\begin{tabular}{|c|c|c|c|c|}
\hline $\begin{array}{l}\text { TRATAMENTOS / } \\
\text { PRODUTOS }\end{array}$ & $\begin{array}{c}\text { DOSE kg } \\
\text { go i.a/ha }\end{array}$ & $\begin{array}{l}\text { FREQUENCIA } \\
\text { DE CHUVAS }\end{array}$ & $\begin{array}{l}\text { \% MEDIA } \\
\text { CONTROLE }\end{array}$ & $\begin{array}{c}\text { CONTRAS } \\
\text { TE }\end{array}$ \\
\hline 15. Glifosate+Triton AG-98 & $1,8+0,2 \% v / v$ & $\begin{array}{l}2 \text { horas } \\
4 \text { horas } \\
6 \text { horas } \\
8 \text { horas }\end{array}$ & $\begin{array}{l}51,25 \\
52,08 \\
58,75 \\
74,58\end{array}$ & $\begin{array}{l}b(*) \\
b \\
b \\
a\end{array}$ \\
\hline 20. Glifosate+NU-Film-P & $1,8+0,1 \% \mathrm{v} / \mathrm{v}$ & $\begin{array}{l}2 \text { horas } \\
4 \text { horas } \\
6 \text { horas } \\
8 \text { horas }\end{array}$ & $\begin{array}{l}43,75 \\
47,08 \\
54,16 \\
76,25\end{array}$ & $\begin{array}{l}b \\
b \\
b \\
a\end{array}$ \\
\hline 22. MON $0139+$ Atlas $63780 \mathrm{~A}$ & $1,8+0,1 \% v / v$ & $\begin{array}{l}2 \text { horas } \\
4 \text { horas } \\
6 \text { horas } \\
8 \text { horas }\end{array}$ & $\begin{array}{l}37,91 \\
44,58 \\
43,75 \\
62,08\end{array}$ & $\begin{array}{l}b \\
b \\
b \\
a\end{array}$ \\
\hline 24. Glifosate+S. amōnio & $1,8+2,5 \% \mathrm{p} / \mathrm{v}$ & $\begin{array}{l}2 \text { horas } \\
4 \text { horas } \\
6 \text { horas } \\
8 \text { horas }\end{array}$ & $\begin{array}{l}47,08 \\
65,83 \\
64,58 \\
66,25\end{array}$ & $\begin{array}{l}b \\
a \\
a \\
a\end{array}$ \\
\hline 26 Glifosate+Natur'Löleo & $1,8+1,0 \% v / v$ & $\begin{array}{l}2 \text { horas } \\
4 \text { horas } \\
6 \text { horas } \\
8 \text { horas }\end{array}$ & $\begin{array}{l}58,33 \\
72,08 \\
67,08 \\
72,08\end{array}$ & $\begin{array}{l}b \\
a \\
a b \\
a\end{array}$ \\
\hline
\end{tabular}

DMS $=11,297$

(*) Médias seguidas pela mesma letra não diferiram entre si estatistica mente pelo teste de Tukey a $5 \%$ de probabilidade. 
de 6 para 4 horas entre a aplicação e a primeira chuva subsequente. TURNER (1976) e O'KEEFFEE e TURNER (1978), obtiveram resultados semelhantes. O efeito positivo do sulfato de amōnio está relacionado também, ao aumento da absorção e trans locação relatado por BLAIR (1975); TURNER (1976); TURNER e LOADER (1978a); FIVELANDT (1978); LUND-HOIE (1979); ZEMANEK et alii (1979); SHARMA e SUNDAR (1981) e GUIMARAES (1981).

Na Tabela 10 , são apresentados os resultados da biomassa verde epigea. Observa-se que os tratamentos que apresentaram os melhores indices de mortalidade estão entre aqueles que apresentaram o menor peso médio por planta a exceção do tratamento glifosate + Natur'L öleo $(1,8 \mathrm{~kg} / \mathrm{ha}+1,0 \%$. $v / v)$.

\subsection{EXPERIMENTO DE CAMPO}

Um terceiro experimento foi instalado em condições de campo para avaliar o efeito dos surfactantes e aditivos na performance do glifosate no controle da grama seda, in dependente do fator chuva.

Na Tabela 11, estão os resultados das avaliações aos 30 e 60 dias apōs aplicação e as comparações de médias pelo teste de Tukey a $5 \%$ de probabilidade, assim comouma anālise conjunta envolvendo as duas épocas de avaliação.

Pelas comparações de mëdias aos 30 dias, veri- 
Tabela 10. Biomassa verde epigea aos 60 DAT envolvendo os quatro interva los de chuva (média de 4 repetições). Experimento 1985.

\begin{tabular}{|c|c|c|}
\hline $\begin{array}{l}\text { TRATAMENTOS/ } \\
\text { PRODUTOS }\end{array}$ & $\begin{array}{c}\text { DOSES } \\
\mathrm{kg} \text { do i.a. /ha }\end{array}$ & $\begin{array}{l}\text { PESO EM GRAMOS } \\
60 \text { DAT }\end{array}$ \\
\hline 01. Glifosate (Roundup) & 1,44 & 0,93 hi * \\
\hline 02. Glifosate (Roundup) & 1,8 & 0,99 efghi \\
\hline 03. Glifosate (Roundup) & 2,16 & $0,95 \mathrm{ghi}$ \\
\hline 04. Glifosate (Sting) & 1,8 & $1,23 a b$ \\
\hline 05. Glifosate (MON 0139) & 1,8 & 1,12 abcdef \\
\hline 06. Glifosate + Frigate & $1,8+0,2 \% v / v$ & 1,03 cdefghi \\
\hline 07. Glifosate + Frigate & $1,8+0,4 \% v / v$ & 1,01 defghi \\
\hline 08. Glifosate + Triton $\times 45$ & $1,8+0,1 \% v / v$ & 1,05 bcdefghi \\
\hline 09. Glifosate + Triton $\times 45$ & $1,8+0,2 \% \mathrm{v} / \mathrm{v}$ & 1,01 defghi \\
\hline 10. Glifosate + Triton $\times 100$ & $1,8+0,1 \% v / v$ & $0,36 \mathrm{fghi}$ \\
\hline 11. Glifosate + Triton $\times 100$ & $1,8+0,2 \% v / v$ & 0,94 ghi \\
\hline 12. Glifosate + Triton $\times 114$ & $1,8+0,1 \% \mathrm{v} / \mathrm{v}$ & 1,09 abcdefgh \\
\hline 13. Glifosate + Triton $\times 174$. & $1,8+0,2 \% \mathrm{v} / \mathrm{v}$ & $1,20 a b c$ \\
\hline 14. Glifosate + Triton $A G-98$ & $1,8+0,1 \% v / v$ & $0,92 i$ \\
\hline 15. Glifosate + Triton AG-98 & $1,8+0,2 \% v / v$ & $0,92 \cdot i$ \\
\hline 16. Glifosate + Triton AF & $1,8+0,1 \% \mathrm{v} / \mathrm{v}$ & 1,08 bdcefghi \\
\hline 17. Glifosate + Triton AF & $1,8+0,2 \%$ & 1,70 abcdefg \\
\hline 18. Glifosate + Sintergente & $1,8+0,2 \% v / v$ & 1,10 abcdefg \\
\hline 19. Glifosate + Sintergente & $1,8+0,2 \% v / v$ & 1,03 cdefghi \\
\hline 20. Glifosate + NU-Film-P & $1,8+0,1 \%$ & 1,16 abcd \\
\hline 21. Glifosate + NU-Film-P & $1,8+0,2 \% v / v$ & $0,93 \mathrm{hi}$ \\
\hline 22. MON $0139+$ At]as G3780A & $1,8+0,1 \% \mathrm{v} / \mathrm{v}$ & 1,05 bcdefghi \\
\hline 23. MON $0139+$ Atlas G3780A & $1,8+0,2 \% v / v$ & 1,14 abcde \\
\hline 24. Glifosate + S. de amonio & $1,8+2,5 \% \mathrm{p} / \mathrm{v}$ & 1,01 defghi \\
\hline 25. Glifosate + S. de amōnio & $1,8+5,0 \% \mathrm{p} / \mathrm{v}$ & 1,25 a \\
\hline 26. Glifosate + Natur' óleo & $1,8+1,0 \% v / v$ & 1,75 abcde \\
\hline 27. Glifosate + Natur' oleo & $1,8+2,0 \% v / v$ & 1,04 cdefghi \\
\hline 28. Glifosate (Testemunha) & 1,8 & 1,10 abcdefg \\
\hline
\end{tabular}

(*) Médias seguidas pela mesma letra não diferiram estatisticamente entre si pelo teste Tukey a $5 \%$ de probabilidade. C. V. $=22,30 \%$. 
Tabela 11. Comportament e comparação entre os tratamentos nas duas épocas de avaliação e a análise conjunta delas (média de 3 repetições).

TRATAMENTOS/

PRODUTOS
DOSE

$\mathrm{kg}$ do ia/ha
$\%$ CONTROLE

30 DAT 60 DAT CONJUNTO

01. GTifosate (Roundup)

02. Glifosate (Roundup)

03. Glifosate (Roundup)

04. Glifosate (Stinq)

05. Glifosate (Rodeo)

06. Glifosate+Frigate

07. Glifosate+Frigate

08. Glifosate+Triton $\times 45$

09. Glifosate+Triton $X 45$

10. Glifosate+Triton $\times 100$

11. Glifosate+Triton $\times 100$

12. Glifosate+Triton $\times 114$

13. Glifosate+Triton $\times 114$

14. Glifosate+Trit on AG-98

15. Glifosate+Triton $A G-98$

16. Glifosate+Triton AF

17. G]ifesate+Triton AF

18. Glifosate+Sintergente

19. Glifosate+Sintergente

20. Glifosate+NU-Film-P

21. Glifosate+NU-Film-P

22. Glifosate+Atlas $33780 \mathrm{~A}$

23. Glifosate+At]as G3780A $1,8+0,2 \% \mathrm{v} / \mathrm{v}$

24. Glifosate+S. de amōnio $1,8+2,5 \% \mathrm{p} / \mathrm{v}$

25. Glifosate+S. de amónio $1,8+5,0 \% \mathrm{p} / \mathrm{v}$

26. Glifosate+Natur'Lóleo $1,8+1,0 \% \mathrm{v} / \mathrm{v} \quad 89,0 \mathrm{abcd}$

27. Glifosate+Natur'Lóleo $1,8+2,0 \% \mathrm{v} / \mathrm{v} 96,67 \mathrm{ab}$

$75,0 \mathrm{~cd}(*)$

$96,67 a b$

$98,33 a$

$95,0 a b$

$90,0 \mathrm{abcd}$

$93,33 a b$

$95,0 a b$

$96,67 a b$

$93,33 a b$

$90,0 \mathrm{abcd}$

$94,33 a b$

$88,33 a b c d$

$90,0 a b c d$

$75,0 \mathrm{~cd}$

$88,33 a b c d$

80,0 bcd

$73,33 d$

$93,33 a b$

$90,0 a b c d$

80, obcd

90,0 abcd

$75,0 \mathrm{~cd}$

$83,33 a b c d$

$83,33 \mathrm{abcd}$

88,33abcd

$$
6,0
$$

6,0

$26,6 \mathrm{~b}$

$73,33 a$

$96,67 a$

$83,33 a$

$90,33 a$

$88,33 a$

$90,0 \mathrm{a}$

$96,67 \mathrm{a}$

$78,33 a$

$93,33 a$

$-96,67 a$

$91,67 a$

$80,0 a$

$73,33 a$

$93,33 \mathrm{a}$

$68,33 a$

$75,0 \mathrm{a}$

$91,67 \mathrm{a}$

$95,0 \mathrm{a}$

$83,33 a$

$86,67 a$

$81,67 \mathrm{a}$

$75,0 \mathrm{a}$

$76,67 a$

$73,33 a$

$88,33 a$

$95,0 \mathrm{a}$
$50,83 f$

$85,0 a b c d$

$97,5 a$

$89,16 a b c d$

$90,16 a b c$

$90,83 \mathrm{abcd}$

92, $5 \mathrm{abc}$

$96,67 a b$

$85,83 \mathrm{abcd}$

91,67 abcd

$95,0 a b c$

$90,0 \mathrm{abcd}$

85, Oabcd

$74,7 \mathrm{de}$

$90,83 a \bar{b} c d$

$74,16 \mathrm{de}$

$74,76 \mathrm{de}$

$92,5 a b c$

$92,5 a b c$

$81,67 \mathrm{abcd}$

$88,33 a b c d$

$78,33 \mathrm{~cd}$

$79,16 \mathrm{bcd}$

$80,0 a b c d$

$80,83 a b c d$

$88,67 a b c d$

$95,83 a b c$

C.V. (\%)

12,07

(*) Médias seguidas pela mesma letra näo diferiram entre si estatisticamente pelo teste de Tukey ao nivel de $5 \%$ de probabilidade. 
fica-se que os tratamentos apresentaram comportamento semelhante com ligeira discrepancia para os tratamentos glifosate $(1,44 \mathrm{~kg} / \mathrm{ha}, \mathrm{glifosate}+$ Triton $A G-98(1,8 \mathrm{~kg} / \mathrm{ha}+0,1 \% \mathrm{v}$ /v); glifosate + Triton AF $(1,8 \mathrm{~kg} / \mathrm{ha}+0,2 \% \mathrm{v} / \mathrm{v})$ e MON 0139 + Atias $G-3780 \mathrm{~A}(1,8 \mathrm{~kg} / \mathrm{ha}+0,2 \% \mathrm{v} / \mathrm{v})$. Aos 60 dias após apli cação apenas o tratamento glifosate $(1,4 \mathrm{~A} \mathrm{~kg} / \mathrm{ha})$; moustrou se diferente estatistica e significativamente dos demais. Con siderou-se como melhores tratamentos aqueles que aos 60 dias apresentaram indices de mortalidade superiores ao limite mîni mo considerado de $80 \%$. Eles foram:

- glifosate $(2,16 \mathrm{~kg} / \mathrm{ha})$;

- glitosate (Sting) (1,8 kg/ha);

- MON $0139(1,8 \mathrm{~kg} / \mathrm{ha})$;

- glifosate + Frigate $(1,8 \mathrm{~kg} / \mathrm{ha}+0,2$ e $0,4 \% \mathrm{v} / \mathrm{v})$;

- glifosate + Triton $\times 45(1,8 \mathrm{~kg} / \mathrm{ha}+0,1 \% \mathrm{v} / \mathrm{v})$;

- glifosate + Triton $\times 100(1,8 \mathrm{~kg} / \mathrm{ha}+0,1$ e $0,2 \% \mathrm{v} / \mathrm{v})$;

- glifosate + Triton $\times 114(1,8 \mathrm{~kg} / \mathrm{ha}+0,1$ e $0,2 \% \mathrm{v} / \mathrm{v})$;

- glifosate + Triton AG-98 (1,8 kg/ha+0,2\% v/v);

- glifosate + Sintergente $(1,8 \mathrm{~kg} / \mathrm{ha}+0,1$ e $0,2 \% \mathrm{v} / \mathrm{v})$;

- glifosate + NU-Film-P (1,8 kg/ha + 0,le $0,2 \% \mathrm{v} / \mathrm{v})$;

- MON $0139+$ Atlas G3790A $(1,8 \mathrm{~kg} / \mathrm{ha}+0,1 \% \mathrm{v} / \mathrm{v})$;

- glifosate + Natur'L óleo $(1,8 \mathrm{~kg} / \mathrm{ha}+1,0$ e $2,0 \% \mathrm{v} / \mathrm{v})$.

Comparando-se, aos 60 dias após aplicação. (Tabela 11), a dose de $1,8 \mathrm{~kg} / \mathrm{ha}$ de glifosate (como Roundup), so zinho e em mistura, observa-se que os surfactantes e o óleo ve- 
getal tenderam a aumentar a atividade deste herbicida no controle da grama-seda. Este resultado está concordante com a literatura onde a maioria dos trabalhos são coerentes sobre - aumento da atividade do glifosate no controle de vārias espécies de plantas daninhas pela adição de surfactantese óleos. Estes mesmos trabalhos mostraram que o efeito foi mais eviden te à medida que se aumentou a concentração do surfactante ná calda de $0,1 \%$ v/v atē um limite máximo de $1,0 \%$ v/v, numa relação inversa à dose do glifosate ou seja, em doses menores que 1-2,0 kg/ha do que em doses mais altas que estas, WIRILL (1976); MCWHORTER (1977); BUNDICK E MITCHELL (1979); CANADA AGRICULTE RE (1980); O'SULLIVAN e O'DONOVAN (1980); CHYKALIUK et alii (1980); JORDAN (1980); ERICKSON E DUKE (1981); TROUTMAN et alij (1981); STUDT e NELSON (1981) e DUTT (1981).

Sugere-se continuar os estudos nesta linha de pesquisa envolvendo as estações do ano como uma variāvel para se determinar o efeito das condições climáticas sobre a efici éncia do glifosate, assim como a inclusão nos trabalhos do agente complexante EDTA. 
Pela anālise dos resultados obtidos, nas condi ções que os experimentos foram conduzidos, concluiu-se que:

a) Os surfacantes Triton $\times 45(0,2 \% \mathrm{v} / \mathrm{v})$; Triton $\times 100(0,1-0,2 \% \mathrm{v} / \mathrm{v})$; Triton $\times 174(0,2 \% \mathrm{v} / \mathrm{v})$; Triton $A G-98(0,2 \% \quad \mathrm{v} / \mathrm{v})$ e sintergente $(0,2 \% \mathrm{v} / \mathrm{v})$, a mentaram a velocidade da penetração cuticular e a absorção do glifosate nas doses testadas;

b) Uma chuva ocorrida 4 horas apōs aplicação não afetou a eficiência dos seguintes tratamentos:

- glifosate + Triton $\times 100(1,44 \mathrm{~kg} / \mathrm{ha}+0,2 \% \mathrm{v} / \mathrm{v})$;

- glifosate + Triton $\times 114(1,44 \mathrm{~kg} / \mathrm{ha}+0,2 \% \mathrm{v} / \mathrm{v})$;

- glifosate + Sintergente $(1,44 \mathrm{~kg} / \mathrm{ha}+0 ; 2 \% \mathrm{v} / \mathrm{v})$;

- glifosate + Triton $A G-98(1,44 \mathrm{~kg} / \mathrm{ha}+0,2 \% \mathrm{v} / \mathrm{v})$;

- glifosate + Natur'L óleo (1,44-1,8 kg/ha+1,0\% v/v); 
- glifosate + Triton $\times 45(1,8 \mathrm{~kg} / \mathrm{ha}+0,2 \% \mathrm{v} / \mathrm{v})$;

- glifosate + Sulfato de amônio $(1,8 \mathrm{~kg} / \mathrm{ha}+2,5 \% \mathrm{p} / \mathrm{v})$;

c) Não se observou um efeito marcante da ionogeneidade dos surfactantes utilizados sobre o efeito do glifosate;

d) O aditivo que proporcionou os melhores resultados foi o Natur'L óleo a $1,0 \% \mathrm{v} / \mathrm{v}$;

e) Nenhum tratamento proporcionou, de maneira eficiente, a redução para 2 horas entre a aplicação e a primeira chuva subsequente. 


\section{Literatura Citada}

AHMADI, M.S.; L.C. HADERLIE e G.A. HICKS, 1980. Effect of growth stage and water stress on barnyardgrass Echnochiloa crus-galli) control and on glyphosate absorption and trans location. Weed Science, 28(3): 277-282.

AMPONG-NYARKO, K., 1980. The effects of ammonium sulphate, surfactants and spray volume on the activity of glyphosate on Cyperus rotundus. Reading, 87p. (MSc - University of Reading).

BAIRD, D.D.; R.P. UPCHURCH, W.B. HOMESLEY E J.E. FRANZ, 1971. Introduction of a new broad spectrum postemergence herbici de class with for herbaceous perennial weed control. Proc. North. Cent. Weed Contr. Conf., 26: 64-68.

BALS, E.J., 1978. Reduction of active ingredient dosage by selecting appropriat droplet size for the Target. In: Symposium on Controlled drop application, First, Reading Univ. BCPC. Proceedings, Monografia no 22: 101-106. 
BALYAN, R.S.; U.M. BHAN; R.K. KAMBOJ e S.P. SING, 1981. Trans location of foliage applied glyphosate into the rizomes of cattai1. Proceedings of the Eight Asian-Pacific Weed Science society Conference, p.341-345.

BARRIGA, G.G., 1984. Comportamento de herbicidas aplicados em prë-emergência e em pōs-emergēncia através do pulverizador de gotas uniformes. Piracicaba, 167p. (Mestrado ESALQ).

BEHRENS, R. e M. ELAKKAD, 1972. Quackgrass control with glyphosate. Proc. Nort. Centr. Weed Contr. Conf., 27: 54.

BEHRENS, R. e M.A. ELAKKAD, 1981. Influence of rainfal1 on the phytotoxicity of foliarly applied 2,4-D. Weed Science, $\underline{29}(3): 349-355$.

BLACKMAN, G.E.; R.S. BRUCE e K. KOLLY, 1958. Interrelationships between specific differences in spray retention and selective toxicity. Journal Exp. Bot., g: 175-205.

BLAIR, A.M., 1975. The addition of ammonium salts or a phosphate ester to herbicides to control Agropyron repens (L.) Beauv. Weed Research, 15(2): 101-105.

BUHLER, D.D. e O.C. BURSIDE, 1983a. Effect of water quality, carrier volume, and acid on glyphosate toxicity. Weed Science, $31(2): 163-169$.

BUHLER, D.D. e 0.C. BURNSIDE, 1983b.. Effect of spray components on glyphosate toxicity to annual grasses. Weed Scien. ce, 31(1): 124-130. 
BUNDICK, E. e W.H. MITCHELL, 1979. Influence of surfactants on activity of glyphosate and paraquat in no-tillage soybeans. Proceedings, Northeastern Weed Science Society, 33: p.75.

CANADA, Agriculture Canada, Research Station, 1981. Report. Research Branch Report, 1980. Agriculture Canada, p. 351 359 .

CHASE, R.L., 1979. Control of Cyperus rotundus (L.) with gly phosate. Dissertation Abstracts International, B, 39(11): 5177-5178.

CHASE, R.L. e A.P. APPLEBY, 1979: Effects of humidity and moisture stress on glyphosate control of cyperus rotundus L. Weed Research, 19(4): 241-246.

CHYKALIUK, P.; J.R. ABERNATHY e J.R. GIPSON, 1979. Differen tial response of perennial weeds to glyphosate. Absctract of 1979 Meeting of the Weed Science Society of America, p. $106-107$.

CHYKALIUK, P.B.; J.R. ABERNATHY e J.R. GIPSON, 1980. Effect of additives on herbicide uptake and control of Texas Blue weed woolyleaf bursage and silverleaf nightshade. Procee dings of the 33 rd Annual Meeting of the Southern Weed Scien. ce Society, 236p.

CONOVER, W.J., 1980. Practical nonparametric statistics. 2nd ed. New York, John Wiley \& Sons. $493 p$.

COLLS, W.G. e S.J. LOCASCI0, 1977. Control of purple nutsedge (Cyperus rotundus, L.) as influenced by season of appli cation of glyphosate and nitrogen rate. Proc. South. Weed. Sci. Soc., 30: 158-164. 
COUPLAND, D., 1983. Influence of light, temperature and humidity on the translocation and activity of glyphosate in Agropyton repens. Weed Research, 23: 347-355.

DAVIES, E.L.L.P. e W.A. TAYLOR, 1981. The biological activity of three herbicides when applied by differing hidraulic nozzle types. In: British Crop Protection Council, 1980. 0xford, U.K. Proceddings, Monografia, 24:49-54. Apud. Abstracts, $30(2): 772$.

DEVINE, M.D. e J.D. BANDEEN, 1983. Fate of glyphosate in Agropyron repens (L.) Beauv, growing under low temperature conditions. Weed Research, 23(2): 69-75.

DOLL, J.D. e W. PIEDRAHITA, 1982. Effect of glyphosate on the sprouting of Cyperus rotundus L.tubers. Weed Research, 22(3): 123-128.

DUTT, T.E., 1981. Annual weed control in trees and vines with glyphosate. Proceedings of the Western Society Weed Scien ce, 34: 139-140.

ERICKSON, C.G., 1981. The effect of glyphosate and surfactant concentrations on quackgrass (Agropyron repens (L.) Beauv. control anci foliar arbsorption. Dissertation Abstracts Interna tional, B, 42(4): 1260.

ERICKSON, C.G. e W.B. DUKE, 1981a. The effect of glyphosate and surfactant concentrations on quackgrass. Proceedings Northeartern Weed Science Society, 35: p.32.

ERICKSON, C.G. e W.B. DUKE, 1981b. The effect of glyphosate and surfactant concentrations an subsequent penetration and translocation in quackgrass. Proceedings, Northeartern We ed Science Society, 35: p.33. 
85.

FIVELANDT, T.J., 1978. Addition of ammonium sulphate to gly phosate. In: Weeds and Weed Control. 19th Swedish Weed Conference, Uppsala.

GHANUNI, A.M.M., 1981. Effects of glyphosate on xylogenesisin explants Romaine lettuce (Laciuca sativa L. Romana) and effects of dicamba on glyphosate activity in field lundweed (Convolvolus arvensis). Dissertation Abstracts Inter national, B, $41(11): 3972$.

GOTTRUP, 0.; P.A. O'SULLIVAN; R.J. SCHRAA e W.H. VANDEN BORN, 1976. Uptake, translocation, metabolism and selectivityof glyphosate in Canada thistle and leafy spurge. Weed $\mathrm{Re}$ search, 16 13$): 197-201$.

GUIMARAES, S.C., 1981. Influência da idade de corte e de adj tivos na ação do glifosate sobre a tiririca. Viçosa, 87p (Mestrado - EAUFV).

HARRISON, S.K.; J.R. ABERNATHY e J.R. GIPSON, 1981. Absorption and translocation of dicamba and glyphosate in wolly eaf bursage. Proceedings 34 th Annual Meeting Southern Weed Science, $239 p$.

HARVEY, J.J. e M.J. POTTS, 1978. A cost effective approach to the control of Agropyron repens in ceral stubbles with glyphosate. In: Proceeding 1978, British crop Protection Conference-Weexs, London.

HARVEY, J.J.; P.J. ATTWOOD e M.J. POTTS, 1981. The control of Agropyron repens in cereal stubbles with glyphosate. Pro ceedings of the Conference on Grass Weeds in Cereals in the United Kingdom Rearing, p.155-165. 
HILLER, L.K. e D.SMID, 1981. Giyphosate phytotoxicity and translocation in potatoes prior to tuber initiation: Proceedings of the Western Society of Weed Science, 34: 8687.

INDIA, Tea Research Association, 1977. Annual Scientific Report, 1977. Tocklai Experimental Station:

JORDAN, T.N., 1977. Effects of temperature and humidity on the toxicity of glyphosate to bermudagrass (Cynodon dactylon). Weed Science, 25(5): $448-451$.

JORDAN, T.N., 1981. Effects of diluent volumes and surfactant on the phytotoxicity of glyphosate to bermudagrass. (Cynodon dactylon). Weed Science, 29(1): 79-83.

LAKE, J.R. e W.A. TAYLOR, 1974. Effect of the form of a deposit on the activity of barban applied to Averia fatua, L. Weed Research, 14: 13-18.

LISH, J.M. e C.G. MESSERSMITH, 1979. Factors affecting Cana da thistle control. Proceedings North Central Weed Control Conference, 34: 4 .

LIU, K.J., 1981. The herbicidal properties of $N$ - phosphono methylglycine. Plant Physiology Communications, 40: $30-$ 34.

LOBAT0, 0.J. da S.M., 1972. Disponibilidade hĩdrica e fórmu la climática do muniḉpio de Goiānia e municîpios limitrofes. In: Anais da Escola de Agronomia e Veterināria da Universidade Federal de Goiäs, Ano 2, Goiānia, EAV-UFG, no 1. p. $7-16$. 
LUND-HOEIE, K., 1979. The physiological fate of glyphosate $-14 C$ in Betula verrucosa and Fraxinus excelsior. The effect of ammonium sulphate and the environment conditions on the herbicide. Meldinger Franorges Landbrukshogs Koie, 58 (30), $24 p$.

MAJEK, B.A., 1980. The effect of environemntal factors on quackgrass (Agropyron repens L.) Beauv. growth and giyphosate penetration and trarislocation. Dissertation Abstracts International, B; $41(4): p .1194$.

MCALLISTER, R.S. e L.C. HADERLIE, 1979. Techniques for treat ing plants with radio-labelled herbicides. Proceedings. North Central Weed Control Conference, 34: 5-6.

MCWHORTER, C.G., 1977. Weed control in soybeans with glyphosate applied in the recirculating sprayer. Weed science, 25(2): $135-141$.

MCWHORTER, C.G. e T.N. JORDAN, 1976. Effects of adjuvants and environment on the toxicity of dalapon to johnsongrass. Weed Science, 24: 257-260.

MCWHORTER, C.G.; T.N. JORDAN E G.D. WILLS, 1980. Transloca tion of $14 C-g l y p h o s a t e$ in soybeans and johnsongrass. Weed Science, 28(1): 113-118.

MERRITT, C.R., 1980. Studies on the very low volume, contro? led drop size application of MCPA, Difenzoquat, paraquat e glyphosate. Bath, UK, University of Bath, 133p. (Tese de Doutoramento). 
88.

MERRITT, C.R. e W.A. TAYLOR, 1978. Effects of volume rate and drop size on the retention of on aqueous solution by Avena fatua L. In: Symposium on Controlled Drop Applica tion, First Reading Univ. BCPC. Proceedings. Monografia n? $22,59-66$.

MOOSAVI-NIA, H. e J. DORE, 1979a. Foctors affecting glyphosate activity in Imperata cylindrica (L.) Beauv. and Cyperus rotundus (L.). Weed Research, 19(2): 137-143.

MOOSAVI-NIA, H. e J. DORE, 1979b. Factors affecting glyphosa te activity in Imperata cylindrica (L.) Beauv. and cyperus rotundus (L.). I I. Effect of shade. Weed Research, 19: $327-327$.

O'KeEfFE, M.G. e TURNER, E.W., 1978. Chemical control of Agropyron repens, Summary report 1977. Agriculture, 1978. 13.

O'DONOVAN, J.T. e P.A. O'SULLIVAN, 1982. The antagonistic ac tion of 2,4-D and Bromoxynil on glyphosate priytotoxicity to barley (Hordeum vulgare). Weed Science, 30(1): 30-34.

O'SULLIVAN, P.A. E J.T. O'DONOVAN, 1980. Influerice of various herbicides and Tween 20 on the effectiveness of giyphosate. Canadian Journal of Plant Science, 60(3): 939 945 .

PENNER, D. e F. ROGGENBUCK, 1979. Susceptibility of recalcitrant species to glyphosate in turfgrass renovation. Pro ceedings North Central Weed Control Conference, 34: 79-80.

PREEST, D.S., 1975. Effect of additives on Bracken control by a sulam and glyphosate. Proceedings of the $28 \mathrm{th}$ New Zea. land Weed and Pest Control Conference, p.49-52. 
PULVER, E.L. e C. ROMER0, 1976. Estudios sobre la absorcion foliar y translocation de glifosate en cyperus rotundus (L) Revista Comalfi, $3(2): 94-113$.

RAO, U.S.; F. RAHMAN; H.S. SINGH; A.K. DUTTA, M.C. SAIKIA; S. N. SHARMA e B.C. PHUKAN, 1978. Effective weed control in tea by glyphosate. Indian Journal of Weed Science, 8 (1): $1-14$.

RICHARD Jr., E.P. e SLIFE, F.W., 1979. "in vivo" and "in vitro" characterization of the entry of glyphosate in Hemp Dogbane (Apocynum cannabinum). Weed Sci., 27(4): 426 433 .

RIEMER, D.N., 1973. Effects of rate spray volume and surfac tant on the control of phragmites with glyphosate. Procee dings of the Northeastern Weed Science Society, New York, 27: $101-104$.

SALINAS, F.G., 1981. Evaluacion de herbicidas para el control de Zacate Bermuda (Cynodon dactylon) en cultivos pere nes. In: Congresso Nacional de la Ciencia de la Maleza, II Univ. Chaningo. Resumos, p.23-24.

SCHOLEY, J.M.,. 1984. The evaluation of NU-Film-F as a protectant for Roundup Against loss of efficacy from rain. Nothingham, Cropwater, Environmental Services Ltda. $17 p$.

SHARMA, V.A.; N. SATYANARAYANA E K. RAMACHANORAN, 1980. Addi tives and herbicides efficiency of glyphosate. Pesticides, 14 (3): 19-20. 
SHARMA, U.S. e K.R. SUNDAR, 1981. Kaolin and ammonium sulphate as additives to increase the herbicidal efficacy of glyphosate. Proceedings of the Eigth Asian-Pacific Weed Science Society Conference, p.335-339.

SHEA, P.J. e D.R. TUPY, 1983. Reversing divalent cation-indu ced reductions in glyphosate activity with chelating agents. Abstracts, 1983 Meeting of the Weed Science Society of Ame rica, 28p.

SETZER, J., 1967. Atlas climatico ecológico do Estado de São Pauro, Comissão Interéstaduâr da Bacia Paranā-UruguaiCESP, $61 \mathrm{p}$.

SOTERES, J.K., 1982. Growth and Development of honeyvine milk weed. Dissertation Abstracts International, $B ; 42(9): 3529$ 3530 .

SOTERES, J.K.; D.S. MURRAY E E. BASLER, 1933. Absorption of 2,4-D, dicamba e glyphosate in excised tioneyvine milkweed, (Cynanchum laeve). Weed Science, 3] (2): 271-274.

SPRANKLE, P.; W.F. MEGGITT e D. PENNER, 1975b. Adsorption ác tion and translocation of glyphosate. Weed science, 23: $235-240$.

STUDT, D.M. e J.E. NELSON, 1979. Controlling jerusalem artichoke in corn in Iowa. Proceedings North Central Weed Con. trol Conference, 34: 57-58.

STUDT, D.M. e J.E. NELSON, 1981. Influence on non-ionic surfactants, ammonium sulphate, water quality and spray volume on the phytotoxicity of glyphosate. Canadian Journal of Plant Science, 61 (2): $391-400$. 
SUWUNNANMEK, U. e C. PARKER, 1975. Control of Cyperus rotundus with glyphosate: The influence of ammonium sulphate and other additives. Weed Research, 15(1): 13-19.

TAYLOR, W.A., 1981. Controlled drop application of herbicides. Outlook on Agriculture, 10(7): 333-336.

TROUTMAN, B.C.; J.W. KING e R.E. FRANS, 1981. Wild garlic (Allium vineale) control with glyphosate. Weed Science, 29(6): 717-722.

TURNER, D.J.e M.E.C. LOADER, 1974. Studies with solubilized herbicide formulations. Proceedings 12 th British Weed Con trol Conference, London UK, p.177-184.

TURNER, D.J., 1976a. Improving the performance of herbicides. Span, $19(2): 75-77$.

TURNER, D.J., 1976b. Preliminary results of research into improving herbicide performance by the use of additives. Sixth Report, Agricultural Research Council Weed Research. Organization, 1974-1975, p.82-90.

TURNER, D.J. e M.P.C. LOADER, 1978a. Complexing agents as herbicide additives. Weed Research, 18: 199-207.

TURNER, D.J. e M.P.C. LOADER, 1978b. Controlled drop applica tion of glyphosate, difenzoquat and dichlorprop. In: Symposium on Controlled drop application, First, Reading, Univ. BCPC Proceedings. Monografia no 22: 179-184.

TURNER, D.J. E M.P.C. LOADER, 1980. Effect of ammonium sulphate and other additives upon the phytotoxicity of glypho sate to Agropyton repens. Weed Research, 20(3): 139-146. 
TURNER, D.J., 1981. The effect of additives on the control of Agropyron repens with glyphosate. In: Proceedings of the Conference of Grass Weeds in Cereals in the UnitedKingdom, Reading.

TURNER, D.J. e LOADER, M.P.C., 1984. Effect of ammonium sulphate and related salts in the phytotoxicity of dichiorprop and other herbicides used for broadleaved weed control in cereals. Heed Research, 24: 67-77.

UK, MINISTRY OF AGRICULTURA, Fisheries and Food, Agricultu ral Development and Advisory Service, 1978. Summaries of 1977 R\&D Report, Northern region development committee. Nwecastle upon Tyne, UK, $54 \mathrm{p}$.

WHITWELL, T. e P.W. SANTELMANN, 1978. Influence of growth stage and soil conditions on bermudagrass susceptibility to glyphosate. Agri Journal, 70(4): 653-656.

WHITWELL, T.; P. BANKS; E. BASLER e P.W. SANTELMANN, 1980. Gly phosate absorption and translocation in bermudagrass (cyno don dactylon) and activity in horsenettle (Solanum carolinense). Weed Science, 28(1): 93-96.

WILLS, G.D., 1978. Factors affecting toxicity and transloca tion of glyphosate in cotton. Weed Science, 26(5): 509516 .

WYRILL, J.B.III, 1976. Absorption, translocation and break down of 2,4-D and glyphosate in common milkweed and hemp doghbane. Lincoln, NE, Univ. of Neb., 72p. (Tese de Douto ramento). 
WYRILL, J.B., 1976. Mode of action of 2,4-D and glyphosate in common milkweed and hemp doghbane. Dissertation Abstra cts. International, B; $37(5): 2010$.

WYRILL, III, J.B. e 0.C. BURNSIDE, 1377. Glyphosate toxicity to common milkweed and hemp doghbane as influenced by surfactants. Weed Scierice, 25: 275-287.

ZAMBIA, Departament of Agriculture, Mount Makulu Research Sta tion, Wee Control Research and Extension Team, 1979. Annual Report, $58 p$.

ZANOSTRA, B.H. e R.K. NISHIMOTO, 1977. Movement and activity of glyphosate in purple nutsedge. Weed Science, 25(3): 268 274.

ZEMANEK, J.; J. KUBROVA e R. STERBA, 1979. A study. of the biological properties of glyphosate. Proceedings, 7 th Czechosiovak Plant Protection Conference, 302p. 